\title{
Prevention of VTE in Orthopedic Surgery Patients
}

\section{Antithrombotic Therapy and Prevention of Thrombosis, 9th ed: American College of Chest Physicians Evidence-Based Clinical Practice Guidelines}

\author{
Yngve Falck-Ytter, MD; Charles W. Francis, MD; Norman A. Johanson, MD; \\ Catherine Curley, MD; Ola E. Dahl, MD; Sam Schulman, MD, PhD; \\ Thomas L. Ortel, MD, PhD; Stephen G. Pauker, MD; and Clifford W. Colwell Jr, MD
}

Background: VTE is a serious, but decreasing complication following major orthopedic surgery. This guideline focuses on optimal prophylaxis to reduce postoperative pulmonary embolism and DVT.

Methods: The methods of this guideline follow those described in Methodology for the Development of Antithrombotic Therapy and Prevention of Thrombosis Guidelines: Antithrombotic Therapy and Prevention of Thrombosis, 9th ed: American College of Chest Physicians Evidence-Based Clinical Practice Guidelines in this supplement.

Results: In patients undergoing major orthopedic surgery, we recommend the use of one of the following rather than no antithrombotic prophylaxis: low-molecular-weight heparin; fondaparinux; dabigatran, apixaban, rivaroxaban (total hip arthroplasty or total knee arthroplasty but not hip fracture surgery); low-dose unfractionated heparin; adjusted-dose vitamin $\mathrm{K}$ antagonist; aspirin (all Grade 1B); or an intermittent pneumatic compression device (IPCD) (Grade 1C) for a minimum of 10 to 14 days. We suggest the use of low-molecular-weight heparin in preference to the other agents we have recommended as alternatives (Grade $2 \mathrm{C} / 2 \mathrm{~B}$ ), and in patients receiving pharmacologic prophylaxis, we suggest adding an IPCD during the hospital stay (Grade 2C). We suggest extending thromboprophylaxis for up to 35 days (Grade $2 B$ ). In patients at increased bleeding risk, we suggest an IPCD or no prophylaxis (Grade 2C). In patients who decline injections, we recommend using apixaban or dabigatran (all Grade 1B). We suggest against using inferior vena cava filter placement for primary prevention in patients with contraindications to both pharmacologic and mechanical thromboprophylaxis (Grade 2C). We recommend against Doppler (or duplex) ultrasonography screening before hospital discharge (Grade 1B). For patients with isolated lowerextremity injuries requiring leg immobilization, we suggest no thromboprophylaxis (Grade 2B). For patients undergoing knee arthroscopy without a history of VTE, we suggest no thromboprophylaxis (Grade 2B).

Conclusions: Optimal strategies for thromboprophylaxis after major orthopedic surgery include pharmacologic and mechanical approaches.

CHEST 2012; 141(2)(Suppl):e278S-e325S

Abbreviations: DUS = Doppler (or duplex) ultrasonography; GCS = graduated compression stockings; HFS = hip fracture surgery; INR = international normalized ratio; IPCD = intermittent pneumatic compression device; IVC $=$ inferior vena cava; $\mathrm{LDUH}=$ low-dose unfractionated heparin; $\mathrm{LMWH}=$ low-molecular-weight heparin; $\mathrm{PE}=$ pulmonary embolism; PEP = Pulmonary Embolism Prevention trial; RCT = randomized controlled trial; RR = risk ratio; THA = total hip arthroplasty; TKA = total knee arthroplasty; $\mathrm{UFH}=$ unfractionated heparin; $\mathrm{VFP}=$ venous foot pump; VKA = vitamin $\mathrm{K}$ antagonist 


\section{SUMMARY OF RECOMMENDATIONS}

Note on Shaded Text: Throughout this guideline, shading is used within the summary of recommendations sections to indicate recommendations that are newly added or have been changed since the publication of Antithrombotic and Thrombolytic Therapy: American College of Chest Physicians EvidenceBased Clinical Practice Guidelines (8th Edition). Recommendations that remain unchanged are not shaded.

2.1.1. In patients undergoing total hip arthroplasty (THA) or total knee arthroplasty (TKA), we recommend use of one of the following for a minimum of 10 to 14 days rather than no antithrombotic prophylaxis: low-molecular-weight heparin (LMWH), fondaparinux, apixaban, dabigatran, rivaroxaban, low-dose unfractionated heparin (LDUH), adjusted-dose vitamin $\mathrm{K}$ antagonist (VKA), aspirin (all Grade 1B), or an intermittent pneumatic compression device (IPCD) (Grade 1C).

Remarks: We recommend the use of only portable, battery-powered IPCDs capable of recording and

Revision accepted August 31, 2011.

Affiliations: From the Department of Medicine (Dr Falck-Ytter), School of Medicine, Case Western Reserve University, Cleveland, $\mathrm{OH}$; Hematology/Oncology Unit (Dr Francis), University of Rochester Medical Center, Rochester, NY; Department of Orthopaedic Surgery (Dr Johanson), Drexel University College of Medicine, Philadelphia, PA; Division of Hospital Medicine (Dr Curley), MetroHealth Medical Center, Case Western Reserve University, Cleveland, OH; Innlandet Hospitals (Dr Dahl), Brumunddal, Norway; Thrombosis Research Institute (Dr Dahl), Chelsea, London, England; Department of Medicine (Dr Schulman), Division of Hematology and Thromboembolism, McMaster University, Hamilton, ON, Canada; Hemostasis and Thrombosis Center (Dr Ortel), Duke University Health System, Durham, NC; Tufts Medical Center (Dr Pauker), Boston, MA; and Shiley Center for Orthopaedic Research and Education at Scripps Clinic (Dr Colwell), La Jolla, CA.

Funding/Support: The Antithrombotic Therapy and Prevention of Thrombosis, 9th ed: American College of Chest Physicians Evidence-Based Clinical Practice Guidelines received support from the National Heart, Lung, and Blood Institute [R13 HL104758] and Bayer Schering Pharma AG. Support in the form of educational grants was also provided by Bristol-Myers Squibb; Pfizer, Inc; Canyon Pharmaceuticals; and sanofi-aventis US.

Disclaimer: American College of Chest Physician guidelines are intended for general information only, are not medical advice, and do not replace professional medical care and physician advice, which always should be sought for any medical condition. The complete disclaimer for this guideline can be accessed at http:// chestjournal.chestpubs.org/content/141/2_suppl/1S.

Correspondence to: Yngve Falck-Ytter, MD, Department of Medicine, School of Medicine, Case Western Reserve University, Case and VA Medical Center, 10701 East Blvd, Cleveland, OH 44106; e-mail: Yngve.Falck-Ytter@case.edu

(C) 2012 American College of Chest Physicians. Reproduction of this article is prohibited without written permission from the American College of Chest Physicians (http://www.chestpubs.org/ site/misc/reprints.xhtml).

DOI: $10.1378 /$ chest.11-2404 reporting proper wear time on a daily basis for inpatients and outpatients. Efforts should be made to achieve $18 \mathrm{~h}$ of daily compliance. One panel member believed strongly that aspirin alone should not be included as an option.

2.1.2. In patients undergoing hip fracture surgery (HFS), we recommend use of one of the following rather than no antithrombotic prophylaxis for a minimum of 10 to 14 days: LMWH, fondaparinux, LDUH, adjusted-dose VKA, aspirin (all Grade 1B), or an IPCD (Grade 1C).

Remarks: We recommend the use of only portable, battery-powered IPCDs capable of recording and reporting proper wear time on a daily basis for inpatients and outpatients. Efforts should be made to achieve $18 \mathrm{~h}$ of daily compliance. One panel member believed strongly that aspirin alone should not be included as an option.

2.2. For patients undergoing major orthopedic surgery (THA, TKA, HFS) and receiving LMWH as thromboprophylaxis, we recommend starting either $12 \mathrm{~h}$ or more preoperatively or $12 \mathrm{~h}$ or more postoperatively rather than within $4 \mathrm{~h}$ or less preoperatively or $4 \mathrm{~h}$ or less postoperatively (Grade 1B).

2.3.1. In patients undergoing THA or TKA, irrespective of the concomitant use of an IPCD or length of treatment, we suggest the use of LMWH in preference to the other agents we have recommended as alternatives: fondaparinux, apixaban, dabigatran, rivaroxaban, LDUH (all Grade 2B), adjusted-dose VKA, or aspirin (all Grade 2C).

Remarks: If started preoperatively, we suggest administering $\mathrm{LMWH} \geq 12 \mathrm{~h}$ before surgery. Patients who place a high value on avoiding the inconvenience of daily injections with LMWH and a low value on the limitations of alternative agents are likely to choose an alternative agent. Limitations of alternative agents include the possibility of increased bleeding (which may occur with fondaparinux, rivaroxaban, and VKA), possible decreased efficacy (LDUH, VKA, aspirin, and IPCD alone), and lack of long-term safety data (apixaban, dabigatran, and rivaroxaban). Furthermore, patients who place a high value on avoiding bleeding complications and a low value on its inconvenience are likely to choose an IPCD over the drug options.

2.3.2. In patients undergoing HFS, irrespective of the concomitant use of an IPCD or length of treatment, we suggest the use of LMWH in preference to the other agents we have recommended as alternatives: fondaparinux, LDUH 
(Grade 2B), adjusted-dose VKA, or aspirin (all Grade 2C).

Remarks: For patients in whom surgery is likely to be delayed, we suggest that LMWH be initiated during the time between hospital admission and surgery but suggest administering LMWH at least $12 \mathrm{~h}$ before surgery. Patients who place a high value on avoiding the inconvenience of daily injections with LMWH and a low value on the limitations of alternative agents are likely to choose an alternative agent. Limitations of alternative agents include the possibility of increased bleeding (which may occur with fondaparinux) or possible decreased efficacy (LDUH, VKA, aspirin, and IPCD alone). Furthermore, patients who place a high value on avoiding bleeding complications and a low value on its inconvenience are likely to choose an IPCD over the drug options.

2.4. For patients undergoing major orthopedic surgery, we suggest extending thromboprophylaxis in the outpatient period for up to 35 days from the day of surgery rather than for only 10 to 14 days (Grade $2 \mathrm{~B}$ ).

2.5. In patients undergoing major orthopedic surgery, we suggest using dual prophylaxis with an antithrombotic agent and an IPCD during the hospital stay (Grade 2C).

Remarks: We recommend the use of only portable, battery-powered IPCDs capable of recording and reporting proper wear time on a daily basis for inpatients and outpatients. Efforts should be made to achieve $18 \mathrm{~h}$ of daily compliance. Patients who place a high value on avoiding the undesirable consequences associated with prophylaxis with both a pharmacologic agent and an IPCD are likely to decline use of dual prophylaxis.

2.6. In patients undergoing major orthopedic surgery and increased risk of bleeding, we suggest using an IPCD or no prophylaxis rather than pharmacologic treatment (Grade 2C).

Remarks: We recommend the use of only portable, battery-powered IPCDs capable of recording and reporting proper wear time on a daily basis for inpatients and outpatients. Efforts should be made to achieve $18 \mathrm{~h}$ of daily compliance. Patients who place a high value on avoiding the discomfort and inconvenience of IPCD and a low value on avoiding a small absolute increase in bleeding with pharmacologic agents when only one bleeding risk factor is present (in particular the continued use of antiplatelet agents) are likely to choose pharmacologic thromboprophylaxis over IPCD.
2.7. In patients undergoing major orthopedic surgery and who decline or are uncooperative with injections or an IPCD, we recommend using apixaban or dabigatran (alternatively rivaroxaban or adjusted-dose VKA if apixaban or dabigatran are unavailable) rather than alternative forms of prophylaxis (all Grade 1B).

2.8. In patients undergoing major orthopedic surgery, we suggest against using inferior vena cava (IVC) filter placement for primary prevention over no thromboprophylaxis in patients with an increased bleeding risk or contraindications to both pharmacologic and mechanical thromboprophylaxis (Grade 2C).

2.9. For asymptomatic patients following major orthopedic surgery, we recommend against Doppler (or duplex) ultrasound (DUS) screening before hospital discharge (Grade 1B).

3.0. We suggest no prophylaxis rather than pharmacologic thromboprophylaxis in patients with isolated lower-leg injuries requiring leg immobilization (Grade 2C).

4.0. For patients undergoing knee arthroscopy without a history of prior VTE, we suggest no thromboprophylaxis rather than prophylaxis (Grade 2B).

$\mathbf{T}$ otal hip arthroplasty (THA) and total knee arthroplasty (TKA) are performed with increasing frequency, with close to 200,000 procedures for THA alone in the United States each year. ${ }^{1}$ The risk for VTE in major orthopedic surgery, in particular THA and hip fracture surgery (HFS), is among the highest for all surgical specialties, and deaths from VTE still occur, albeit very infrequently. This article discusses prophylaxis of VTE in patients undergoing orthopedic surgery, including THA, TKA, and HFS; belowknee injuries; and arthroscopic procedures. We have included only the drugs that have been approved by regulatory agencies in more than one country.

\subsection{Methods}

\subsection{Outcomes of Interest}

All recommendations are based on the use of prophylaxis to reduce the patient-important outcomes of fatal and symptomatic pulmonary embolism (PE) and symptomatic DVT balanced against the hazard of an increase in symptomatic bleeding events. The design and reporting of clinical trials creates challenges in applying this approach. Studies have used varying definitions of important bleeding, and it was sometimes difficult to extract data regarding patient-important bleeding outcomes (those that led to transfusion or an intervention, such as reoperation). Additionally, most 


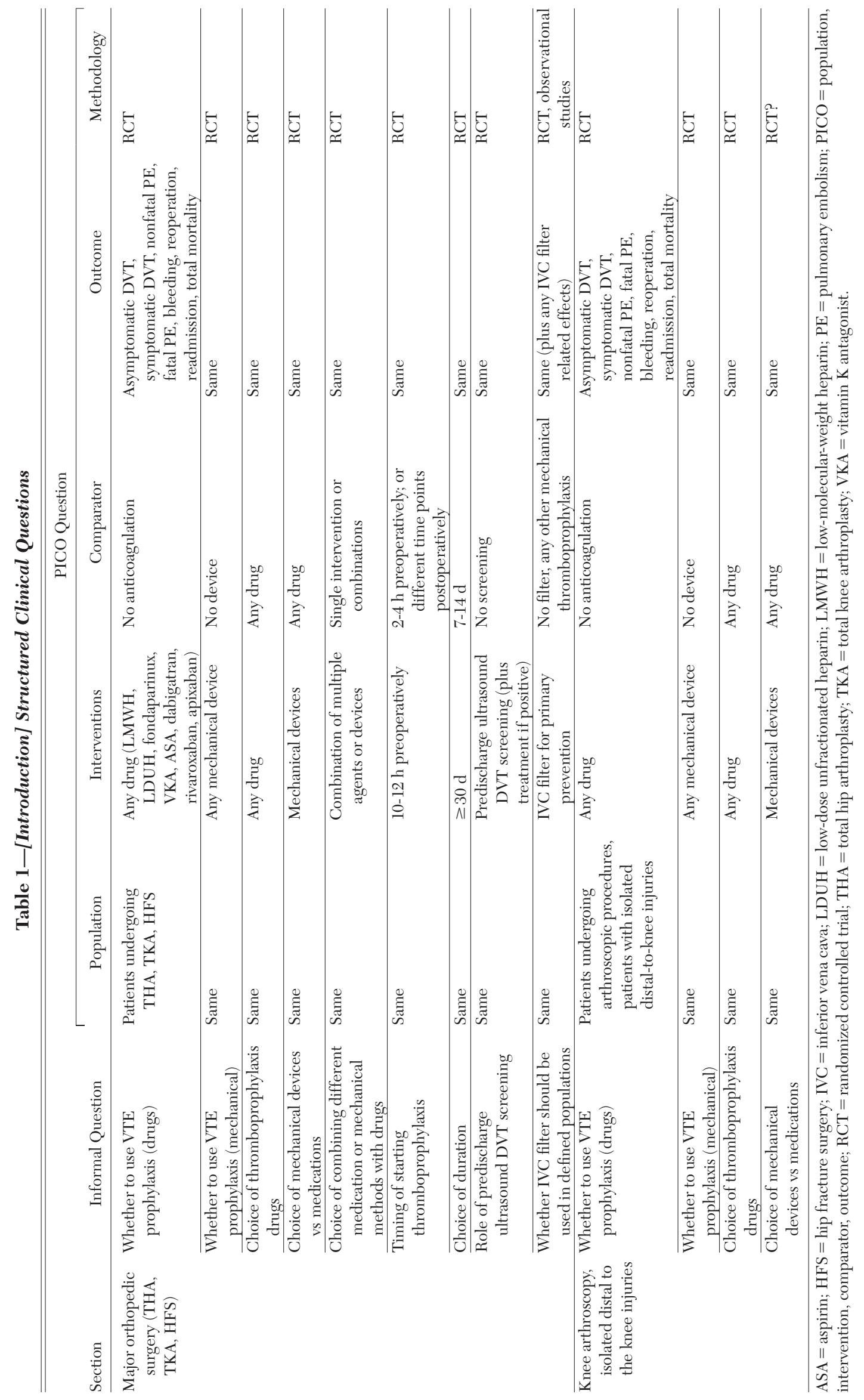


trials before 2000 used asymptomatic DVT detected by screening tests as a primary end point. When symptomatic DVTs were not reported, we used the relative risk estimate from asymptomatic DVT. Pulmonary embolisms (PEs) were assumed to be symptomatic unless the study described systematic screening for PE. ${ }^{2}$ Table 1 summarizes the questions we addressed.

\subsection{Evaluating and Summarizing Evidence}

If available, we used existing systematic reviews as the basis of evidence. If existing reviews were unavailable or not up to date or the outcomes of interest were not reported, we performed additional analyses. For example, we relied on a recent, well-done systematic review ${ }^{3}$ to inform relative effects of low-dose unfractionated heparin (LDUH) vs no prophylaxis because studies were performed in the 1970s and 1980s and critical appraisal of the search strategy made it unlikely that studies would have been missed. However, we performed an update of the same comprehensive literature search for all interventions listed in Table 1 to include the time frame from January 2008 to December 2010. Sources included Medline, the Cochrane Library (including the Cochrane database of controlled trials), meeting abstracts, conference proceedings, and reference lists of studies that were manually reviewed. No language restriction was applied.

For additional analyses, we pooled the data using a randomeffects model for three or more studies (fixed-effects model for two studies). When the analysis showed a similar relative effect for THA, TKA, and HFS, we used this single best relative risk estimate to inform absolute risk differences in VTE reduction and bleeding risk increase. When effects differed, we used effects specific to the surgery.

For our own analyses, we excluded studies that failed to confirm VTE with accurate methods, such as pulmonary angiogram, CT scan, ventilation/perfusion scanning, venography, and compression Doppler (or duplex) ultrasonography (DUS), and instead used clinical signs and symptoms, plethysmography, or fibrinogen uptake as the sole detection method. However, for well-done systematic reviews, we accepted the authors' choice of study selection, even if a less-reliable detection method was used in some of the studies.

Where possible, we removed doubly counted events from the outcomes presented in the evidence summaries. For instance, if a patient died of a PE, the event would only be counted in mortality and would not appear again under PE. We report deaths from PE together with all other mortal events, but a footnote presents a description of those events as deaths from VTE, deaths from unexplained causes (unable to rule out PE), fatal bleeding, and death from other causes. Because studies often presented outcomes as composites, the number of events in our analysis may at times differ from the result highlighted in the publication.

Different categories of bleeding events have very different impacts on patients. Trials, therefore, have separated bleeding into categories, of which traditionally there have been two: major bleeding and minor bleeding. More recent trials have introduced another, intermediate category: clinically relevant nonmajor bleeding. However, clinically relevant nonmajor bleeding remains hard to define, and we decided not to include this outcome in our evidence summaries, instead exclusively focusing on major bleeding.

Studies usually defined major bleeding events as any fatal bleeding, bleeding into a critical organ (eg, retroperitoneal, intracranial, intraocular, or intraspinal), clinically overt (eg, GI) bleeding associated with $a \geq 2 \mathrm{~g} / \mathrm{dL}$ drop in hemoglobin level or requiring $\geq 2$ units of blood transfused, and bleeding leading to reoperation. We separated fatal bleeding and bleeding requiring reoperation from other major bleeding events because these outcomes are the least ambiguous. We usually accepted the major bleeding definition of the study but recorded any bleeds requiring reoperation in a separate category to avoid double counting.

Because patients undergoing surgery have some blood loss and surgeons may have a low threshold for transfusing blood when autologous blood is used (with perioperative transfusion rates of $40 \%$ not being unusual), ${ }_{4}$ drop in hemoglobin level and transfusion requirements are hard to interpret. The effect of such transfusion practices on the significance of the outcome of major bleeding is unknown. However, major bleeding that followed the above definition appears to have a clinical impact. A regression analysis of major bleeding events involving $>13,000$ patients enrolled in fondaparinux trials demonstrated a hazard ratio of death of close to 7 (8.6\% vs $1.7 \%$ ), demonstrating a strong relationship between major bleeding and poor outcome irrespective of the study drug used. ${ }^{5}$ Whether this finding can be generalized to other populations and interventions is unknown.

The major advantage of our outlined approach is that the evidence summaries allow for direct trade-off of undesirable events. These trade-offs are fewer symptomatic PE and DVT with thromboprophylaxis vs increased major bleeding. ${ }^{2}$

\subsection{Deriving Baseline Risks}

1.3.1 Baseline Risk for VTE: We made considerable effort to determine the baseline risk of symptomatic VTE and bleeding in the absence of prophylaxis. For this purpose, we analyzed all controlled trials that had a placebo or no-treatment group extending back to $1959 .{ }^{6}$ This has obvious limitations because of important changes in surgical care, including changes in operative technique, earlier ambulation, and earlier discharge that have had an impact on rates of thrombosis and bleeding. For instance, although the average length of stay after HFS in the 1960s was 35 days, ${ }^{7}$ current averages of 3.2 days have been reported in a large cohort after arthroplasties, ${ }^{8}$ and early mobilization starts at 2 to $4 \mathrm{~h}$ after surgery. ${ }^{8}$ Randomized controlled trial (RCT) data typically showed a symptomatic VTE event rate of $15 \%$ to $30 \%$ without prophylaxis prior to $1980,6,9-12$ and observational data suggest a further drop from around $5 \%$ to $1 \%$ to $2 \%$ in the years from 1989 to $2001 .{ }^{13}$

In recent years, there have been no large placebo controlled trials, and we did not identify any large, well-designed cohort studies to provide a baseline risk relevant to current practice. However, there are several large RCTs that have used low-molecular-weight heparin (LMWH), and we have estimated baseline risk by applying the observed risk of symptomatic VTE in patients treated with LMWH and adjusting it by the relative risk reduction in symptomatic VTE from prior randomized trials of LMWH compared with placebo.

First, we estimated contemporary average on-prophylaxis rates with LMWH for symptomatic DVT to be $0.8 \%$ and for PE to be $0.35 \%$ by averaging the LMWH event rates from trials enrolling $>16,000$ patients since 2003.,14-26 We selected the year 2003 because of a shift in surgical technique since that time to be less invasive and possibly less thrombogenic. Concerns that those rates could be too low given the sometimes highly selected nature of clinical trials, we compared this rate with older data from a large observational study. ${ }^{27}$ The investigators identified 133 of 19,586 (0.7\%) VTE events during the initial hospitalization for patients receiving prophylaxis (estimated prophylaxis compliance, $88 \%$ ), suggesting that the symptomatic VTE rate of $1.15 \%$ we used is not too low.

Second, if we assume the effect of LMWH is similar in asymptomatic and symptomatic DVT, then the best evidence suggests that LWMH reduces the risk for DVT by $50 \%$ to $60 \%$ and PE by about two-thirds. ${ }^{3}$ Using this estimate, the contemporary offprophylaxis rates are $\sim 1.8 \%$ for symptomatic DVT and $1 \%$ for PE for the first 7 to 14 days (the initial prophylaxis period most RCTs used and that correspond to the nonextended prophylaxis period). 
The untreated baseline risk for the extended, out-of-hospital period, defined as the time period starting at around postoperative day 15 and extending up to 35 days, is likely to be somewhat lower because the VTE risk is highest close to surgery and the median time of diagnosis for thromboembolic events is 7 days after TKA and 17 days after THA. ${ }^{27}$ We found only one trial that enrolled patients after 2003 that examined extended, out-ofhospital prophylaxis using a placebo group control to estimate the baseline risk for this time period. ${ }^{4}$ Extracting events from the timeto-event graph and from the text, 11 of $1,207(0.91 \%)$ symptomatic VTE events were observed up to postoperative day 39, starting from the time enoxaparin was stopped at an average of 12 days postoperation. A trial that enrolled patients slightly before our cutoff years (2001 and 2002) found a higher rate in the placebo arm (symptomatic VTE, 8/330 [2.4\%]). ${ }^{28}$

In summary, we have estimated a symptomatic VTE rate that is about one-half the rate observed in the immediate postoperative period (1.5\%; symptomatic DVT, $1 \%$; PE, $0.5 \%$ ). For this guideline, we therefore estimated a combined 35-day untreated baseline risk for symptomatic VTE of $4.3 \%$.

Although epidemiologic data from the early 1990s suggest that the cumulative 90-day symptomatic VTE risk for THA is higher than that for TKA ( $2.8 \%$ vs $2.1 \%$, respectively), ${ }^{27}$ randomized trials fail to confirm this finding. Follow-up epidemiologic data from the mid-1990s also demonstrated that cumulative 90-day symptomatic VTE rates after HFS did not exceed those reported for arthroplasty (HFS, 1.9\%; THA, 2.4\%; TKA, 1.7). ${ }^{29}$ We therefore concluded that a $4.3 \%$ combined symptomatic VTE untreated baseline risk for the first 35 days is the best approximation for all three major orthopedic surgeries. Table 2 and Figure 1 present a summary of the estimated symptomatic VTE rates for this guideline.

Because VTE-related deaths were rarely observed in trials since 2003, the data were insufficient to estimate current baseline risk. In addition, competing risks, such as cardiovascular and infectious causes of death, often outnumber the risk of death from VTE, particularly in HFS. When pooling study data, total mortality-because this outcome includes fatal bleeding-was selected to better represent the overall balance of fatal events. The majority of mortal events were seen in HFS populations that are elderly and experience considerable comorbidity.

1.3.2 Baseline Risk for Major Bleeding Events: The risk for major bleeding with LMWH, and in particular without treatment, remains difficult to estimate because better operative techniques make deriving the untreated bleeding event rate from the placebo group of past RCTs in major orthopedic surgery problematic. To estimate untreated bleeding risk, we first determined the median major bleeding event rate from the placebo (or graduated compression stockings [GCS]) arm of LMWH trials and the Pulmonary Embolism Prevention (PEP) trial (subgroup that did not receive any heparin) because those trials were more recent. ${ }^{30-39}$

Table 2-[Section 1.3.1] Estimated Nonfatal, Symptomatic VTE Rates After Major Orthopedic Surgery

\begin{tabular}{lccc}
\hline \hline & $\begin{array}{c}\text { Initial } \\
\text { Prophylaxis, } \\
\text { Postoperative } \\
\text { Days 0-14 }\end{array}$ & $\begin{array}{c}\text { Extended } \\
\text { Prophylaxis, } \\
\text { Postoperative } \\
\text { Days 15-35 }\end{array}$ & $\begin{array}{c}\text { Cumulative, } \\
\text { Postoperative } \\
\text { Days 0-35 }\end{array}$ \\
\hline No prophylaxis & VTE 2.80\% & VTE 1.50\% & VTE $4.3 \%$ \\
& (PE 1.00\%, & (PE 0.50\%, & (PE 1.50\%, \\
& DVT 1.80\%) & DVT 1.00\%) & DVT 2.80\%) \\
\hline LMWH & VTE 1.15\% & VTE 0.65\% & VTE $1.8 \%$ \\
& (PE 0.35\%, & (PE 0.20\%, & (PE 0.55\%, \\
& DVT 0.80\%) & DVT 0.45\%) & DVT 1.25\%) \\
\hline
\end{tabular}

See Table 1 legend for expansion of abbreviations.

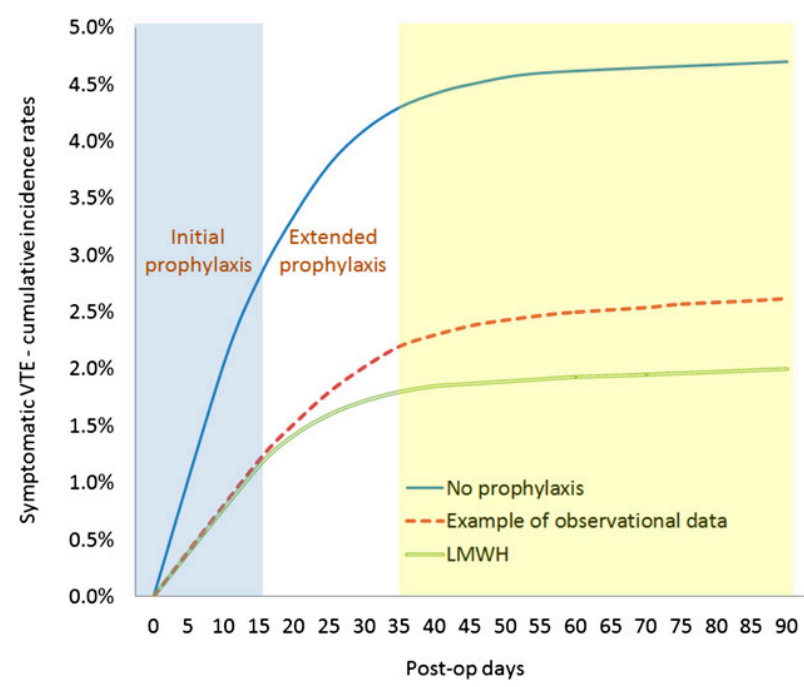

FIGURE 1. [Section 1.3.1] Schematic of estimated incidence rates for LMWH and no prophylaxis for major orthopedic surgery used for this guideline. Additional example data are from observational studies (dashed line), which usually represents a cumulative incidence rate resulting from high rates of prophylaxis in the first 7 to 14 days and low rates or no prophylaxis during the extended prophylaxis period. $\mathrm{LMWH}=$ low-molecular-weight heparin.

The median rate was $1.5 \%$, but because of the low event rate in the LMWH trials, variability in the definitions of major bleeding across trials makes this estimate uncertain. This is, however, consistent with a systematic review that estimated the absolute untreated bleeding risk to be between $1 \%$ and $2 \%{ }^{3}$

Second, we selected the major bleeding event rate for LMWH from a recent review that examined the reporting definitions and event rates from the enoxaparin control arm of recent trials. ${ }^{40} \mathrm{We}$ chose a rate of $1.5 \%$, which was slightly higher than the average (1.4\%) and higher than 12 of 14 trials that enrolled $>16,000$ patients since 2003 that we included in the estimate of baseline VTE risk (median, 0.91\%; maximum, 1.9\%).4,14-26 Recognizing the sometimes highly selective process of RCTs in enrolling patients with low bleeding risk, we believe that a selected bleeding rate that is somewhat higher than the median is therefore close to what would be observed in clinical practice. The baseline major bleeding rate of $1.5 \%$ (15 of 1,000$)$ and that expected with LMWH are shown in Table 3 and Table $\mathrm{S} 1$ and are very close. (Tables and figures that contain an "S" before the number denote supplementary information not contained in the body of the article and available instead in an online data supplement; see the "Acknowledgments" for more information.) Intuitively, a greater bleeding rate might be expected with the use of LMWH, but this increased risk is likely within the large CI.

\subsection{VTE and Bleeding Risk Assessment}

Individual risk factor assessment for VTE focuses on patientspecific characteristics, incorporating surgery-specific risk in addition to medical factors. Alternatively, group-specific recommendations for thromboprophylaxis, such as major orthopedic surgery, exist. Although individualized risk factor assessment carries considerable appeal, it is limited by lack of validation in orthopedic surgery. In addition, although we can find ORs for individual risk factors for VTE, the interaction of these factors in a given patient is not well understood. Such risk factors include (multivariate ORs): previous VTE (OR, 3.4-26.9), ${ }^{41-43}$ cardiovascular disease (OR, 1.4-5.1), ${ }^{41,42}$ Charlson comorbidity index $\geq 3$ (OR, 1.45-2.6), ${ }_{41,44}$ BMI $>25 \mathrm{~kg} / \mathrm{m}^{2}(\mathrm{OR}, 1.8),{ }^{43}$ age $(\mathrm{OR}, 1.1$ for each 5 -year increment 


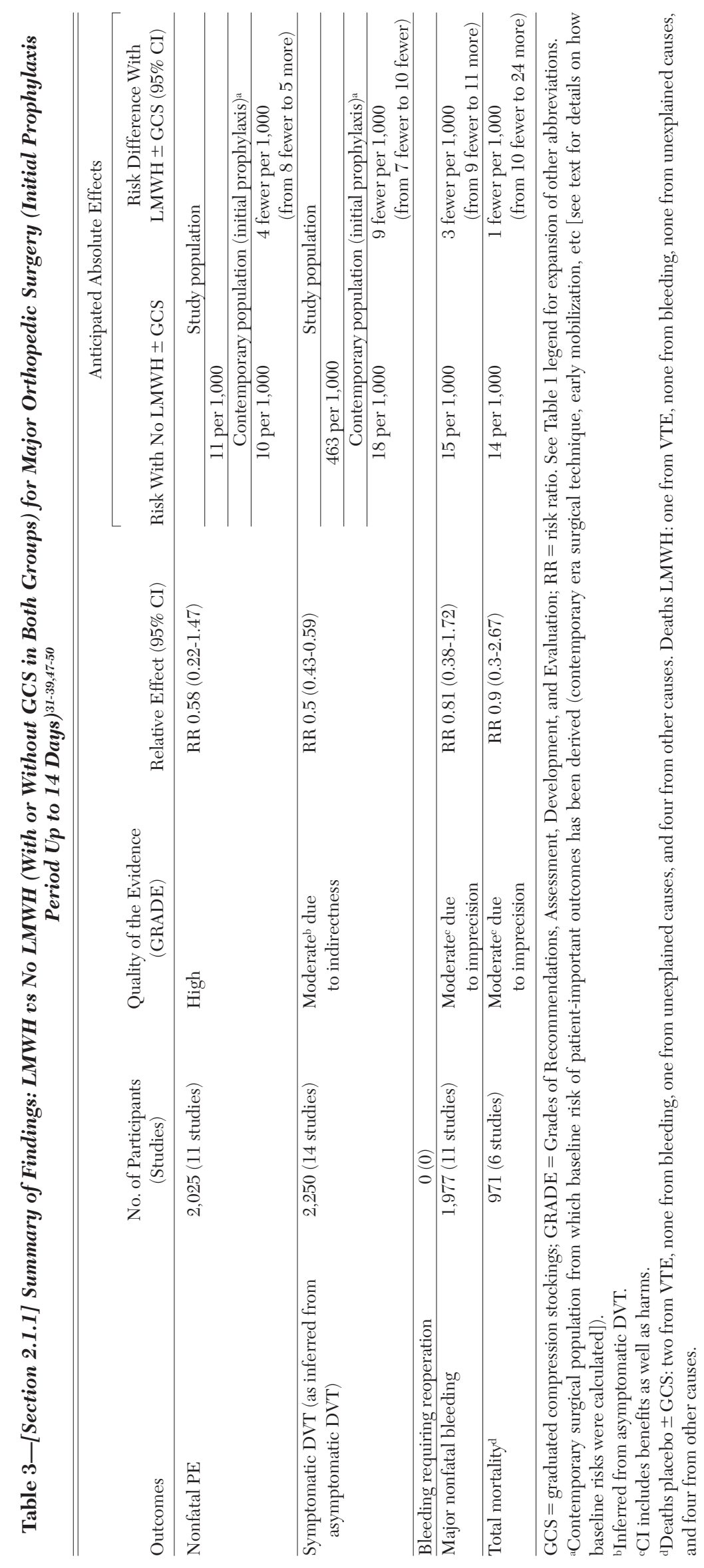

Prevention of VTE in Orthopedic Surgery Patients 
vs age $<40$ years), ${ }^{29}$ advanced age $\geq 85$ years (OR, 2.1), ${ }^{43}$ varicose veins (OR, 3.6), ${ }^{42}$ and ambulation before day 2 after surgery (OR, 0.7). ${ }^{42}$

However, for major orthopedic surgery, the surgery-specific risk far outweighs the contribution of the patient-specific factors. For instance, a population-based case-control study looked at 635 patients with first-time VTE during a period from 1976 to 1990 compared with controls. ${ }^{45}$ The factor hospitalized with recent surgery resulted in an OR of 22 (95\% CI, 9-50). In our view, individual risk estimation is not sufficiently secure to mandate different recommendations for different risk strata.

Similarly, we did not find any bleeding risk assessments that have been sufficiently validated in the orthopedic surgery population. Table 4 lists general risk factors for bleeding in the setting of orthopedic surgery, but specific thresholds for using mechanical compression devices or no prophylaxis instead of anticoagulant thromboprophylaxis have not been established.

\subsection{Values and Preferences}

Both symptomatic VTE and bleeding are important, unwanted outcomes from the perspective of a patient. There is little information available on the opinion of patients regarding the relative disutility of these two outcomes. This is, however, a very important consideration because many of the approaches to reducing postoperative VTE use anticoagulants, and these all increase the risk of bleeding. Therefore, it is critical to judge the relative balance of disutility between an episode of symptomatic VTE and of bleeding. To do this, we used available literature and the results of a rating exercise of physicians involved in developing the Antithrombotic Therapy and Prevention of Thrombosis, 9th ed: American College of Chest Physicians Evidence-Based Clinical Practice Guidelines recommendations. ${ }^{46}$ On balance, it was believed that the adverse consequences of a major postoperative bleeding event were approximately equal to those of symptomatic VTE. In developing recommendations, we therefore considered these as equivalent in their aversiveness or disutility.

\subsection{Patients Undergoing Major OrTHOPEDIC SURGERY: THA, TKA, HFS}

\subsection{Thromboprophylaxis Compared With No Prophylaxis}

\subsubsection{LMWH vs No Prophylaxis-Initial and} Extended-Period Prophylaxis: LMWH has become the thromboprophylaxis agent against which newer drugs are compared. Several studies published in the mid-1980s, during the 1990s, and as recently as 2008 have investigated LMWH compared with no prophylaxis in $>2,000$ patients to test the hypothesis that LMWH decreases the incidence of VTE after arthro-

Table 4-[Sections 1.4, 2.6, 2.8] General Risk Factors for Bleeding

\footnotetext{
- Previous major bleeding (and previous bleeding risk similar to current risk)

- Severe renal failure

- Concomitant antiplatelet agent

- Surgical factors: history of or difficult-to-control surgical bleeding during the current operative procedure, extensive surgical dissection, and revision surgery
}

plasty $^{31-39,47,48}$ and HFS. ${ }^{49,50}$ Our analysis included all studies of LMWH vs no prophylaxis whether GCS were used in both groups because this would not affect the relative risk observed for LMWH. This allowed us to make more-precise estimates for risk reduction of VTE and bleeding. We decided against pooling across other patient groups, such as nonorthopedic surgery patients, because of differences in risk and technique. In those trials, LMWH usually was continued for 6 to 14 days, which coincided with discharge from the hospital at the time those trials were conducted.

For THA or TKA, LMWH consistently reduces asymptomatic DVT by $\sim 50 \%$ (combined risk ratio [RR], $0.50 ; 95 \%$ CI, 0.43-0.59). Similar results were seen in two studies in HFS involving 218 patients. ${ }^{49,50}$ Combining results from all relevant studies failed to demonstrate or to exclude a beneficial effect of LMWH on PE (RR, 0.58; 95\% CI, 0.22-1.47). On the basis of moderate-quality evidence, the use of LMWH for the initial prophylaxis period (10-14 days) is expected to prevent 13 VTE per 1,000 patients undergoing major orthopedic surgery, assuming a baseline risk of $1 \%$ for $\mathrm{PE}$ and $1.8 \%$ for symptomatic DVT.

The definition and reporting of major bleeding was inconsistent across studies, and the results failed to demonstrate or to exclude a detrimental effect of LMWH on the occurrence of major bleeding (RR, $0.81 ; 95 \%$ CI, 0.38-1.72); the $95 \%$ CI was nine fewer to 11 more major bleeding events per 1,000. Few deaths occurred, and these were mainly seen in HFS patients; two VTE-associated deaths were seen in the placebo groups compared with one in the LMWH arm (Table 3, Figs S1-S4, Table S1).

Extended Prophylaxis With LMWH-Observational data suggest that the incidence of VTE after TKA and THA returns to the presurgical risk levels at about 3 months postoperation. ${ }^{13,27}$ Extending thromboprophylaxis beyond 10 to 14 days, which coincided with the duration of hospital stay in older trials, is now used often, and recent trials have included prophylaxis for $>30$ days, particularly after THA.

Three systematic reviews ${ }^{51-53}$ have examined the effect of extended-use LMWH vs placebo from seven trials enrolling $>2,600$ patients mainly after THA $^{54-60}$; one trial also included TKA patients. ${ }^{55}$ Most trials randomized patients at discharge (which occurred 6-14 days postoperation) to continue with LMWH vs placebo until postoperative days 27 to 35 . Because most studies screened patients at discharge and only enrolled patients without asymptomatic DVT, some authors have argued that the absolute event rate may be inaccurate. ${ }^{51}$ However, as discussed in the Methods section, the relative VTE risks should not be affected. Additionally, we are providing baseline risks based on contemporary practice. 
No PE was observed in the LMWH group compared with five of 1,104 in the placebo group. Symptomatic DVT was reduced by more than one-half (RR, 0.46; 95\% CI, 0.26-0.82). Results failed to demonstrate or exclude an effect of LMWH on major bleeding (RR, $0.43 ; 95 \%$ CI, 0.11-1.65) or on total mortality (RR, 0.39; 95\% CI, 0.08-1.98), although the only two deaths from VTE were in the placebo group. On the basis of high-quality evidence, extending thromboprophylaxis up to 35 days postoperation compared with 10 to 14 days will result in nine fewer symptomatic VTE per 1,000 without an appreciable increase in major bleeding (Table 5, Figs S5-S8, Table S2).

\subsubsection{LDUH vs No Prophylaxis-Initial Prophylaxis} Period: Numerous RCTs examined LDUH vs no prophylaxis throughout the 1970s and early 1980s. A systematic review involving close to 7,000 patients demonstrated a relative risk reduction of $58 \%$ ( $\mathrm{RR}$, 0.42 ; 95\% CI, 0.36-0.50) in the incidence of asymptomatic DVT found by screening across 57 trials from surgical and nonsurgical populations. ${ }^{3}$ Only four of the 12 studies in orthopedic surgery used venography to confirm thrombotic events; the others used fibrinogen uptake. The relative effect estimates were similar for the eight studies involving $>500$ patients undergoing elective hip replacement (RR, $0.53 ; 95 \% \mathrm{CI}$, $0.32-0.89)$ and six trials in HFS (RR, 0.56 ; $95 \% \mathrm{CI}$, 0.39-0.81) compared with the entire population.

A significant reduction in PE was observed by pooling all trials from surgical and nonsurgical populations (RR, 0.69; 95\% CI, 0.49-0.99). Unfractionated heparin (UFH) was associated with a trend toward an increased risk of major bleeding (RR, 1.26; 95\% CI, 0.99-1.6). Using our estimates of baseline risk, the relative effect translates into a reduction of 13 symptomatic VTEs per 1,000 with UFH, with an increase in major bleeding events of four per 1,000. Mortal events in major orthopedic surgery were only reported for HFS trials (RR, 0.96; 95\% CI, 0.55-1.67), and across all patient groups, UFH appeared to have little or no effect on overall mortality (RR, 0.91; 95\% CI, 0.8-1.04). The underlying quality of evidence was moderate (Table 6, Table S3).

\subsubsection{Vitamin K Antagonist vs No Prophylaxis-} Initial Prophylaxis Period: Evidence for use of vitamin K antagonists (VKAs) comes from eight RCTs involving 703 patients, most with hip fracture, that demonstrated a $55 \%$ relative risk reduction in primarily asymptomatic DVT (RR, 0.45; 95\% CI, 0.32-0.62). ${ }^{3}$ PEs were reduced by almost $80 \%$ (RR, $0.21 ; 95 \%$ CI, 0.08-0.53), although this result is based on only 32 events. Although patients and clinicians in those trials were not blinded, two trials blinded the thrombosis outcome adjudicators. VKA use was associated with a trend toward increased bleeding ( RR, 1.50; 95\% CI, 0.92-2.43), which was described as wound hematomas, wound bleeding, wound leakage, hematuria, and hematemesis. There was also more blood transfused and one intracerebral hemorrhage in the VKA group. ${ }^{61}$ Results showed a trend toward a mortality reduction (RR, 0.76; 95\% CI, 0.54-1.07). Based on moderate-quality evidence, VKA prophylaxis for 10 to 14 days would result in 18 fewer VTEs and seven more major bleeding events per 1,000 (Table 7, Table S4).

\subsubsection{Aspirin vs No Prophylaxis-Initial Plus} Extended Prophylaxis Period: Aspirin is inexpensive, orally administered, and widely available. In the 1970s and 1980s, a number of studies investigated the use of aspirin in THA, ${ }^{10,62-65}$ TKA, ${ }^{66}$ and HFS.$^{67-72}$ Those studies used high doses of aspirin of up to $3.8 \mathrm{~g}$ daily. They suffer from serious methodologic limitations, including the use of an unreliable method for DVT screening, such as fibrinogen uptake; lack of blinding; and lack of allocation concealment. Additionally, there was strong evidence of reporting and publication bias.

Because of this low quality of evidence, a subsequent trial, PEP, was initiated to study the effects of $160 \mathrm{mg}$ of aspirin given for 35 days against placebo in a routine practice setting that allowed for additional antithrombotic intervention if deemed necessary. ${ }^{30}$ This multicenter trial enrolled 17,444 patients predominantly after HFS in the mid-1990s and included patients after hip arthroplasty. This study has been criticized because of perceived changes in the primary outcome and adjustments of sample size. There were additional problems with the presentation of the results that made evaluation of the bleeding end point difficult. The PEP study, however, had considerable strengths, including concealment of allocation through remote randomization; blinding of patients, caregivers, and investigators; and an independent, blinded adjudication committee that interpreted objectively confirmed end points, such as venographically or DUS-confirmed DVT, high probability ventilation/ perfusion scans, or pulmonary angiograms. In addition, there was near-complete follow-up (99.6\%).

Although the combined results (arthroplasty and HFS) failed to demonstrate or exclude a beneficial effect of aspirin on nonfatal PE, there was a modest $28 \%$ relative risk reduction in symptomatic DVT $(\mathrm{RR}$, $0.72 ; 95 \%$ CI, 0.53-0.96). The upper boundary of the CI crosses a threshold of $10 \%$ that clinicians consider the desirable minimum clinical effect, and the CI of the absolute effect includes as few as one less DVT in 1,000. The results, therefore, are imprecise, despite the large number of patients enrolled. Although there were $19 \mathrm{VTE}$-associated deaths in the aspirin group compared with 45 in the placebo 


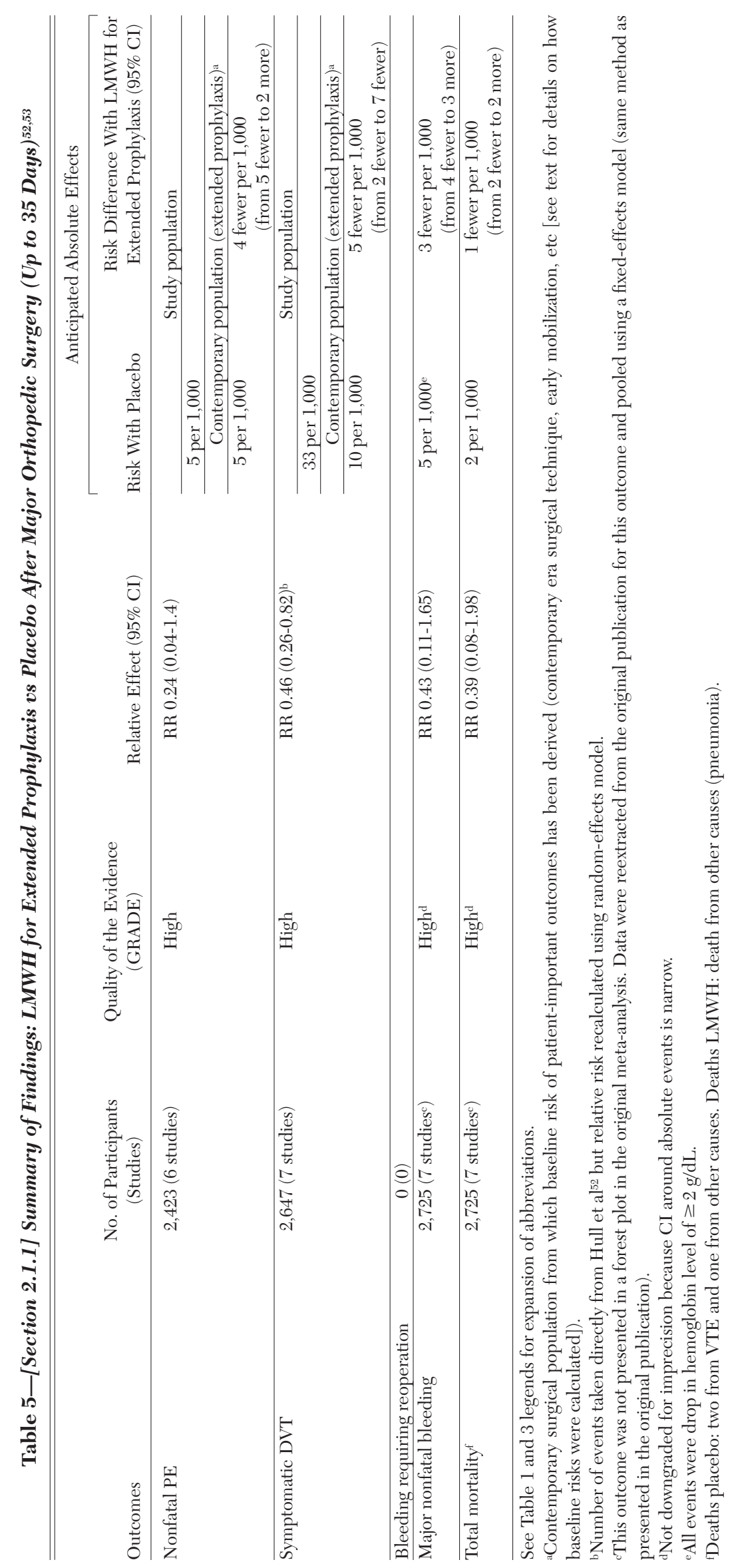




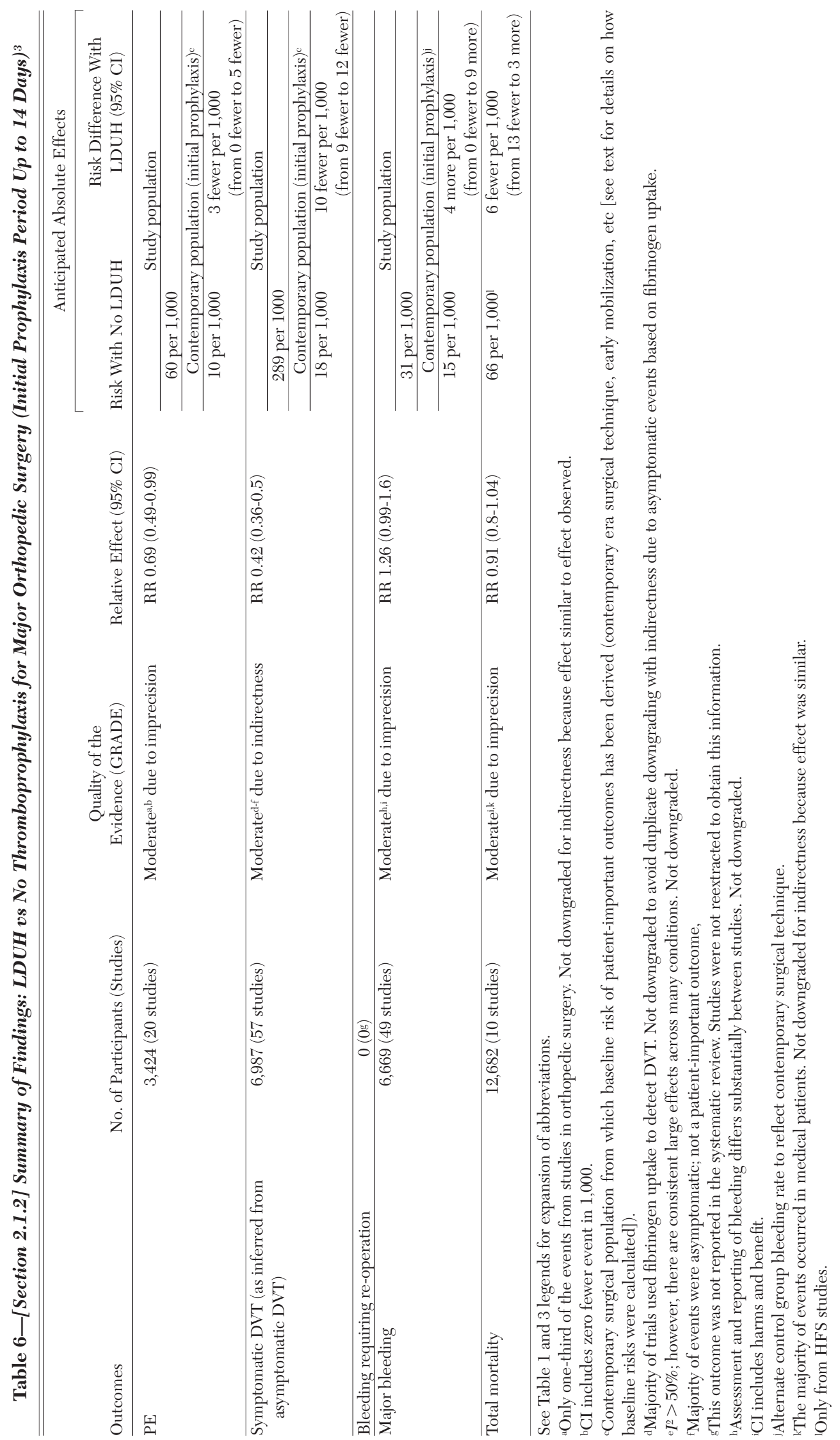

Prevention of VTE in Orthopedic Surgery Patients 


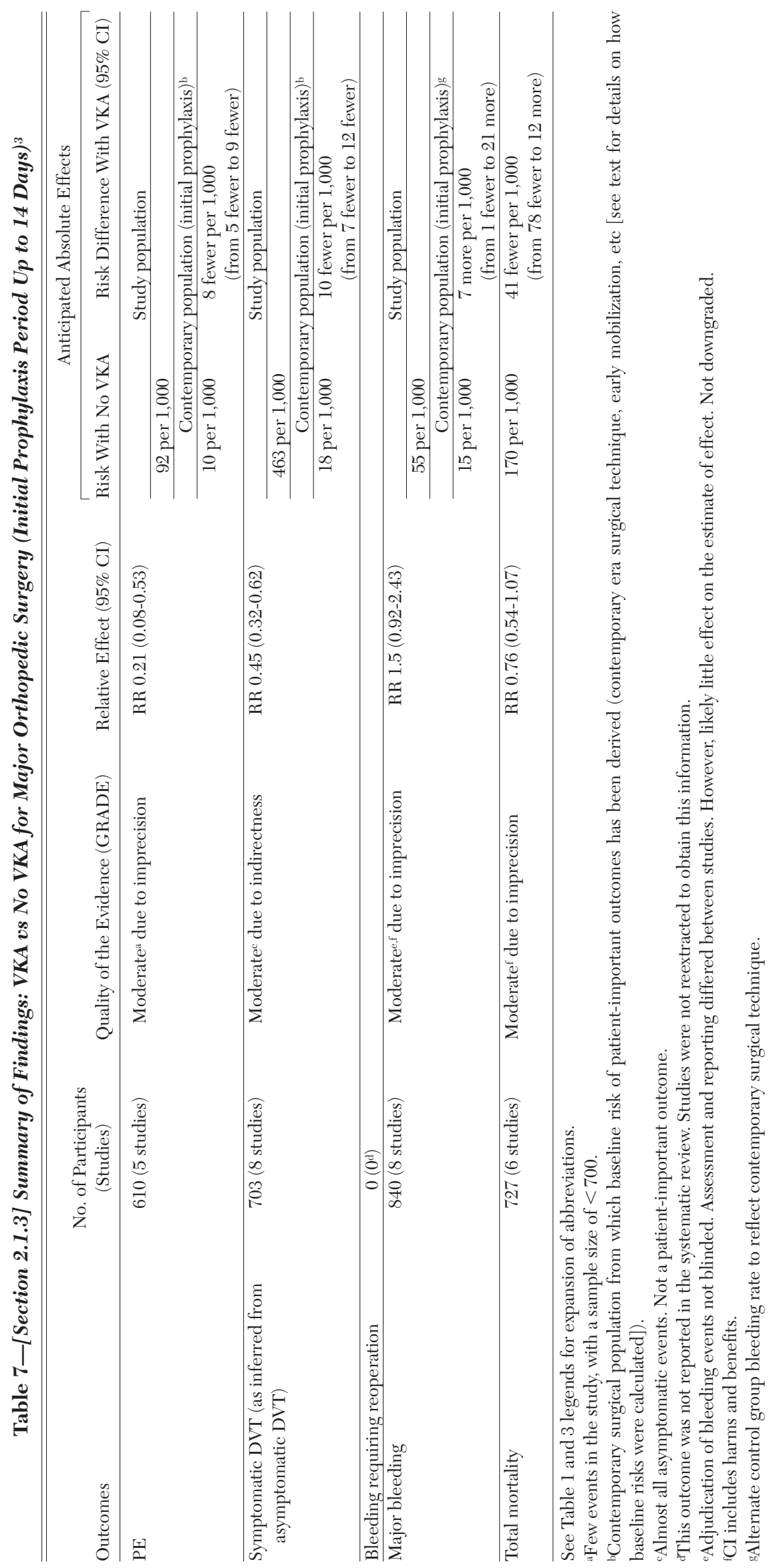


group, the RR for overall mortality was 0.96 (95\% CI, 0.85-1.09). There was a trend toward more major nonfatal bleeding associated with aspirin ( $\mathrm{RR}, 1.12$; 95\% CI, 0.94-1.34), but there were no difference in bleeding requiring reoperation or bleeding deaths. In addition, the investigators reported no difference in major bleeding in the subgroup that did not receive additional heparin (aspirin alone, 95 of 3,711; placebo alone, 94 of 3,789). Perioperative aspirin use was associated with a trend toward more nonfatal myocardial infarctions (RR, 1.59; 95\% CI, 0.98-2.57).

In summary, given the moderate-quality evidence, it appears that low-dose aspirin given before major orthopedic surgery and continued for 35 days will result in seven fewer symptomatic VTEs per 1,000 but at the expense of a possible three more major bleeding episodes and two additional nonfatal myocardial infarctions per 1,000, thus resulting in a close balance between desirable and undesirable effects (Table 8, Figs S9-S14, Table S5).

When considering aspirin vs anticoagulants, the impact of anticoagulants on myocardial infarction has not been studied. The relative effects of aspirin are likely similar whether other additional thromboprophylaxis, including heparins or mechanical interventions, are used. The absolute reduction in thrombosis, however, will be greater in the absence of anticoagulants than in their presence, and the absolute increase in bleeding, if present, is likely to be less in the absence of anticoagulants than in their presence.

\subsubsection{Fondaparinux vs No Prophylaxis-Extended} Prophylaxis Period: We did not identify trials examining fondaparinux vs placebo for the initial prophylaxis period. However, one trial that used fondaparinux for 6 to 8 days in HFS randomized 656 patients on postoperative days 6 to 8 to either extended fondaparinux for an additional 19 to 23 days or placebo. ${ }^{28}$ No PE was observed in the fondaparinux group compared with two of 330 in the placebo group. The results for symptomatic DVT failed to demonstrate or to exclude a beneficial effect (RR, 0.17; $95 \% \mathrm{CI}$, 0.02-1.39). Six major bleeding events occurred in the fondaparinux group compared with none in the placebo group (RR, 13; 95\% CI, 0.74-231), and results failed to exclude a beneficial or detrimental effect of fondaparinux on total mortality (RR, 0.76; 95\% CI, 0.27-2.16) (Table 9, Figs S15-S20; Table S6).

Based on moderate-quality evidence, 12 fewer symptomatic VTE per 1,000 would be expected with the use of fondaparinux, but this beneficial effect would be offset by an increase of at least 12 major bleeds per 1,000. The close balance between desirable and undesirable effects makes the use of fondaparinux for extended thromboprophylaxis less appealing, particularly compared with LMWH.
2.1.6 Mechanical Interventions vs No ProphylaxisInitial Prophylaxis: There are few data regarding the use of GCS compared with no prophylaxis in major orthopedic surgery, although they are used frequently in conjunction with other thromboprophylaxis. A systematic review identified nine trials in a variety of patient populations, ${ }^{3}$ but only one small trial included orthopedic surgery patients. ${ }^{73}$ The pooled results from all trials failed to demonstrate or to exclude a beneficial or detrimental effect of GCS on PE (RR, 0.63; 95\% CI, 0.32-1.25). Although GCS showed a beneficial effect on asymptomatic, venographically confirmed DVT overall (RR, 0.51; 95\% CI, 0.36-0.73), evidence from a higher-quality large trial in patients with stroke ${ }^{74,75}$ only showed a trend toward reduced symptomatic DVT (RR, 0.92; 95\% CI, 0.77-1.09), and this was offset by a fourfold increase in skin complications (Table 10, Table S7).

Mechanical approaches to perioperative thromboprophylaxis with pneumatic compression devices have the potential advantage of reducing the incidence of VTE but without the risk for increased bleeding. In addition, an intermittent pneumatic device (IPCD) can be used in the contralateral leg even during surgery and the immediate postoperative period.

Seven RCTs that included $>900$ patients undergoing arthroplasty or HFS compared mechanical compression to no thromboprophylaxis. ${ }^{31,66,76-79}$ Six used an IPCD, and one a venous foot pump (VFP). ${ }^{77}$ The risk of bias varied. For instance, in most trials, it was unclear whether allocation was concealed. Blinding of patients and caregivers is not possible in such studies, and not all provided blinded VTE adjudication. In addition, a systematic review indicated funnel plot asymmetry, raising the possibility of publication bias. ${ }^{80}$ Variation in design and performance of the devices as well as information about compliance, which was rarely reported in older trials, introduce uncertainty in how to apply the evidence.

Taken together, the evidence is of low quality. Nevertheless, a relative risk reduction of $>50 \%$ was observed for both DVT and PE in THA, TKA, and HFS (PE RR, 0.4; 95\% CI, 0.17-0.92; DVT RR, 0.46; 95\% CI, 0.35-0.61). The corresponding estimated absolute risk difference is 16 fewer symptomatic VTE per 1,000 . The results failed to demonstrate or to exclude a beneficial effect on mortality (Table 11, Figs S21-S23, Table S8).

Compliance remains the biggest challenge associated with the use of IPCDs. Most devices currently in use require an external power source, and they often are found not functioning when patients are getting out of bed or being transported. Properly functioning IPCDs were encountered in $<50 \%$ in one study ${ }^{81}$ and as low as $19 \%$ in another. ${ }^{82}$ In addition, those studies reported no significant improvement in compliance 


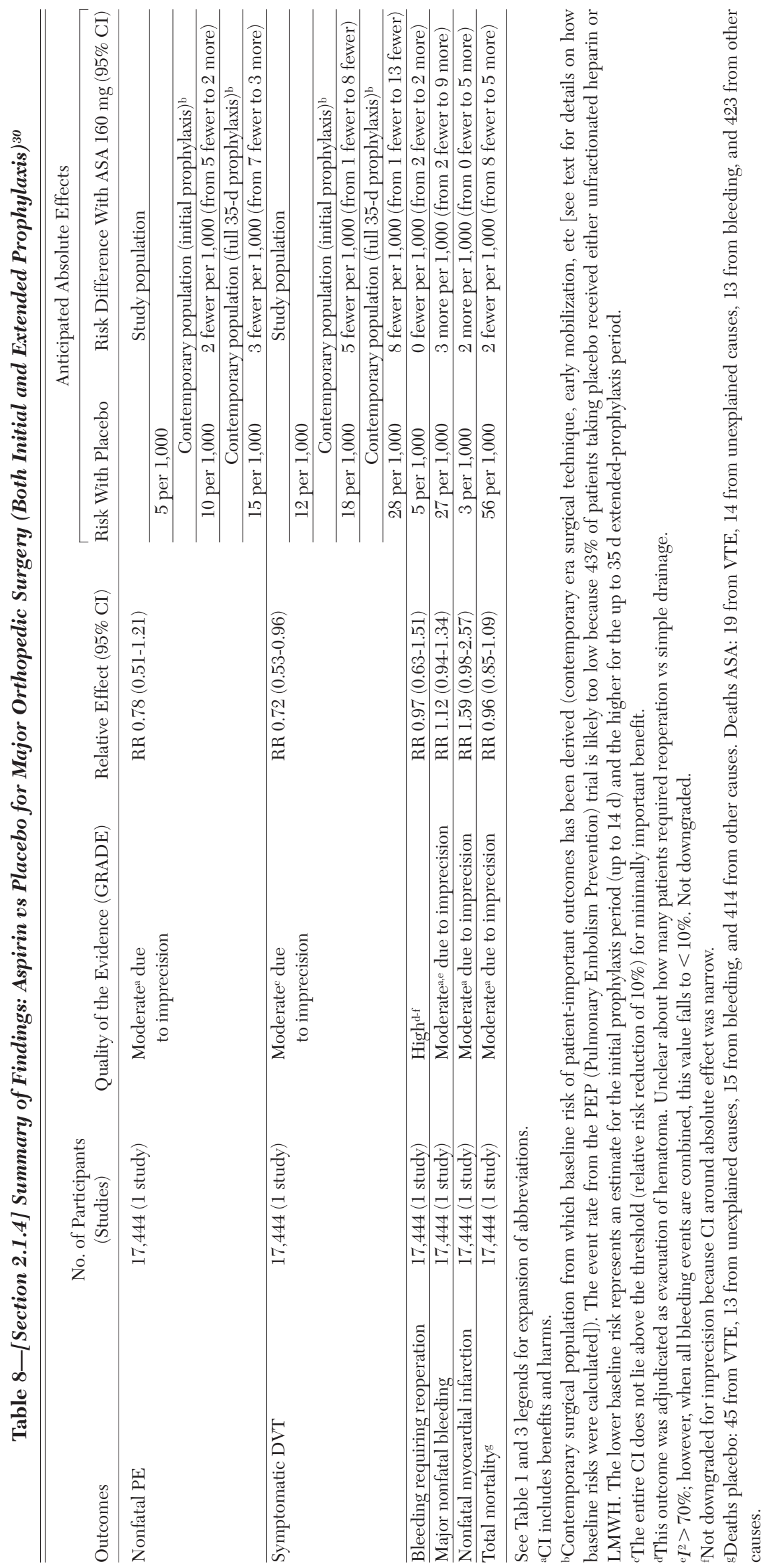




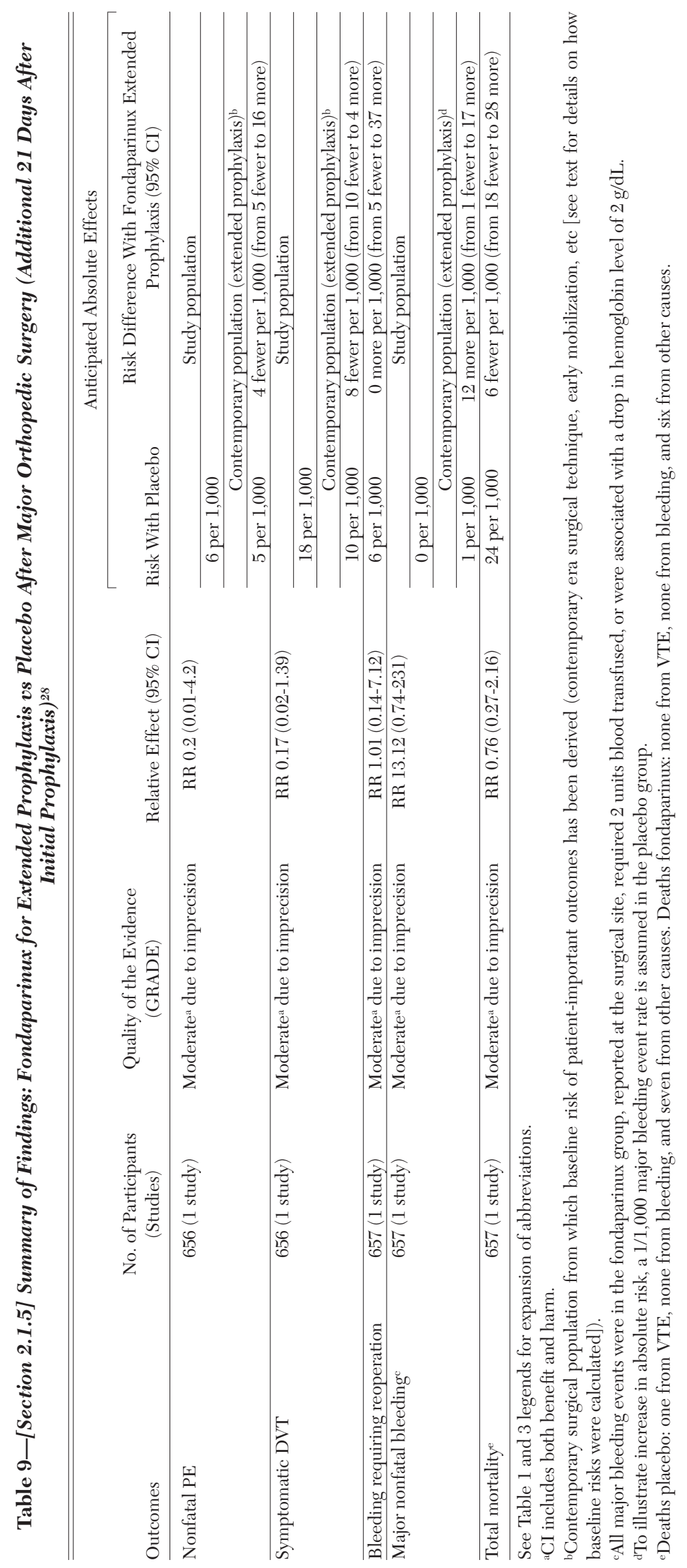

Prevention of VTE in Orthopedic Surgery Patients 


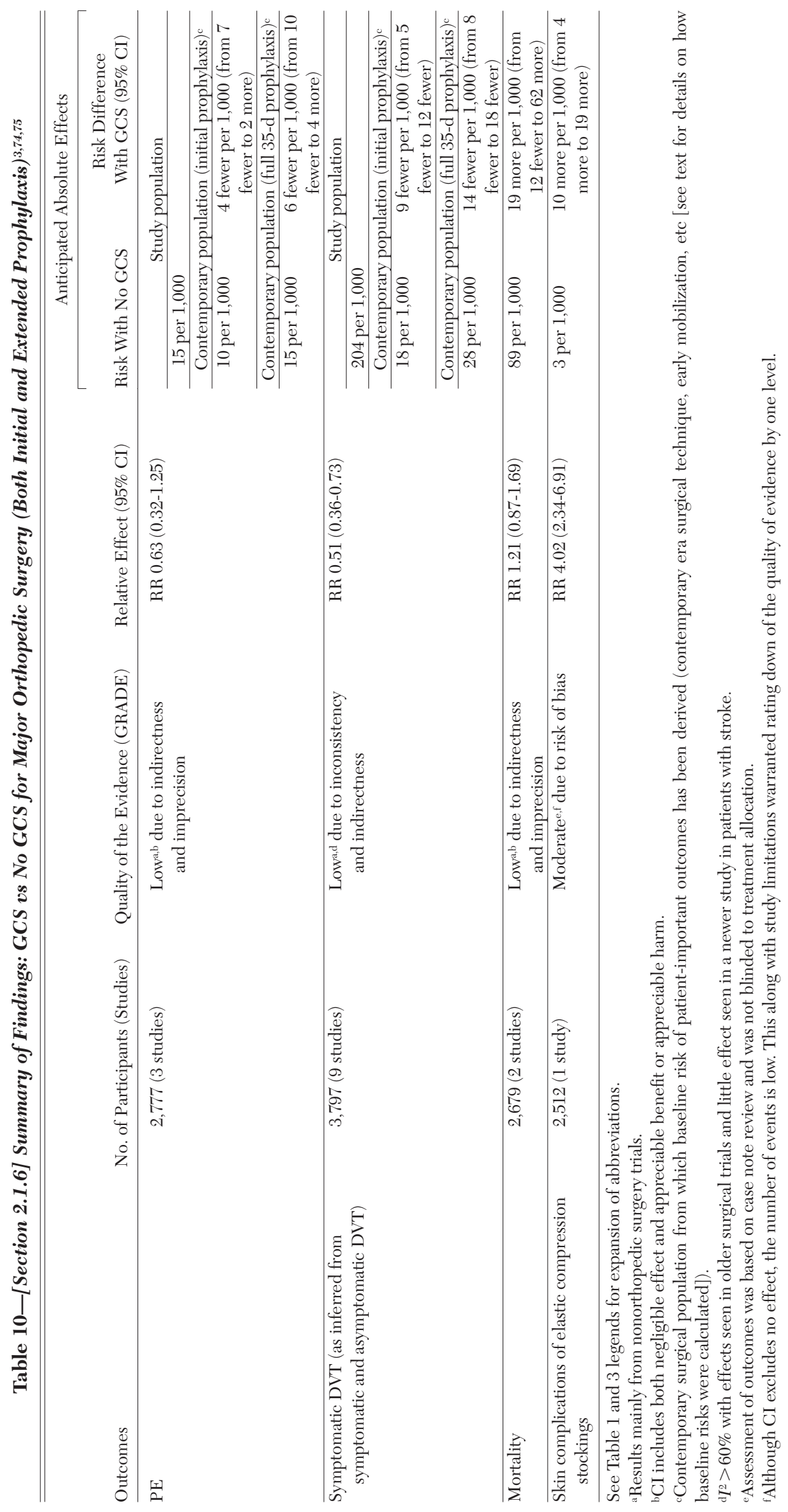




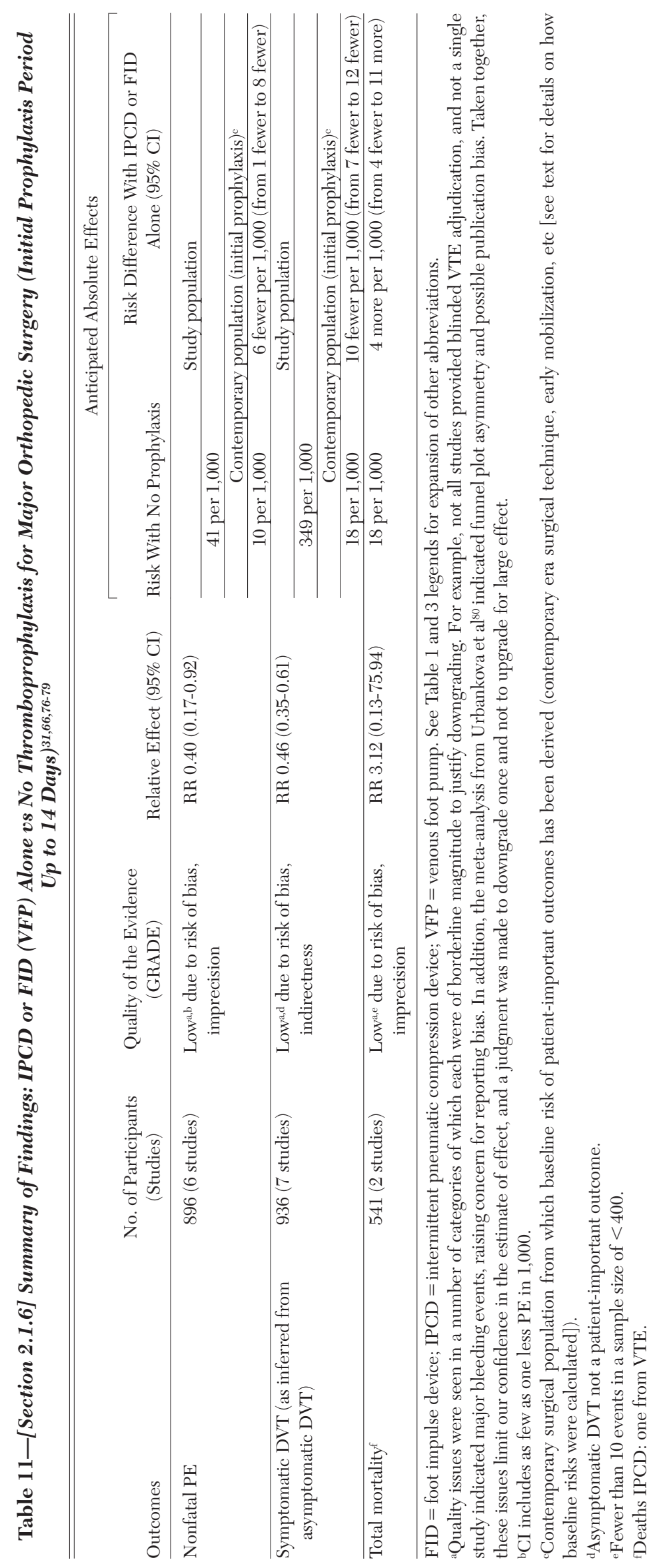


rates with systematic education and training of nursing and other staff. However, because the low compliance is presumably largely due to the IPCD requiring a power outlet, newer battery-powered portable devices are now available, and a recent study reported increased compliance with those devices (77.7\% vs $58.9 \%) .{ }^{83}$

Other disadvantages of IPCDs are logistical and include having enough units available and keeping them in good working condition. Additionally, there are multiple devices available that have differing properties, and this makes comparison of benefits difficult.

In summary, use of an IPCD for thromboprophylaxis is attractive because of its possible effectiveness and likelihood of no increase in bleeding events. However, suboptimal compliance with the use of an IPCD while in the hospital and the inability to continue this treatment at home for most patients may limit their use. Newer battery-powered IPCDs that monitor compliance might be successfully used after discharge.

\subsubsection{Other Modalities vs No Thromboprophylaxis:} Few recent orthopedic trials have compared other thromboprophylaxis agents against placebo. ${ }^{84}$ However, large, well-done trials with direct comparisons against LMWH are available for newer antithrombotic agents, and their similar effects attest to their benefits compared with no prophylaxis. Examples include fondaparinux, apixaban, dabigatran, and rivaroxaban. The latter three have been evaluated in THA and TKA but not in HFS.

Recommendations

2.1.1. In patients undergoing THA or TKA, we recommend use of one of the following for a minimum of 10 to 14 days rather than no antithrombotic prophylaxis: LMWH, fondaparinux, apixaban, dabigatran, rivaroxaban, LDUH, adjusted-dose VKA, aspirin (all Grade 1B), or an IPCD (Grade 1C).

Remarks: We recommend the use of only portable, battery-powered IPCDs capable of recording and reporting proper wear time on a daily basis for inpatients and outpatients. Efforts should be made to achieve $18 \mathrm{~h}$ of daily compliance. One panel member believed strongly that aspirin alone should not be included as an option.

2.1.2. In patients undergoing HFS, we recommend use of one of the following rather than no antithrombotic prophylaxis for a minimum of 10 to 14 days: LMWH, fondaparinux, LDUH, adjusted-dose VKA, aspirin (all Grade 1B), or an IPCD (Grade 1C).

Remarks: We recommend the use of only portable, battery-powered IPCDs capable of recording and reporting proper wear time on a daily basis for inpa- tients and outpatients. Efforts should be made to achieve $18 \mathrm{~h}$ of daily compliance. One panel member believed strongly that aspirin alone should not be included as an option.

\subsection{Timing of Commencement of Anticoagulants}

Risk of bleeding complications is closely linked to the timing of thromboprophylaxis around surgery. For instance, many trials started LMWH before surgery, sometimes as close to surgery as $2 \mathrm{~h}$. Trials in which LMWH was started $2 \mathrm{~h}$ before surgery showed a larger increase in major bleeding. ${ }^{85} \mathrm{~A}$ systematic review compared preoperative (at least $12 \mathrm{~h}$, usually defined as the evening before surgery), postoperative (12-24 $\mathrm{h}$ after surgery), and perioperative $(2 \mathrm{~h}$ before to $\leq 4 \mathrm{~h}$ after) initiation of LMWH. ${ }^{86}$ Perioperative initiation of LMWH resulted in major bleeding rates of $5 \%$ to $7 \%$, whereas rates were in the $1 \%$ to $3 \%$ range with preoperative and postoperative administration. The authors concluded that starting prophylaxis $\sim 12 \mathrm{~h}$ before surgery is no more effective in preventing DVT than starting $12 \mathrm{~h}$ postoperatively and that despite a trend of lower VTE rates associated with perioperative initiation, the increased risk of major bleeding outweighed any potential benefit. These findings were based on venographically confirmed, but mostly asymptomatic DVT, and the comparisons were indirect. It is unknown whether this would be equally true for symptomatic events or would be confirmed with direct comparisons.

Recommendation

2.2. For patients undergoing major orthopedic surgery (THA, TKA, HFS) and receiving LMWH as thromboprophylaxis, we recommend starting either $12 \mathrm{~h}$ or more preoperatively or $12 \mathrm{~h}$ or more postoperatively rather than within $4 \mathrm{~h}$ or less preoperatively or $4 \mathrm{~h}$ or less postoperatively (Grade 1B).

\subsection{Choice of Thromboprophylaxis}

2.3.1 LMWH vs LDUH-Initial Prophylaxis: A systematic review of comparisons between LMWH and LDUH included $>23,000$ patients from 64 trials across surgical and nonsurgical patient groups; 2,800 patients were included in arthroplasty or HFS trials. ${ }^{3}$ Pooled estimates showed a $20 \%$ relative risk reduction of primarily asymptomatic DVT in favor of LMWH (RR, 0.80; 95\% CI, 0.73-0.88), with similar effects seen in the subgroups of THA, TKA, and HFS. LMWH was associated with a trend toward reduced PE in THA, although the pooled results from all groups failed to demonstrate or exclude a beneficial effect of LMWH on PE (RR, 0.78; 95\% CI, 0.49-1.24). There was a trend toward less major 
bleeding with LMWH after THA (RR, 0.59; 95\% CI, 0.34-1.01) but not across all trials (RR, 0.91; 95\% CI, 0.75-1.09). These results suggest that LMWH may reduce symptomatic VTE from 16 per 1,000 with LDUH to 13 per 1,000 without an increase in major bleeding (Table 12, Table S9).

There have been no trials directly comparing the effectiveness of LDUH every $12 \mathrm{~h}$ vs LDUH every $8 \mathrm{~h}$. In 1988, two separate meta-analyses were published that commented on UFH dosing schedules. ${ }^{87,88}$ Collins et al ${ }^{87}$ included studies in orthopedic, urologic, and general surgery. Overall, a 72\% odds reduction was found for the 8 -h regimen and a $63 \%$ odds reduction for the 12-h regimen, which was not a significant difference. In orthopedic surgery studies only, the odds reduction was $68 \%$ for both regimens. In contrast, the meta-analysis by Clagett et al ${ }^{88}$ was confined to general surgery studies and reported DVT rates in pooled analysis of $11.8 \%$ with the 12 -h regimen compared with $7.5 \%$ using the 8 -h regimen. The authors concluded that the 8 -h regimen was superior. Neither meta-analysis reported differences in major bleeding between these regimens. These indirect comparisons provide only low-quality, or perhaps very-low-quality, evidence for the alternate regimens.

\subsubsection{LMWH vs VKAs-Initial and Extended} Prophylaxis: Several RCTs in THA and TKA ${ }^{85,89-95}$ but not HFS have compared LMWH to VKA (mainly warfarin) in $>9,000$ patients for the initial prophylaxis. The results failed to establish or refute a difference in PE (RR, 0.68; 95\% CI, 0.22-2.1), but LMWH use was associated with significantly less asymptomatic DVT (RR, 0.68; $95 \%$ CI, 0.6-0.78) at the cost of an increase in major bleeding events (RR, 1.56; 95\% CI, 1.23-2.0). Most of these trials, however, started LMWH shortly before surgery, which as we have discussed, likely increases the risk of bleeding substantially. Our sensitivity analysis, excluding trials that administered LMWH close to the operation $(<12 \mathrm{~h}$ perioperatively), ${ }^{85,89-91}$ still shows a trend in increased bleeding events, but the magnitude of the effect is smaller (RR, 1.36; 95\% CI, 0.95-1.96). We used this RR in our evidence summaries for the initial thromboprophylaxis period with VKA vs LMWH.

Based on those considerations, we estimate that there will be three fewer symptomatic VTE events per 1,000 with the use of LMWH compared with warfarin, but this benefit is closely balanced by a possible increase of four major bleeding events per 1,000. However, given the two fatal bleeding events with the use of VKA (vs none in the LMWH group), safety concerns with warfarin remain (Table 13, Figs S24-S28, Table S10). Furthermore, the evidence regarding extended prophylaxis, presented next, favors LMWH.
Extended Prophylaxis With LMWH vs VKA-One large trial enrolling $>1,200$ patients scheduled for THA compared LMWH vs adjusted-dose VKA (international normalized ratio [INR] 2-3) given for an extended 6-week period. ${ }^{96}$ No PE was observed in the LMWH group compared with four of 636 in the VKA arm. The results failed to demonstrate or to exclude a beneficial effect of VKA compared with LMWH for asymptomatic DVT (RR, 1.35; 95\% CI, 0.70-2.6). However, almost four times as many major nonfatal bleeds were observed with VKA compared with LMWH (RR, 3.9; $95 \%$ CI, 1.9-8.1). One of the two deaths in the study (both in the VKA group) was related to a fatal GI bleed (Table 14, Figs S29-S32, Table S11). In summary, there is moderate-quality evidence of a substantial increase in major bleeding with the use of VKA compared with LMWH for extended prophylaxis.

\subsubsection{LMWH vs Aspirin-Initial and Extended} Prophylaxis: Two trials compared LMWH against aspirin, with one trial using aspirin $325 \mathrm{mg}$ bid $^{97}$ and the other $650 \mathrm{mg}$ bid (only the abstract was available). ${ }^{98}$ The pooled results showed more asymptomatic DVT in the aspirin group (RR, 1.87; 95\% CI, 1.3-2.7), but PEs were too few to provide a meaningful estimate. No major bleeding events or deaths were reported. Overall, the evidence from a head-tohead comparison of LMWH compared with aspirin is sparse and of low quality. However, indirect evidence from trials of LMWH and aspirin against placebo also shows greater relative efficacy of LMWH (Table 15, Figs S33, S34, Table S12).

2.3.4 LMWH vs Fondaparinux-Initial Prophylaxis: Several large trials compared fondaparinux $2.5 \mathrm{mg}$ started 6 to $8 \mathrm{~h}$ after wound closure with LMWH (started either $12 \mathrm{~h}$ before or after surgery) in THA, ${ }^{99,100}$ TKA, ${ }^{101}$ and HFS. ${ }^{102}$ Because the relative effects across outcomes were similar, we included a trial in abdominal surgery patients, ${ }^{103}$ thus including $>10,000$ patients. In addition, we included all trials, whether GCS were used in all or only in a portion of patients, as long as it was used equally in both arms.

The pooled results failed to demonstrate or exclude a beneficial or detrimental effect of fondaparinux on symptomatic DVT and PE despite a substantial reduction in asymptomatic DVT. There was a substantial increase in bleeding requiring reoperation associated with the use of fondaparinux (RR, 1.85; $95 \%$ CI, 1.1-3.11), but the results failed to demonstrate a difference in nonfatal major bleeding ( RR, 1.35; $95 \%$ CI, 0.89-2.05). VTE deaths were rare and similar in both groups (fondaparinux 5/5,049 vs LMWH $6 / 5,046)$. There were two fatal bleeds with fondaparinux and three with LMWH. Caution is advised 


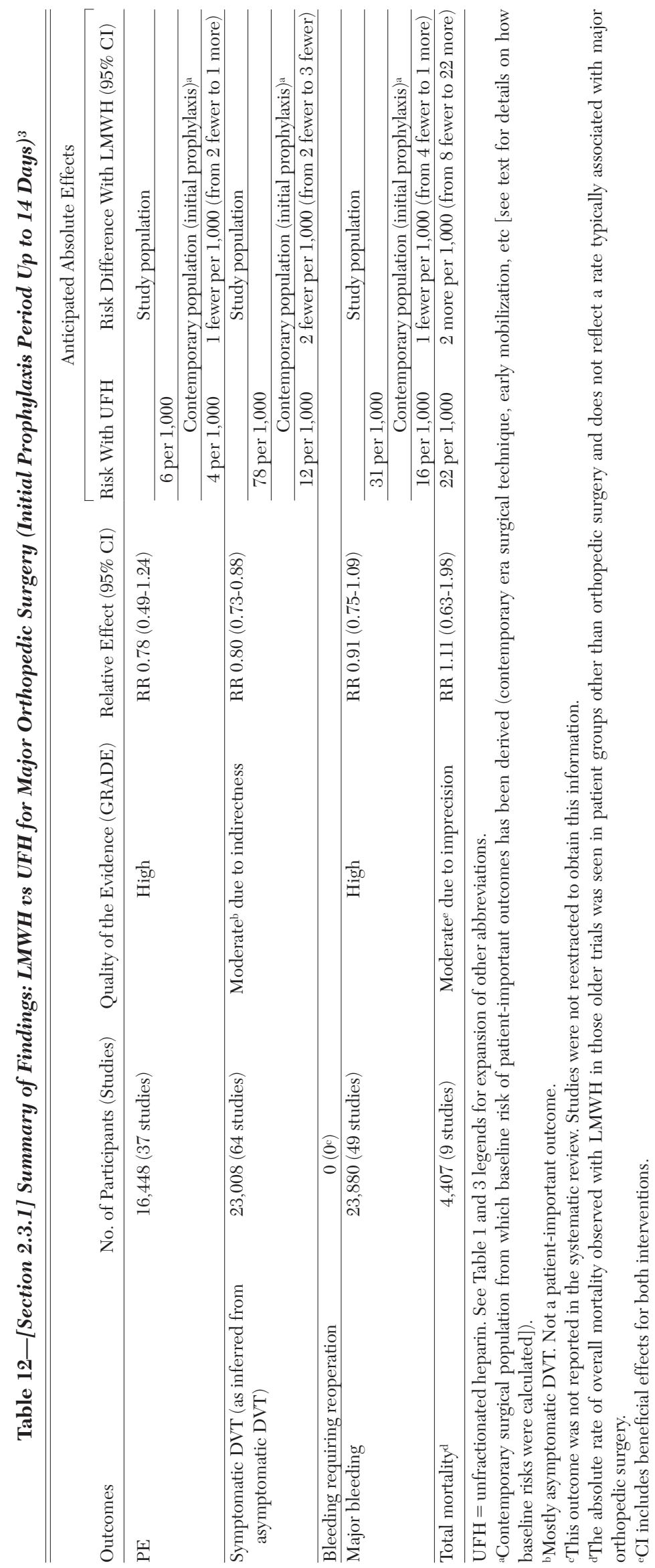




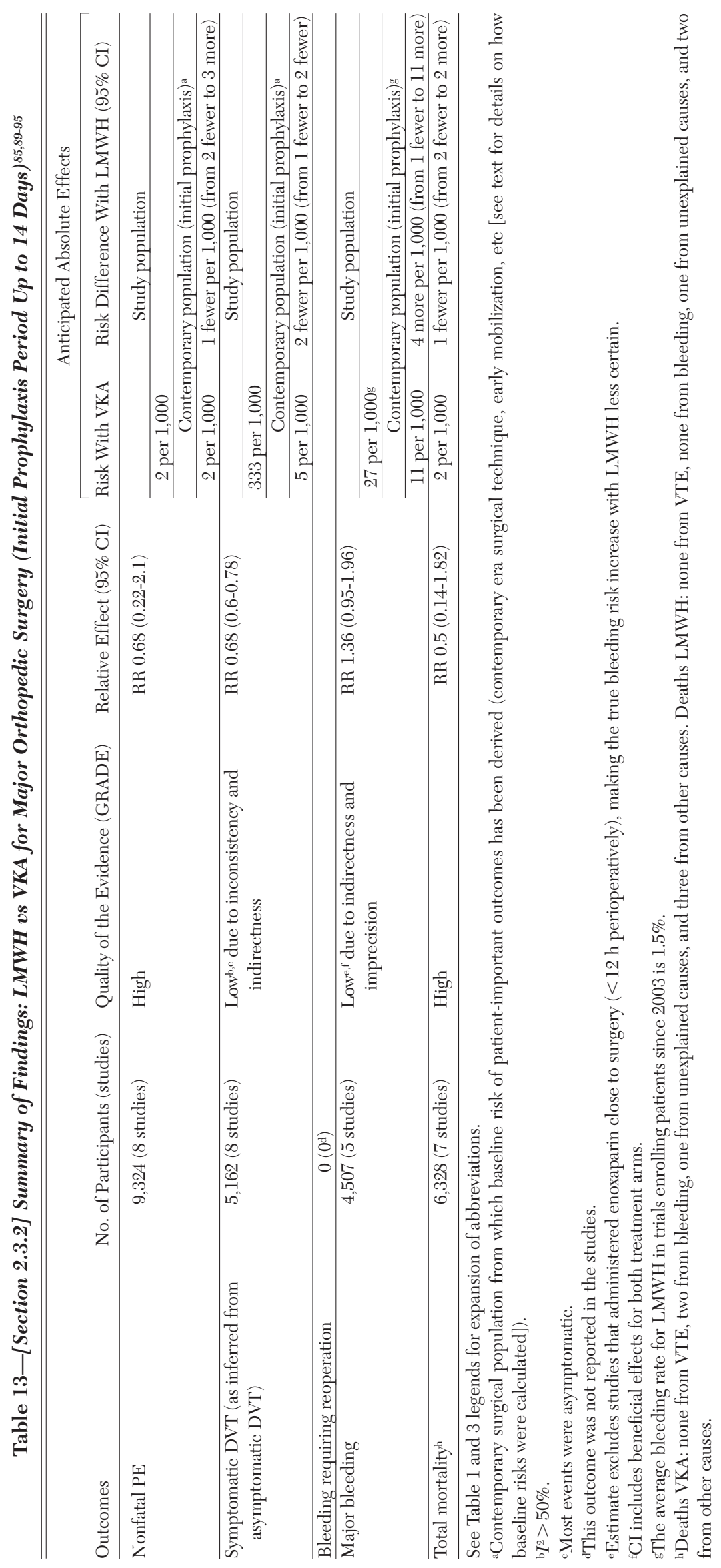




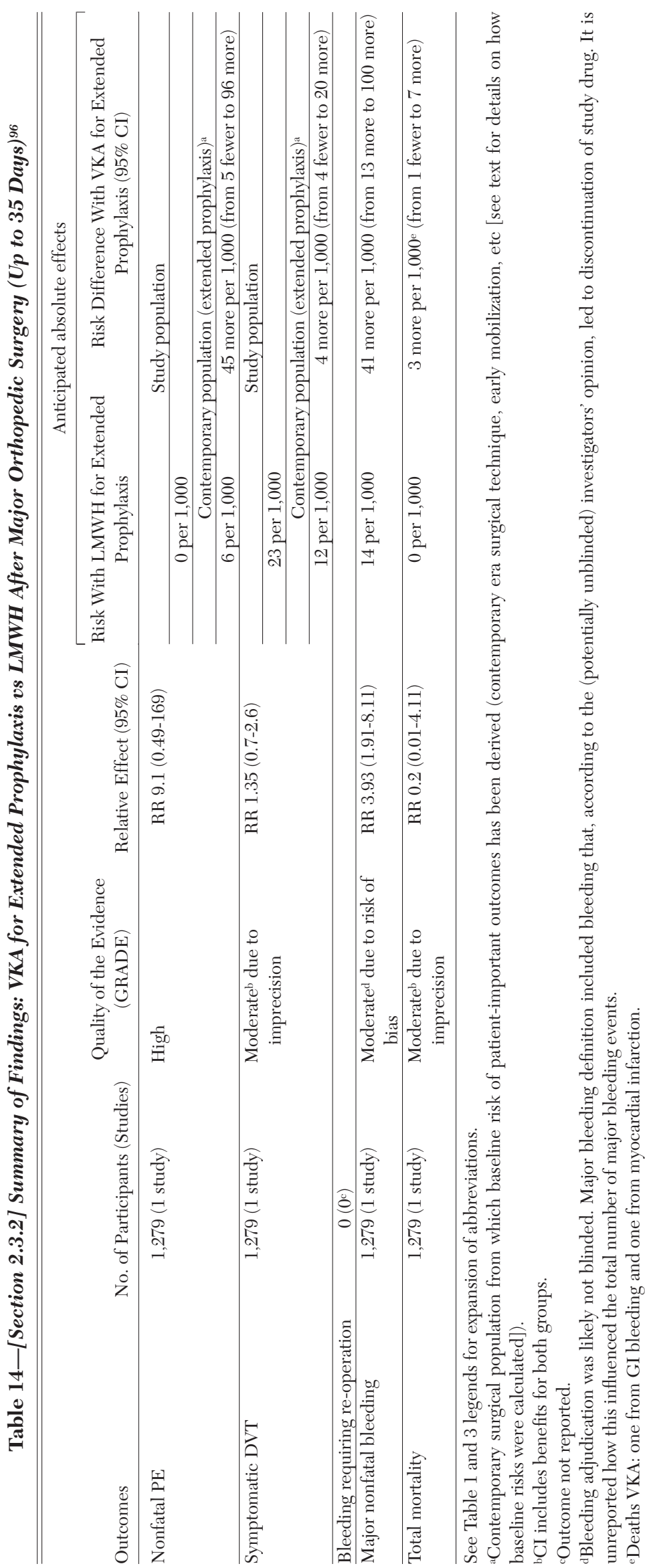




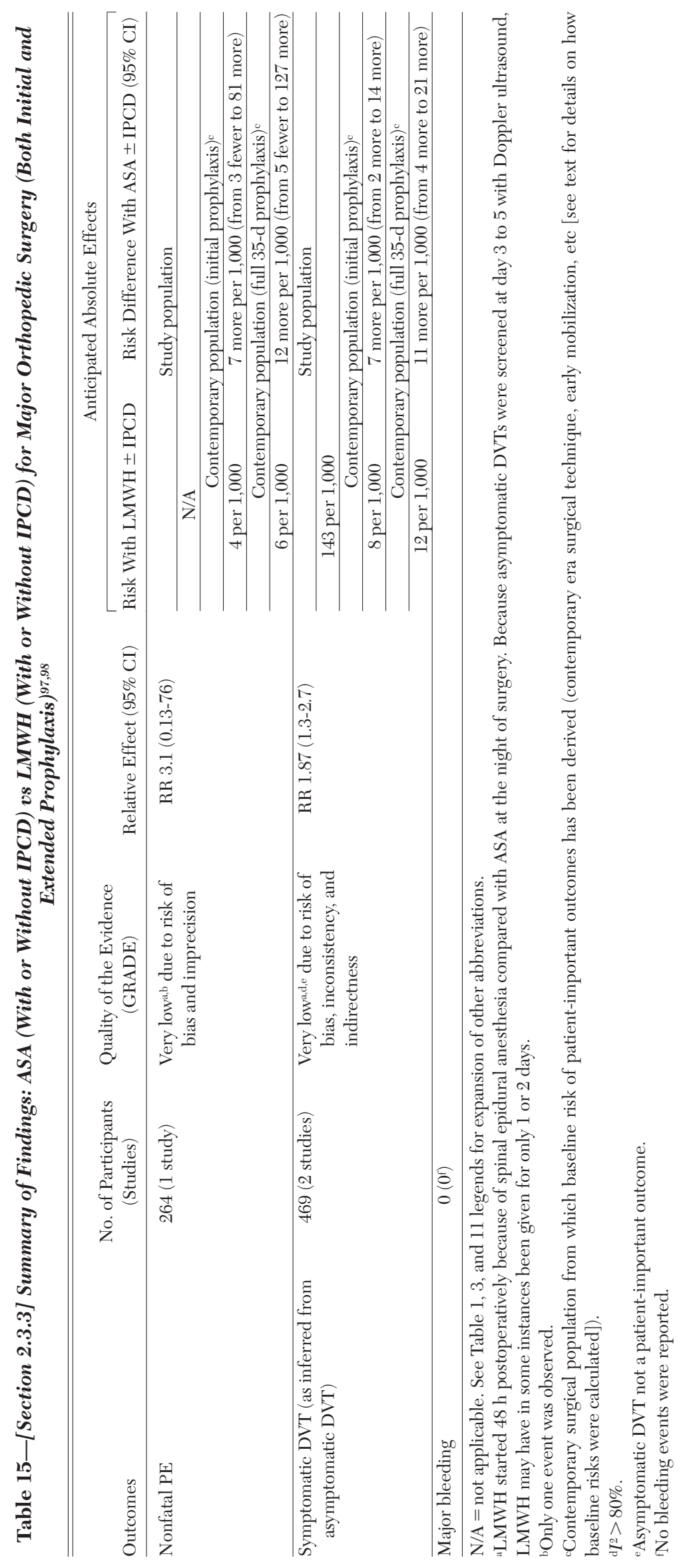


with fondaparinux in patients weighing $<50 \mathrm{~kg}$ (110 lbs) and elderly and frail patients because bleeding complications may be increased. In summary, based on moderate-quality evidence, the use of fondaparinux compared with LMWH does not appear to reduce patient-important VTE events but may increase major bleeding events by nine per 1,000 (Table 16, Figs S35-S40, Table S13).

\subsubsection{LMWH vs Rivaroxaban-Initial and Extended} Prophylaxis: Rivaroxaban, an oral direct factor Xa inhibitor, is approved in the United States, Canada, and Europe for the prevention of VTE after THA and TKA, but it has not been evaluated in HFS. Seven RCTs enrolling $>10,000$ patients after THA ${ }^{18,19,104}$ and TKA ${ }^{20-22}$ examined the efficacy of rivaroxaban $10 \mathrm{mg} / \mathrm{d}$ (started $6-8 \mathrm{~h}$ postoperatively) against enoxaparin $40 \mathrm{mg} / \mathrm{d}$. Enoxaparin was usually started the evening before surgery and continued 6 to $8 \mathrm{~h}$ postoperatively, but two studies used $30 \mathrm{mg}$ bid dosing rather than $40 \mathrm{mg}$ once daily and started $12 \mathrm{~h}$ postoperation. For TKA patients, rivaroxaban usually was given for 10 to 15 days, and earlier trials in THA had similarly short treatment durations, but one later trial treated patients for 31 to 39 days. ${ }^{19}$ Because the relative effects of extended prophylaxis were similar to shorter-term trials, we estimated pooled effects across all rivaroxaban trials to increase precision, as long as rivaroxaban and control treatment were given for the same duration.

Rivaroxaban reduced symptomatic DVT by $>50 \%$ (RR, 0.41; 95\% CI, 0.20-0.83). There was a trend toward increased major bleeding and bleeding requiring reoperation (major bleeding: RR, 1.58; 95\% CI, 0.84-2.97; bleeding requiring reoperation: $\mathrm{RR}, 2.0$; 95\% CI, 0.86-4.83; combined: RR, 1.73; 95\% CI, 0.94-3.17). The absolute rates for major bleeding were low in both arms, and the rates were lower than one would expect from other large trials using similar enoxaparin controls. Unlike other trials, the two major THA studies (RECORD 1 and 2) did not include surgical site bleeding (other than bleeding requiring reoperation), and drop in hemoglobin level was calculated compared with the postoperative instead of the preoperative baseline value. ${ }^{40}$

The evidence summaries therefore include the alternate major bleeding rate of $1.5 \%$ to better illustrate the trade-offs between VTE and bleeding with rivaroxaban: The best estimates suggest that five fewer symptomatic DVT per 1,000 achieved with rivaroxaban over $\mathrm{LMWH}$ will be offset by nine more major bleeding events. In summary, based on moderate-quality evidence, both the possibility of increased major bleeding events and the availability of long-term safety data for LMWH makes LMWH more appealing than rivaroxaban in spite of the incon- venience of subcutaneous administration (Table 17, Figs S41-S47, Table S14).

Extended Prophylaxis With Rivaroxaban: The extended use of rivaroxaban was studied in one trial enrolling $>2,400$ patients after THA. ${ }^{4}$ The control group received short-term LMWH for the first 12 days followed by placebo for an additional 22 days. Rivaroxaban significantly reduced symptomatic VTE (symptomatic DVT: RR, 0.18; 95 \% CI, 0.04-0.82; PE: RR, $0.25 ; 95 \%$ CI, 0.02-2.2). There was only one major bleeding event in both groups. However, in contrast to most other studies, the major bleeding definition in this study excluded surgical site bleeding, and the baseline used for change in hemoglobin level was postoperative day 1 . The result was a major bleeding rate of only one-10th of comparable studies using the same control agent. ${ }^{40}$ Bleeding requiring reoperation was recorded.

Based on moderate-quality evidence, 12 fewer symptomatic VTE would be expected. However, because of the uncertainty about the major bleeding rate, it is unknown whether some of the benefit would be offset by a higher bleeding rate of rivaroxaban compared with placebo (Table 18, Figs S41-S53, Table S15).

\subsubsection{LMWH vs Dabigatran-Initial and Extended} Prophylaxis: Dabigatran, a new oral direct thrombin inhibitor, has been approved by the US Food and Drug Administration since 2010 for stroke prevention in atrial fibrillation, and European and Canadian agencies have granted marketing authorization for the prevention of VTE after total hip and knee arthroplasty. Four RCTs examined the use of dabigatran in $>10,000$ patients undergoing THA $^{23,24}$ and TKA $^{25,26}$ at doses of 220 and $150 \mathrm{mg}$ taken orally once daily (usually started within $4 \mathrm{~h}$ postoperatively at half the dose) compared with enoxaparin (mainly at doses of $40 \mathrm{mg}$ once daily started the evening before surgery, although one study used the $30 \mathrm{mg}$ bid dosing schedule that commenced $12 \mathrm{~h}$ postoperatively). Treatment duration ranged from 10 to 15 days (for TKA) to 28 to 35 days for THA. Again, relative effects were similar to the shorter-term TKA trials, facilitating pooled effects across all dabigatran trials.

The studies using the $220 \mathrm{mg}$ dose of dabigatran failed to demonstrate or exclude a difference in the number of symptomatic VTEs (PE: RR, 1.22; 95\% CI, 0.52-2.85; DVT: RR, 0.7; 95\% CI, 0.12-3.91) or major bleeding events (RR, 1.06; 95\% CI, 0.66-1.72). Point estimates of absolute differences between thrombotic and bleeding events were closely balanced to within one event per 1,000 (Table 19, Figs S54-S59, Table S16).

Although dabigatran at the 150-mg dose reduced asymptomatic DVT less than enoxaparin (RR, 1.2; 


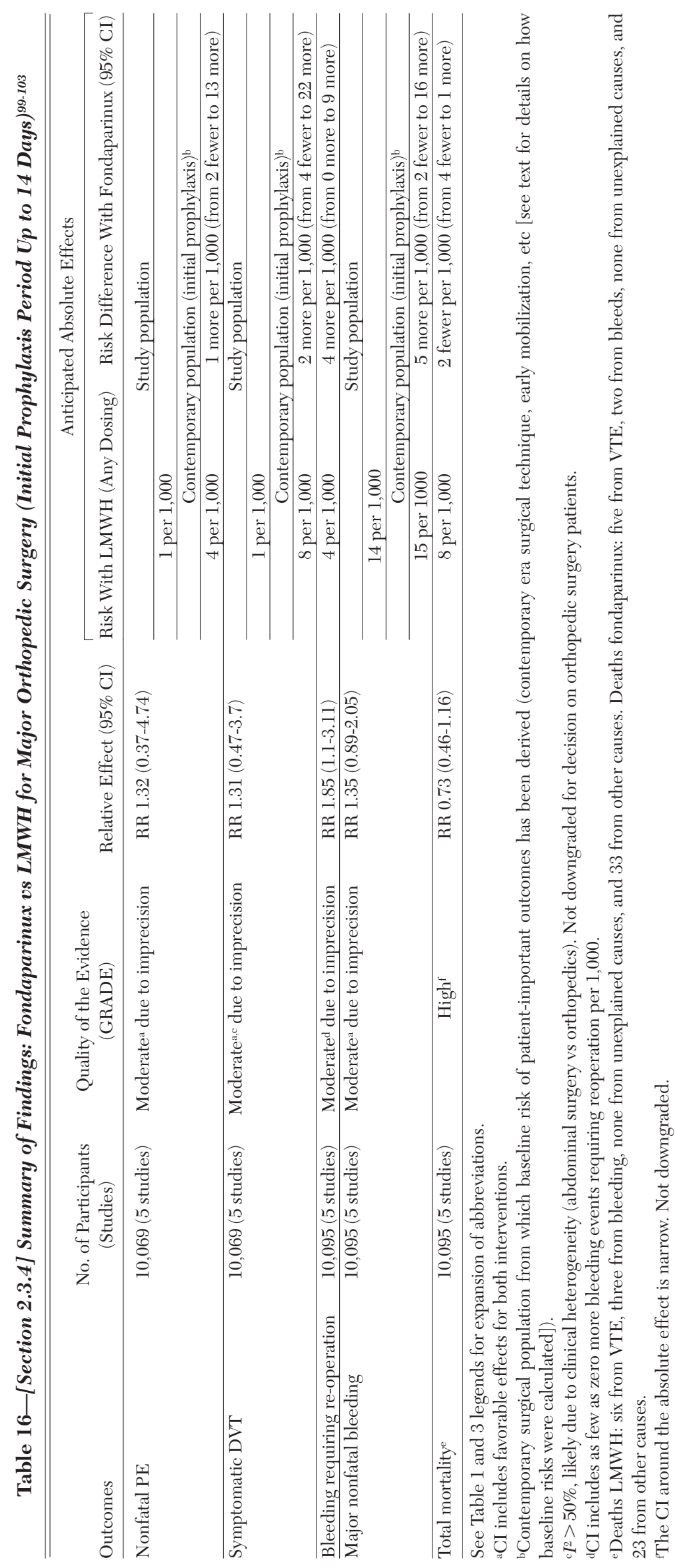




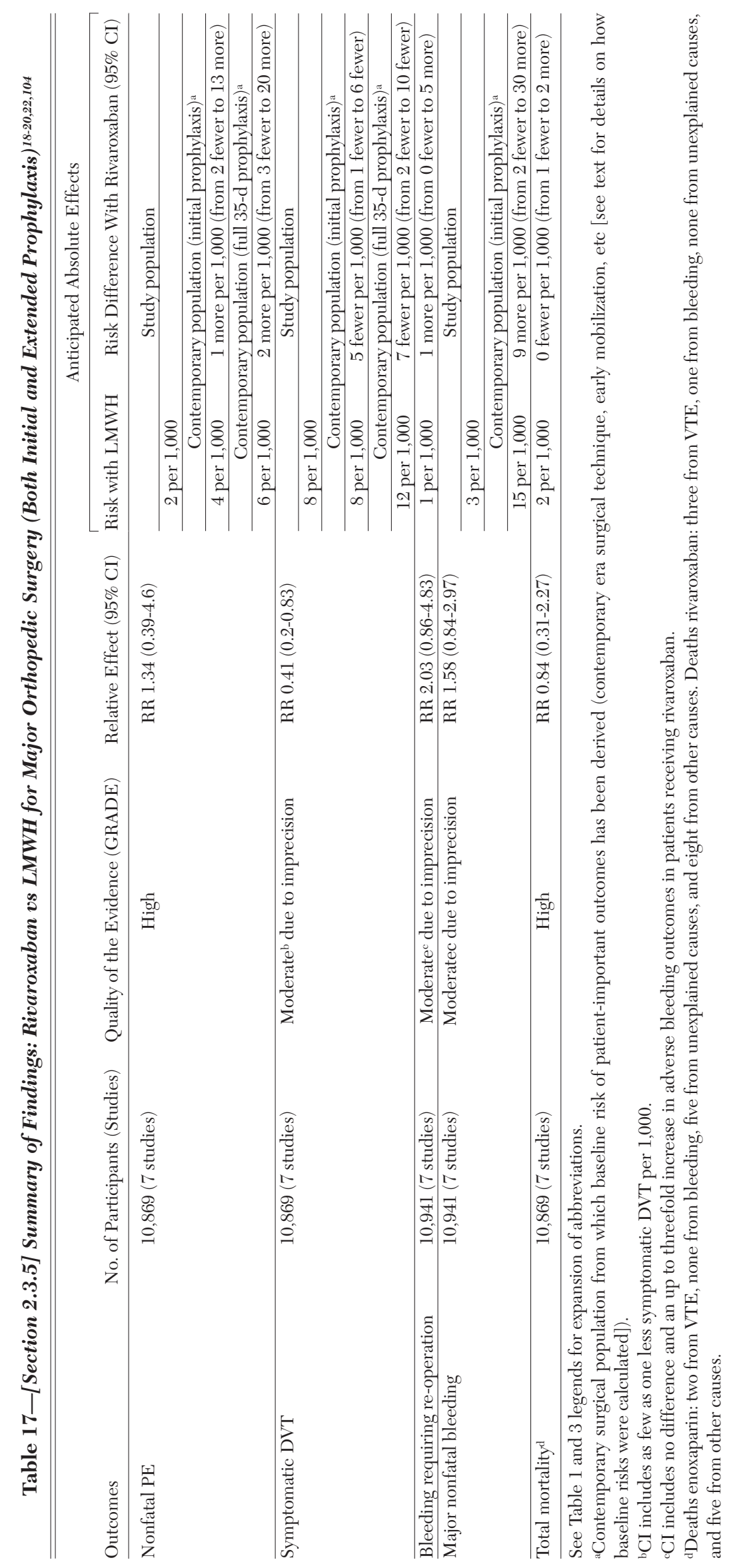




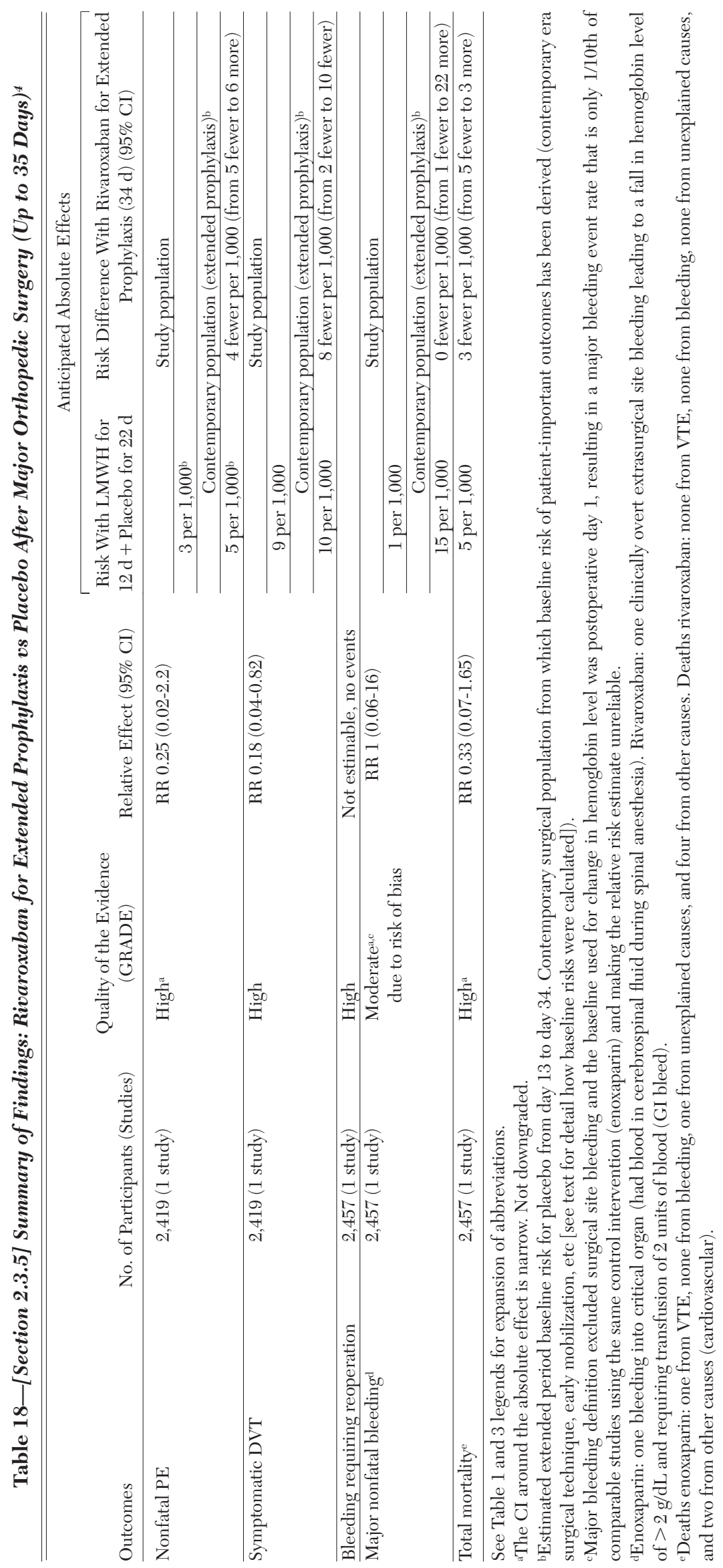


95\% CI, 1.05-1.37), one trial that used a 50\% higher dosing schedule (enoxaparin $30 \mathrm{mg}$ bid) contributed the majority of the excess asymptomatic events. Symptomatic VTE results, however, failed to demonstrate or to exclude a beneficial effect of dabigatran compared with LMWH (PE: RR, 0.31; 95\% CI, 0.04-2.48; symptomatic DVT: RR, 1.52; 95\% CI, 0.45-5.05). Overall, the additional two symptomatic VTE events per 1,000 observed with the lower dose of dabigatran are offset by four additional major bleeding events per 1,000 in the enoxaparin group, although this increased bleeding is more likely with the higher enoxaparin dose of $30 \mathrm{mg}$ bid (Table 20 , Figs S60-S65, Table S17).

In summary, dabigatran is similar to $\mathrm{LMWH}$ in terms of efficacy and propensity to cause bleeding, based on moderate-quality evidence. Greater longterm experience with LMWH still favors its use.

\subsubsection{LMWH vs Apixaban-Initial and Extended} Prophylaxis: Apixaban, an oral direct factor Xa inhibitor, is approved in Europe for the prevention of VTE after THA and TKA but similar to the other newer agents, has not been evaluated in HFS. Four RCTs enrolling close to 12,000 patients after THA $^{14}$ and TKA $^{15-17}$ examined the efficacy of apixaban $2.5 \mathrm{mg}$ bid taken orally (started 12-24 h postoperatively) against enoxaparin. Enoxaparin at the 40-mg dosing schedule was started the evening before surgery and continued after surgery according to the investigators' standard of care (usually $12 \mathrm{~h}$ postoperatively). Two studies used $30 \mathrm{mg}$ bid dosing rather than $40 \mathrm{mg}$ once daily and started $12 \mathrm{~h}$ postoperatively. For TKA patients, apixaban usually was given for 10 to 14 days, and the single trial in THA used an extended protocol of 32 to 38 days.

Apixaban reduced symptomatic DVT by $59 \%$ (RR, 0.41; 95\% CI, 0.18-0.95) and appeared to have little or no effect on major nonfatal bleeding (RR, 0.76; 95\% CI, 0.44-1.32) or bleeding requiring reoperation (RR, 0.82; 95\% CI, 0.15-4.58) compared with enoxaparin. However, similar to the two major rivaroxaban trials, drop in hemoglobin level was calculated compared with the postoperative instead of the preoperative baseline value for the ADVANCE (Apixaban Dosed Orally vs Anticoagulation with Enoxaparin) 2 and 3 trials, which may underestimate the true major bleeding event rate. ${ }^{40}$ Results failed to demonstrate a beneficial or detrimental effect of apixaban on nonfatal PE (RR, 1.09; 95\% CI, 0.31-3.88) and total mortality (RR, 1.87; 95\% CI, 0.61-5.74), and the only five deaths from VTE were found in the apixaban group.

Best estimates suggest that seven fewer symptomatic DVT per 1,000 could be achieved with apixaban over LMWH without an appreciable increase in major bleeding events (from eight fewer to five more per 1,000), although results failed to demonstrate a difference when all nonfatal and fatal VTE were combined (Fig S72).

In summary, based on moderate-quality evidence, apixaban is similar to LMWH in terms of efficacy based on all symptomatic VTEs (including DVT, non-fatal and fatal PE) (see Fig S72) and showed a comparable low risk for major bleeding events. However, the lack of long-term postmarketing safety data (eg, the confirmation of bleeding-related safety) for apixaban currently makes LMWH still the agent of choice (Table 21, Figs S66-S72, Table S18).

\subsubsection{IPCDs vs Pharmacologic Thromboprophylaxis-} Initial Prophylaxis: Compression devices are attractive because they do not increase bleeding. IPCDs were compared against VKAs in $>500$ patients from four trials: three in patients undergoing THA ${ }^{105-107}$ and one with both THA and TKA. ${ }^{108}$ Because of the small sample sizes, no PE was observed. The results for asymptomatic DVT failed to demonstrate or to exclude a beneficial effect of IPCDs over VKAs (RR, 0.79; 95\% CI, 0.5-1.25). All major bleeding events were reported in one study ${ }^{106}$ in which warfarin was started 1 week prior to the operation and the INR was kept initially at $\leq 1.5$ during the operation. In this trial, eight patients required $\geq 4$ units of blood transfusion, and two had higher intraoperative blood loss. Because the usual practice is to give warfarin the night before surgery and adequate anticoagulation levels will not be achieved for several days, those bleeding events may not be applicable to current practice. Using a more-precise estimate of $2 \%$ (90 major bleeds observed in 4,547 patients) as seen in the VKA arm of RCTs vs LMWH, it is likely that 19 more bleeds will occur per 1,000, offsetting the two fewer DVT seen with warfarin (Table 22, Figs S73-S75, Table S19).

Pneumatic compression devices were compared with LMWH in $>1,000$ patients scheduled for THA ${ }^{109-111}$ and TKA ${ }^{31,112}$ : five studies used a VFP, and two used an IPCD. We included studies in our analysis whether GCS were used in both treatment arms. A single nonfatal PE was observed in the IPCD/VFP group. Use of a compression device was associated with a trend toward an increase in asymptomatic DVT (RR, 1.38; 95\% CI, 0.92-2.06). Less major bleeding occurred in the IPCD group (RR, 0.32; 95\% CI, 0.12-0.89). In these studies, bleeding event adjudication was not blinded, and bleeding events were inconsistently reported (eg, bleeding requiring reoperation remained unreported despite the sample size of $>1,000$ ). Three deaths from VTE occurred with the compression device vs none in the LMWH group.

Overall, 10 fewer symptomatic VTE events per 1,000 can be expected with the use of LMWH 


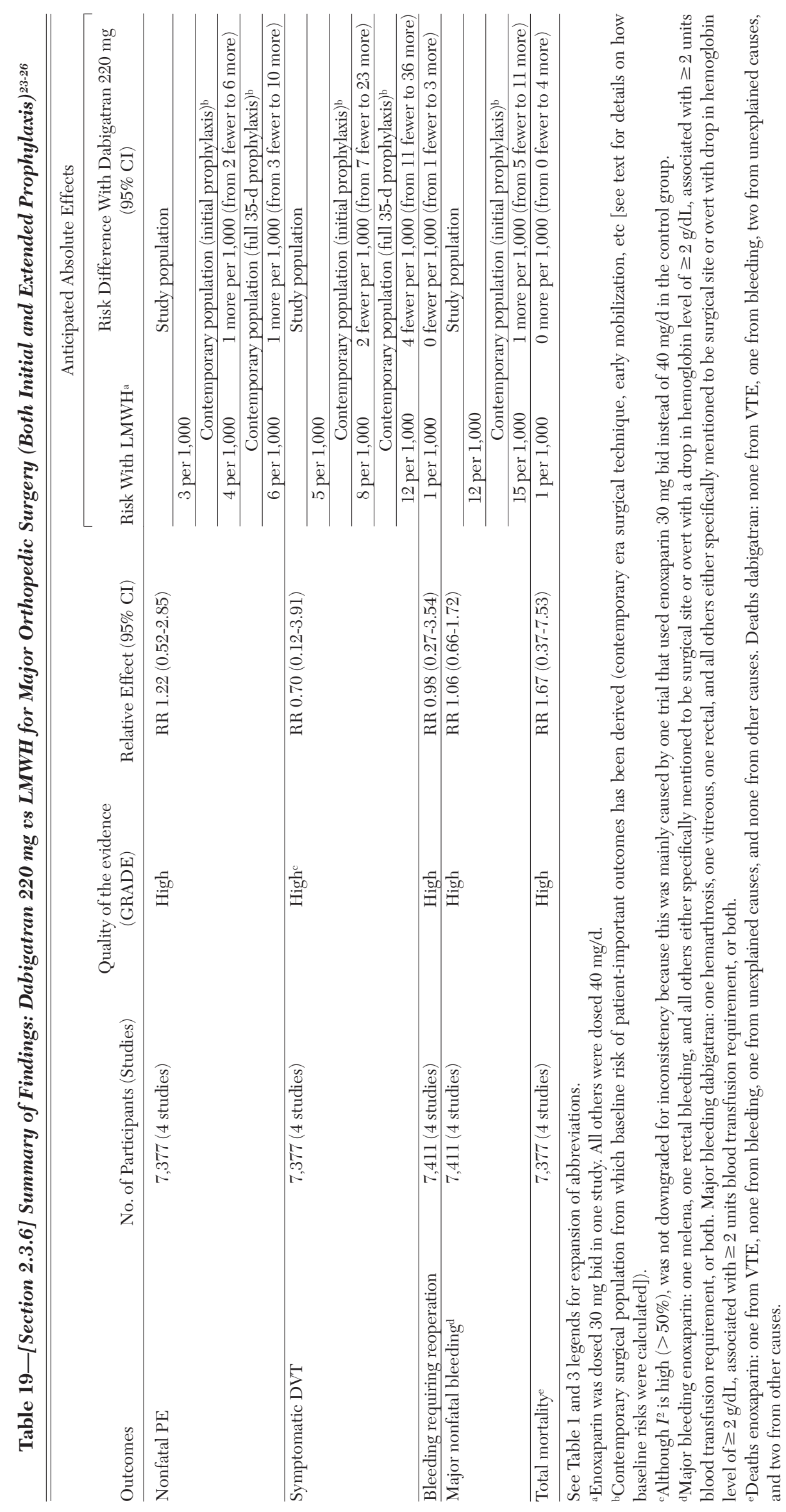

Prevention of VTE in Orthopedic Surgery Patients 


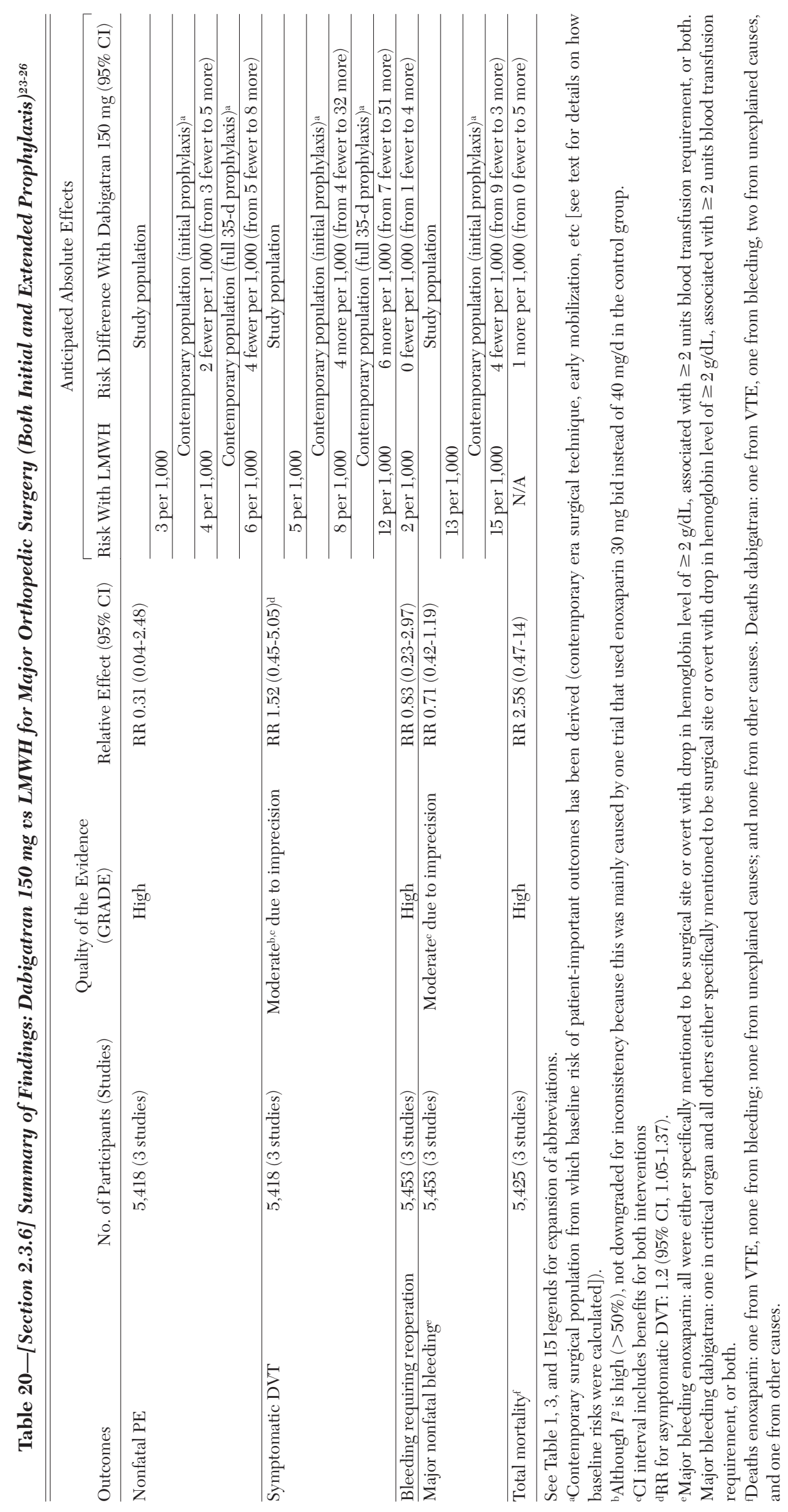




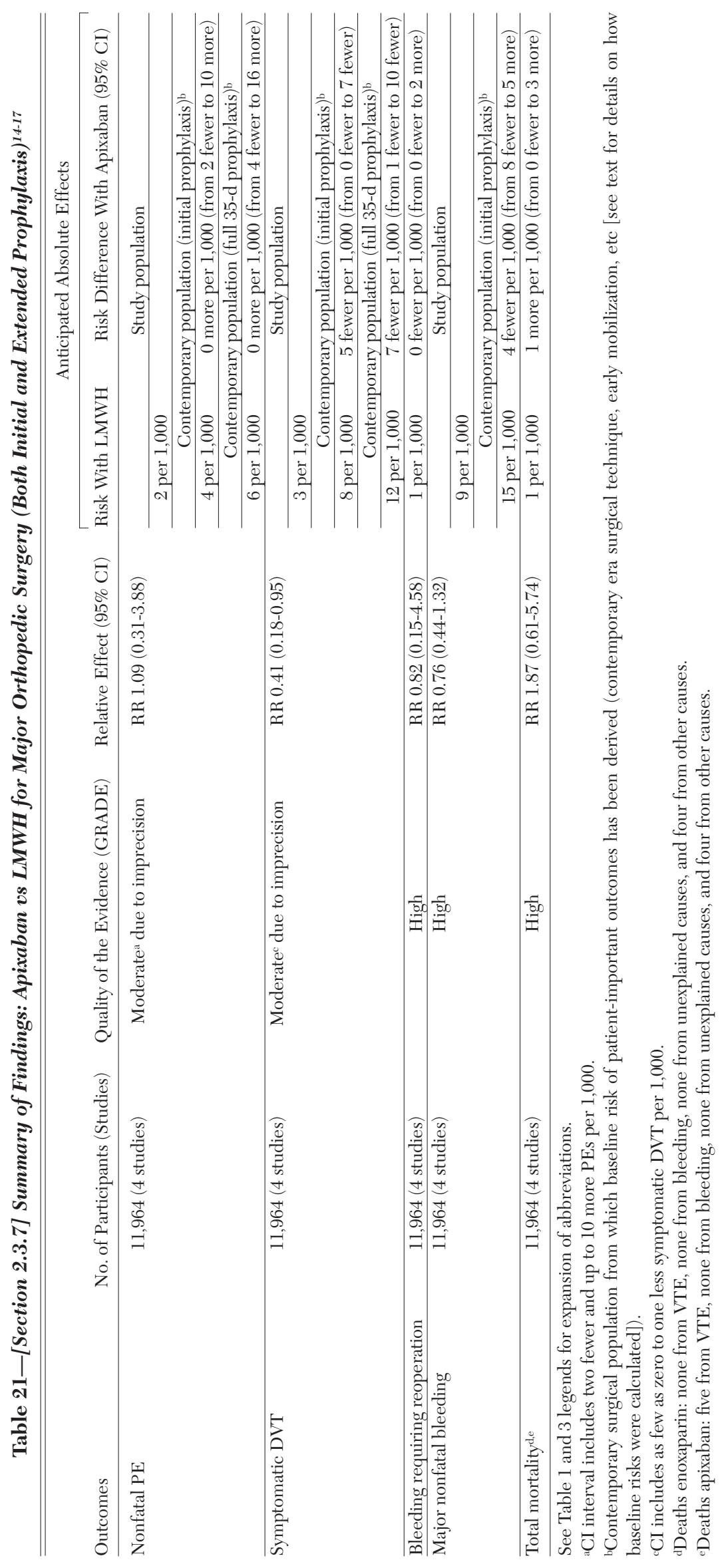




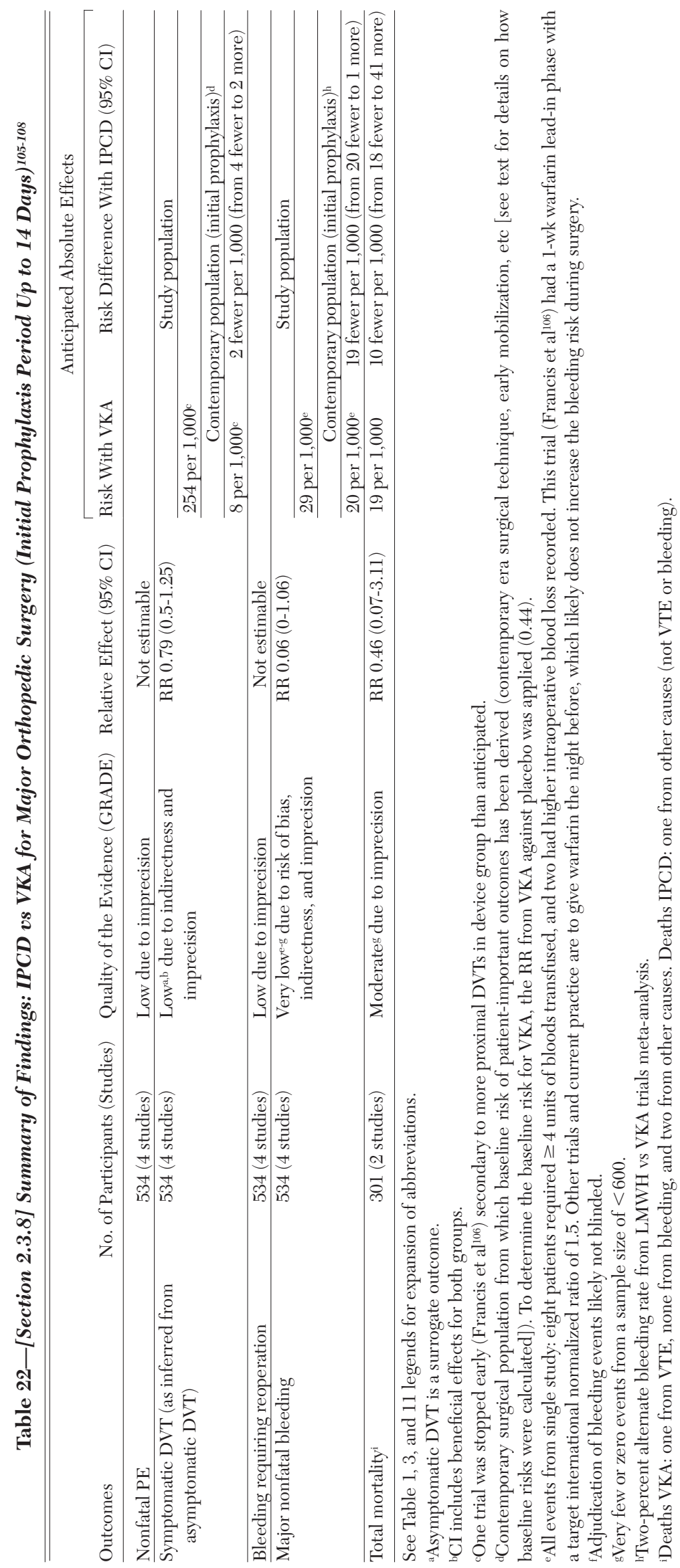


compared with a compression device at the expense of 10 additional major bleeds per 1,000. This closely balanced estimate is sensitive to the baseline bleeding risk, which was set to $1.5 \%$ for LMWH as observed in trials since 2003. Although the actual observed bleeding rate was $2.6 \%$, these trials were performed before our cutoff for contemporary surgical technique and may not be representative of current practice. Additionally, there was no blinding, and this could result in overestimating the number of major bleeds associated with LMWH (Table 23, Figs S76-S79, Table S20). In summary, low-quality evidence, mostly because of imprecision and risk of bias, reduces our confidence in the estimate of the true effect of an IPCD against LMWH and tilts our judgment in favor of LMWH.

Newer-generation IPCDs have the advantage of being portable and able to record effective use time. Two trials compared these IPCDs in combination with low-dose aspirin (81-100 mg) to LMWH in THA ${ }^{113}$ and both THA and TKA ${ }^{114}$ enrolling $>500$ patients. Results failed to demonstrate or to exclude a beneficial effect of the IPCD on PE due to the low number of events observed, but fewer asymptomatic DVT were seen in one of the two trials (pooled RR, 0.47; 95\% CI, 0.24-0.91). Fewer major bleeding events occurred with IPCD in one of the trials with LMWH but not in the other (pooled estimate RR, 0.04; 95\% CI, 0-0.7). However, all results were imprecise because of low numbers of events (total of 42 VTE and 11 bleeding events), and the definition of bleeding differed from other trials, making a direct comparison difficult (Table 24, Figs S80-S82, Table S21).

Overall, there are significant methodologic limitations in the trials of new- and prior-generation IPCD vs LMWH, which include lack of concealment of allocation, an unblinded adjudication process for bleeding, the uncertainty generated by the lack of a standard definition of major bleeding, and a generally small sample size and variation in the properties of pneumatic compression devices. These limitations make it difficult to accept the apparent benefit of new-generation IPCD in combination with aspirin over LMWH based on a simple trade-off of thrombotic events against patient-important bleeding.

\subsubsection{Summary-Choice of Thromboprophylaxis:} Selecting from the range of pharmacologic and mechanical interventions in major orthopedic surgery, the agent that has similar or superior properties of effective thromboprophylaxis combined with little risk of bleeding and extensive clinical experience is LMWH; extending thromboprophylaxis up to 35 days compared with 10 to 14 days results in an additional reduction of symptomatic VTE with a similar safety profile.
In situations where LMWH is unavailable (eg, formulary restrictions) or the patient has a history of heparin-induced thrombocytopenia, reasonable alternate choices include apixaban, dabigatran, rivaroxaban, VKA, fondaparinux, IPCD, or IPCD in combination with low-dose aspirin. The choice of a second-line strategy should be guided by its relative effectiveness, propensity to cause major bleeding (fondaparinux, rivaroxaban, VKA), and challenges with logistics and expected compliance (mechanical devices, VKA, and any drug that requires injections during the out-ofhospital period). Apixaban $2.5 \mathrm{mg}$ bid taken orally as well as dabigatran $220 \mathrm{mg}$ (with the availability of an alternate lower dose of $150 \mathrm{mg}$ ) once daily combined with no monitoring requirement appear to have the most of these desirable properties. However, longterm safety data (eg, the absence of clinically relevant liver toxicity) will be important when using these new oral antithrombotic agents.

Recommendations

2.3.1. In patients undergoing THA or TKA, irrespective of the concomitant use of an IPCD or length of treatment, we suggest the use of LMWH in preference to the other agents we have recommended as alternatives: fondaparinux, apixaban, dabigatran, rivaroxaban, LDUH (all Grade 2B), adjusted-dose VKA, or aspirin (all Grade 2C).

Remarks: If started preoperatively, we suggest administering LMWH $\geq 12 \mathrm{~h}$ before surgery. Patients who place a high value on avoiding the inconvenience of daily injections with LMWH and a low value on the limitations of alternative agents are likely to choose an alternative agent. Limitations of alternative agents include the possibility of increased bleeding (which may occur with fondaparinux, rivaroxaban, and VKA), possible decreased efficacy (LDUH, VKA, aspirin, and IPCD alone), and lack of long-term safety data (apixaban, dabigatran, and rivaroxaban). Furthermore, patients who place a high value on avoiding bleeding complications and a low value on its inconvenience are likely to choose an IPCD over the drug options.

2.3.2. In patients undergoing HFS, irrespective of the concomitant use of an IPCD or length of treatment, we suggest the use of LMWH in preference to the other agents we have recommended as alternatives: fondaparinux, LDUH (Grade 2B), adjusted-dose VKA, or aspirin (all Grade 2C).

Remarks: For patients in whom surgery is likely to be delayed, we suggest that LMWH be initiated 


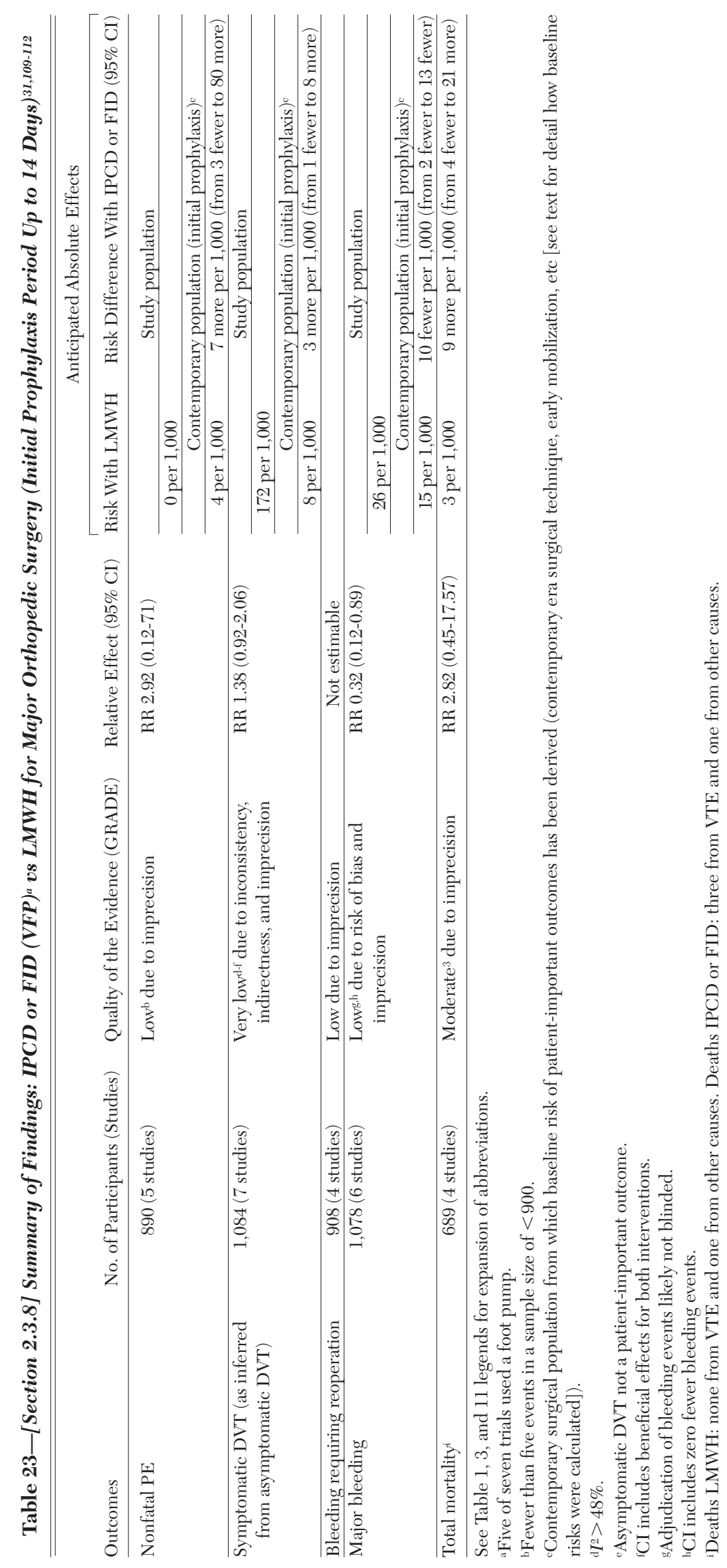




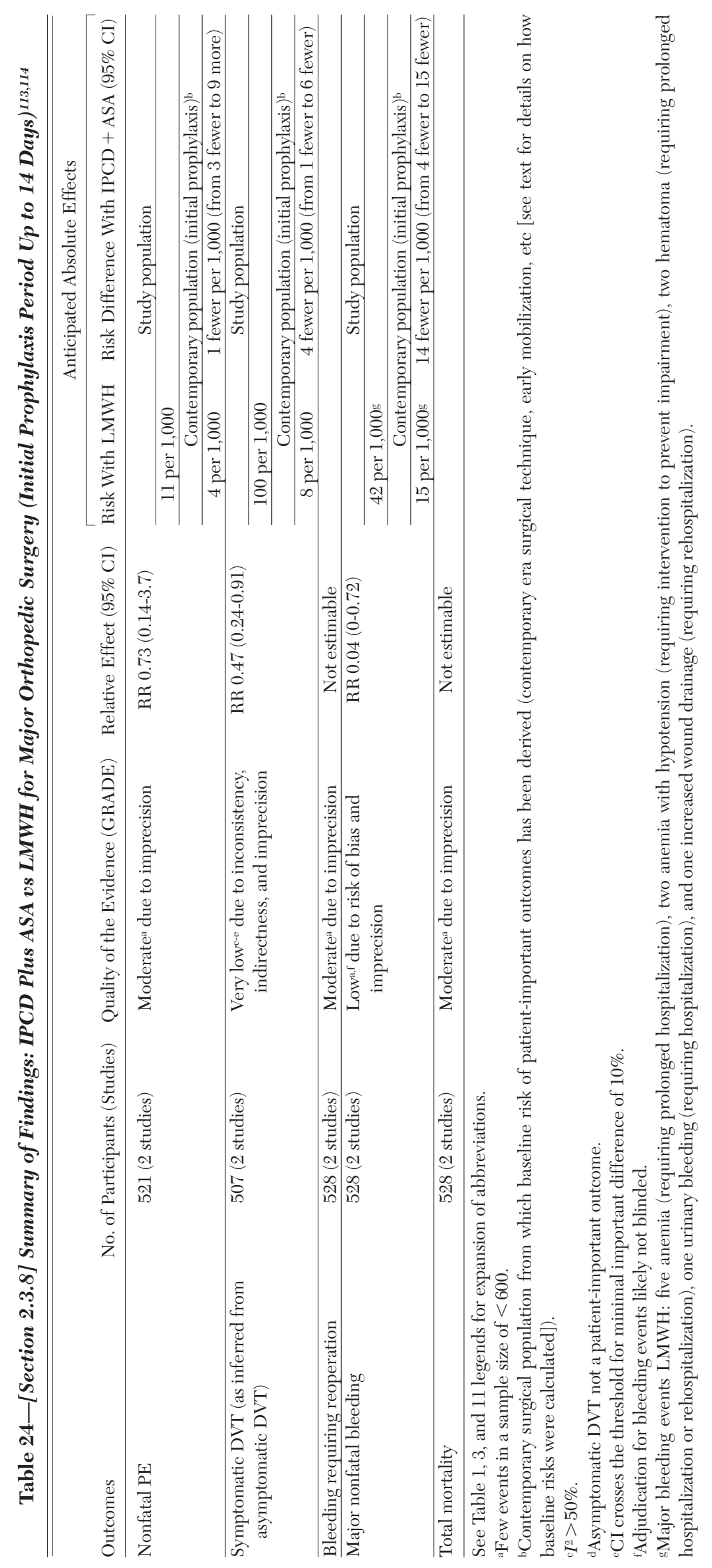


during the time between hospital admission and surgery but suggest administering LMWH at least $12 \mathrm{~h}$ before surgery. Patients who place a high value on avoiding the inconvenience of daily injections with LMWH and a low value on the limitations of alternative agents are likely to choose an alternative agent. Limitations of alternative agents include the possibility of increased bleeding (which may occur with fondaparinux) or possible decreased efficacy (LDUH, VKA, aspirin, and IPCD alone). Furthermore, patients who place a high value on avoiding bleeding complications and a low value on its inconvenience are likely to choose an IPCD over the drug options.

2.4. For patients undergoing major orthopedic surgery, we suggest extending thromboprophylaxis in the outpatient period for up to 35 days from the day of surgery rather than for only 10 to 14 days (Grade $2 B$ ).

\subsection{Use of Combination Thromboprophylaxis}

The combined use of anticoagulant thromboprophylaxis with a compression device may further reduce the rate of VTE. A Cochrane systematic review examined the effects of adding compression devices to anticoagulant prophylaxis in mostly orthopedic populations, but some trials also included other surgical groups. ${ }^{115}$ Four trials were included ${ }^{116-119}$; we identified another study that was published more recently. ${ }^{120}$ We reanalyzed the original data by adding this additional study without reextracting the data in the Cochrane review, bringing the total number of patients included to $>2,400$. Some older trials used LDUH or VKA for thromboprophylaxis, but otherwise, LMWH was the agent used in both arms.

Adding a compression device reduced the incidence of asymptomatic DVT by $>70 \%$ (RR, 0.26; 95\% CI, 0.14-0.48). However, there were a number of methodologic limitations, such as issues with randomization, lack of allocation concealment, and lack of blinding of personnel performing the DVT screening, resulting in low-quality evidence overall. Therefore, the apparently large effect must be interpreted with caution. Bleeding events were not reported, but adding a compression device should have little or no effect on bleeding outcomes (Table 25, Figs S83, S84, Table S22).

Recommendations

2.5. In patients undergoing major orthopedic surgery, we suggest using dual prophylaxis with an antithrombotic agent and an IPCD during the hospital stay (Grade 2C).

Remarks: We recommend the use of only portable, battery-powered IPCDs capable of recording and
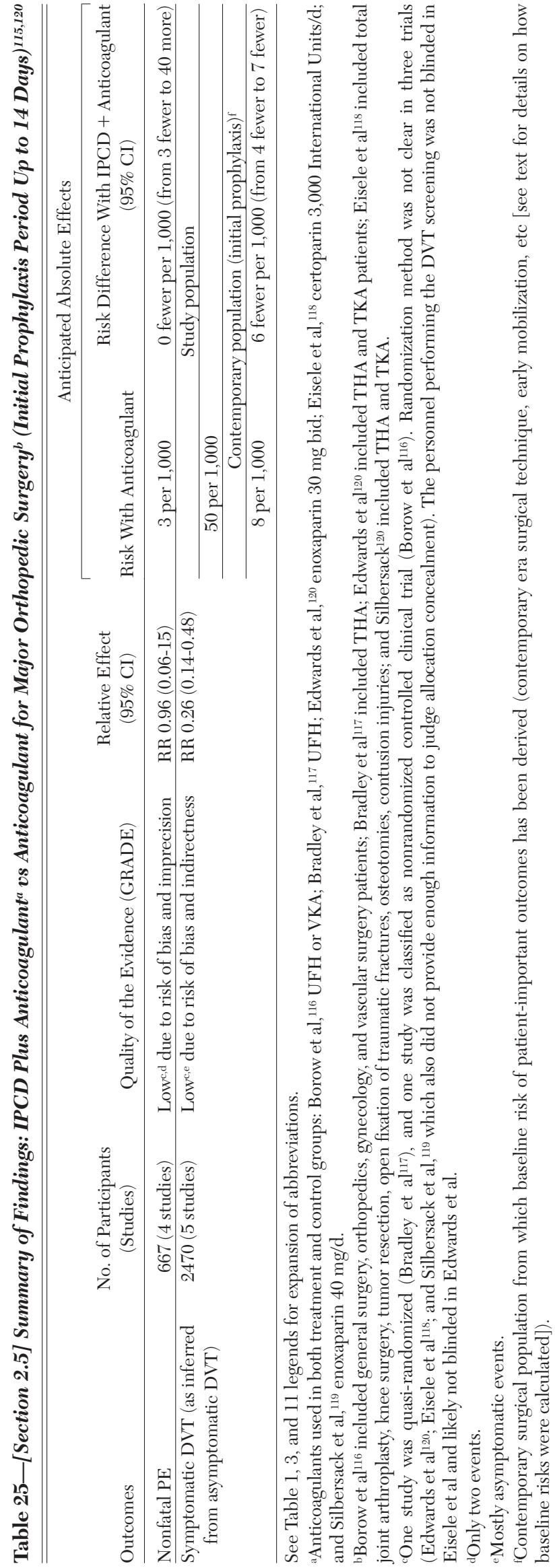

CHEST / 141 / 2 / FEBRUARY, 2012 SUPPLEMENT

e313S 
reporting proper wear time on a daily basis. Efforts should be made to achieve $18 \mathrm{~h}$ of daily compliance. Patients who place a high value on avoiding the undesirable consequences associated with prophylaxis with both a pharmacologic agent and an IPCD are likely to decline use of dual prophylaxis.

2.6. In patients undergoing major orthopedic surgery and increased risk of bleeding (Table 4), we suggest using an IPCD or no prophylaxis rather than pharmacologic treatment (Grade 2C).

Remarks: We recommend the use of only portable, battery-powered IPCDs capable of recording and reporting proper wear time on a daily basis for inpatients and outpatients. Efforts should be made to achieve $18 \mathrm{~h}$ of daily compliance. Patients who place a high value on avoiding the discomfort and inconvenience of an IPCD and a low value on avoiding a small absolute increase in bleeding with pharmacologic agents when only one bleeding risk factor is present (in particular the continued use of antiplatelet agents) are likely to choose pharmacologic thromboprophylaxis over IPCD.

\subsection{Other Considerations}

A systematic review examining nonadherence in outpatient thromboprophylaxis after major orthopedic surgery found a nonadherence rate of $13 \%$ to $37 \%$ in patients receiving LMWH or fondaparinux. ${ }^{121}$ The additional burden of self-injection, or in organizing family members or visiting nurses to come in for daily visits, is believed to contribute to the noncompliance. Newer agents such as apixaban, dabigatran, or rivaroxaban can be taken orally and do not require INR monitoring, potentially improving adherence.

Recommendation

2.7. In patients undergoing major orthopedic surgery and who decline or are uncooperative with injections or an IPCD, we recommend using apixaban or dabigatran (alternatively rivaroxaban or adjusted-dose VKA if apixaban or dabigatran are unavailable) rather than alternative forms of prophylaxis (all Grade 1B).

\subsection{Use of IVC Filter for Thromboprophylaxis}

There have been no randomized trials of the use of IVC filters in the prevention of PE in patients at high risk for DVT but who do not yet have a documented DVT (primary prevention). Rajasekhar et al ${ }^{122}$ published a systematic review of seven observational studies in patients with trauma. Although the potential benefit is substantial $(79 \%$ relative risk reduction in $\mathrm{PE}$ ), the quality of the evidence is very low. Most studies used historical controls, and inconsistent effects were noted for DVT. In addition, substantial harms were documented in $2 \%$ to $6 \%$ of patients receiving an IVC filter. These harms included DVT at the insertion site, occlusion of the IVC due to thrombosis below the filter, and migration of the filter (Table 26, Table S23).

A recent observational study involving $>9,000$ patients reported on the use of IVC filters in orthopedic surgery. ${ }^{123}$ Ninety $(0.96 \%)$ patients received IVC filters, $55(0.6 \%)$ for prophylaxis. Of these, most were arthroplasty or spinal surgery patients. Only 13 were fracture surgery patients. The most commonly cited indication for IVC filter prophylaxis was previous VTE. Only 23 of the $55(42 \%)$ patients with prophylactic filters had a contraindication to anticoagulation. Of the $51 \%$ who had retrievable filters, less than one-half had been removed at 6 months after placement. Two patients had complications of filter removal (carotid artery puncture in one and filter limb migration to right atrium and lung in the other). In summary, given the low-quality evidence for benefit but documented adverse events during placement, during their clinical course, on retrieval, and during the long term (postphlebitic syndrome), the balance tips toward definite net harm, even in patients with high bleeding risk.

Recommendation

2.8. In patients undergoing major orthopedic surgery, we suggest against using IVC filter placement for primary prevention over no thromboprophylaxis in patients with an increased bleeding risk (Table 4) or contraindications to both pharmacologic and mechanical thromboprophylaxis (Grade 2C).

\subsection{Screening for DVT Before Hospital Discharge}

Screening for asymptomatic DVT before discharge has been studied to examine the question of whether DVT seen on compression DUS should be treated to prevent symptomatic DVT and PE occurring after hospital discharge. One study that did not use extended out-of-hospital prophylaxis randomized patients to discharge DUS (and, if positive, 3 months of warfarin treatment) vs sham DUS screening and only warfarin treatment if the patient returned with symptomatic VTE within 90 days. ${ }^{124}$ Study results failed to demonstrate or exclude a beneficial effect: DUS screening detected symptomatic VTE on outof-hospital follow-up in four of 518 patients vs sham screening in five of 506 (RR, 0.78; 95\% CI, 0.21-2.9). One of the patients who was found to have an asymptomatic DVT on DUS screening and was subsequently treated with warfarin for 3 months developed a major bleeding complication (Table 27, Table S24). 


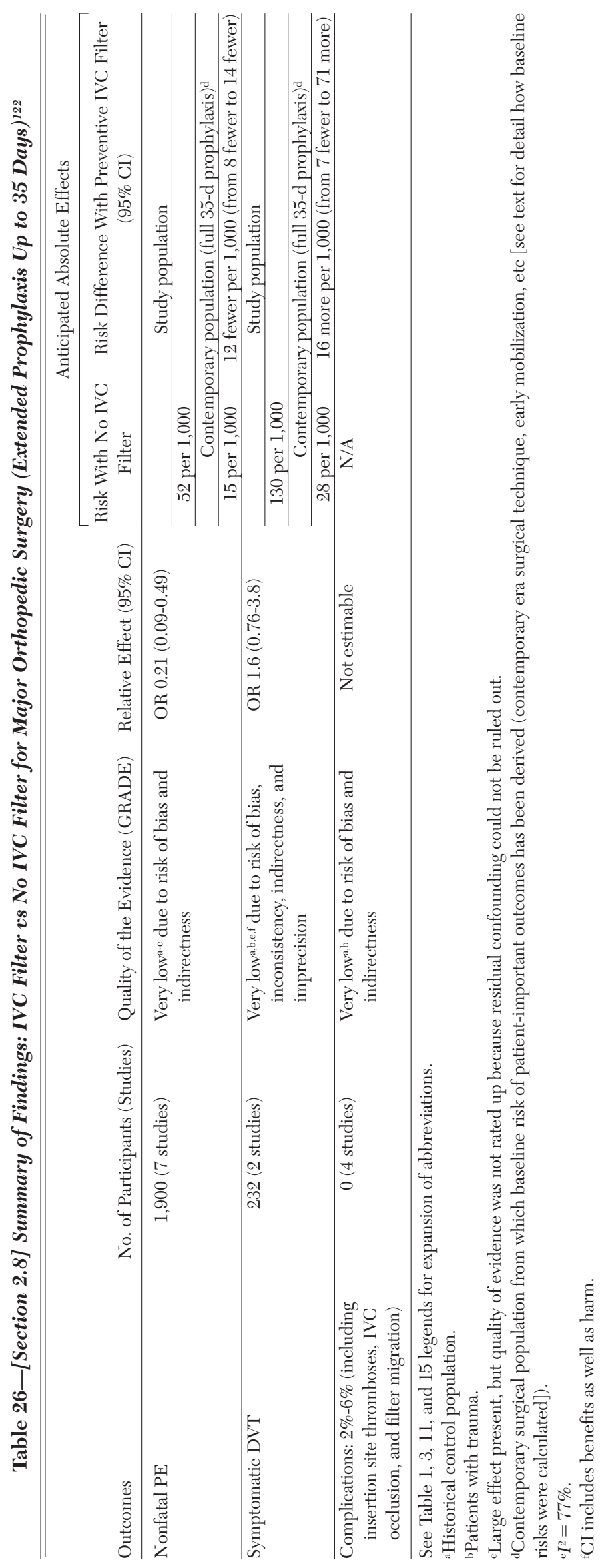


A second trial randomized patients to a combination of DUS screening on discharge and no extended thromboprophylaxis vs no screening but extended prophylaxis until day $35 .{ }^{125}$ Similar to the first study, any asymptomatic DVT detected during discharge DUS screening (day 7 mean) was treated. Again, the results failed to demonstrate or exclude a beneficial effect of predischarge screening (RR, 0.56; 95\% CI, 0.17-1.9), and major bleeding events were seen in only two patients who had been treated after diagnosis of asymptomatic DVT based on screening DUS (Table 28, Table S25).

In summary, moderate-quality evidence indicates that DUS screening before hospital discharge does not result in fewer symptomatic postdischarge VTE. However, screening for asymptomatic DVT appears to cause harm by leading to unnecessary anticoagulation for several months, resulting in a higher risk of major bleeding.

Recommendation

2.9. For asymptomatic patients following major orthopedic surgery, we recommend against DUS screening before hospital discharge (Grade 1B).

\subsection{ISOLATED LOWER-LEG INJURIES Distal TO THE KNEE}

Lower-leg injuries are a heterogeneous mix and include fractures below the knee, tendon ruptures, and cartilage injuries of the knee and ankle. There is less evidence about the incidence of patient-important VTE events associated with these injuries compared with major orthopedic surgery, but the risk of DVT increases with proximity of the fracture to the knee. ${ }^{226}$

A Cochrane systematic review analyzed data from six randomized trials involving close to 1,500 patients who required lower-leg immobilization for at least 1 week and comparing once-daily LMWH vs no thromboprophylaxis continued, typically, until the cast or brace was removed. ${ }^{127}$ We identified an additional multicenter study that has remained published only in abstract form ${ }^{128}$ and updated the meta-analysis by performing our own analysis. We did not reextract the data found in the Cochrane review.

$\mathrm{PE}$ was diagnosed in two of 585 patients in the placebo group and one of 576 in the LMWH group. Results failed to demonstrate or exclude a beneficial effect of LMWH on symptomatic DVT (RR, 0.34; 95\% CI, 0.09-1.28), and two major bleeding events were seen with LMWH vs none in the placebo group. The patient population was quite heterogeneous, and patients with a higher risk for VTE were excluded. Detailed information was not provided with regard to immobility.

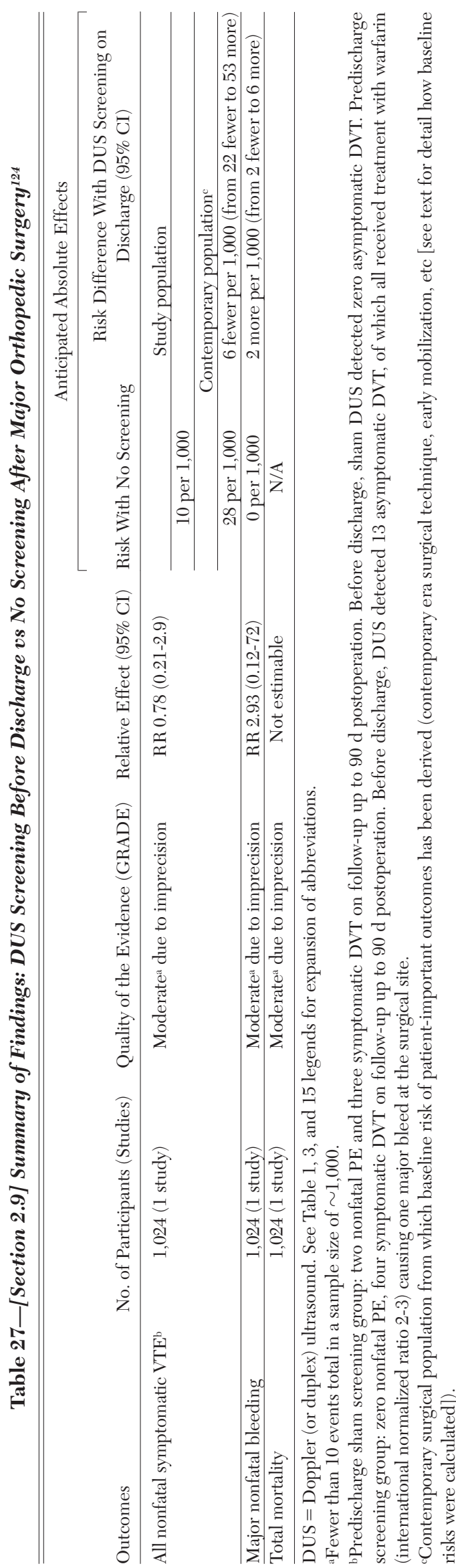

Prevention of VTE in Orthopedic Surgery Patients 
The results did not establish the benefit of thromboprophylaxis in the patients enrolled. Results from higher-risk populations may, however, be reasonably extrapolated to patients at higher risk of DVT (who were excluded from these studies), particularly those with prior VTE (Table 29, Figs S85-S87, Table S26).

Recommendation

3.0. We suggest no prophylaxis rather than pharmacologic thromboprophylaxis in patients with isolated lower-leg injuries requiring leg immobilization (Grade 2C).

\subsection{KNEE ARTHROSCOPY}

Knee arthroscopy and arthroscopic-assisted knee surgery is performed frequently and most often as outpatient procedures in a relatively young patient population. A systematic review ${ }^{129}$ that included four RCTs examined the use of LMWH vs no thromboprophylaxis after arthroscopic knee surgery in 527 patients. ${ }^{130-133}$ The knee surgeries included were anterior cruciate ligament reconstruction, meniscectomies, and other diagnostic and therapeutic arthroscopies. No trial was blinded to patients, outcome adjudication was blinded in only two trials, and allocation concealment was unclear or not done in three trials. One trial was stopped early for benefit. Although asymptomatic DVTs were significantly reduced (RR, 0.16; 95\% CI, 0.05-0.52), this was based on a total of only 23 events, and there were only five symptomatic DVTs reported (LMWH one of 262 vs four of 265) and one symptomatic PE, which was seen in the LMWH group. ${ }^{131}$ No major bleeding events were reported, and there were no bleeding events requiring reoperation. Based on the low-quality evidence from these trials, one would expect nine fewer symptomatic DVTs and four more nonfatal PE per 1,000 , but the sample size was not large enough to estimate the possible increase in bleeding complications (Table 30, Table S27).

These findings are in contrast to a recent trial that randomized $>1,700$ patients to either LMWH or GCS. ${ }^{134}$ This study examined three groups: 14-day nadroparin, 7-day nadroparin, and GCS. The 14-day LMWH arm was stopped early because harms potentially outweighed the benefits. Although numerically more major bleeds were reported in the LMWH group, including one bleeding event requiring reoperation, the effect estimate failed to demonstrate or exclude a detrimental effect on major bleeding events because of low event rates (RR, 2.1; 95\% CI, 0.44-10). Significantly fewer symptomatic DVT were observed in the LMWH groups (RR, 0.2; 95\% CI, 0.07-0.62), 


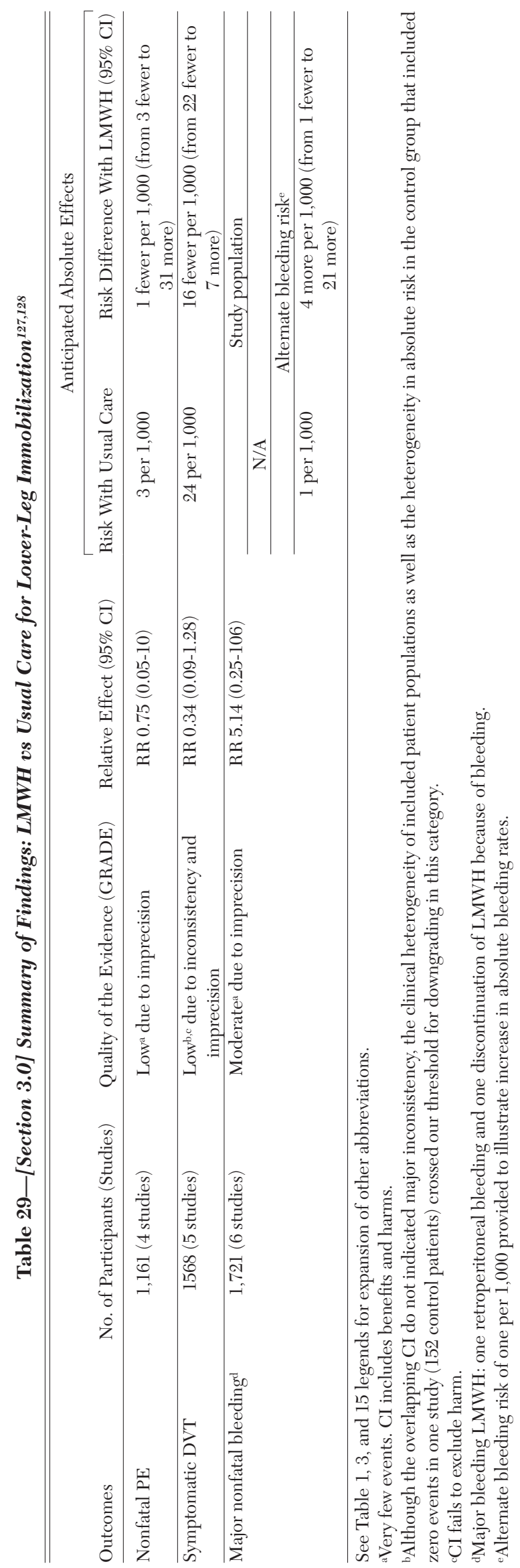

although this was based on only 16 events. The overall quality of evidence from this study was judged to be moderate because of imprecision (Table 31, Table S28).

Given the close balance between the potential risk for major bleeding (three more per 1,000), the occurrence of a bleed requiring reoperation in the $\mathrm{LMWH}$ group and the generally low rate of VTE (1.5\%-2\%, with 14 fewer symptomatic VTE per 1,000 expected with LMWH), routine thromboprophylaxis after an arthroscopic procedure does not appear warranted. However, evidence of benefit from higher-risk populations may be reasonably extrapolated to patients at higher risk of DVT, particularly those with prior VTE (Tables 30, 31, Tables S27, S28).

Recommendation

4.0. For patients undergoing knee arthroscopy without a history of prior VTE, we suggest no thromboprophylaxis rather than prophylaxis (Grade 2B).

\subsection{Direction OF Future Studies}

Large, practical, RCTs are needed to further study thromboprophylaxis after orthopedic surgeries. Those trials should avoid screening for asymptomatic VTE and ensure that symptomatic VTE is recorded up to 3 months after surgery, regardless of duration of intervention. To ensure sufficient methodologic rigor, independent adjudication of outcomes not only for VTE but also for major bleeding events are essential, as is ensuring allocation concealment through central randomization, blinding of data collectors (and optimally patients and caregivers, which may or may not be possible with mechanical devices), and using methods to limit losses to follow-up. In addition to independent adjudication, it is important to provide more-precise and clinically important operational definitions for postoperative bleeding and drainage at the surgical site. Surgical site bleeding and drainage should be routinely reported in clinical trials.

Relative risk differentials for distal vs proximal DVT and portable devices using wireless technology for compliance data for inpatients vs outpatients need to be explored. At a minimum, trials that use mechanical devices for thromboprophylaxis should be able to accurately record and report proper use and daily and cumulative wear time to document compliance. In summary, trials with patientimportant end points and long follow-up should be conducted to evaluate the potential benefits vs risks and downsides of antithrombotic regimens in nonselected populations. ${ }^{135}$ 

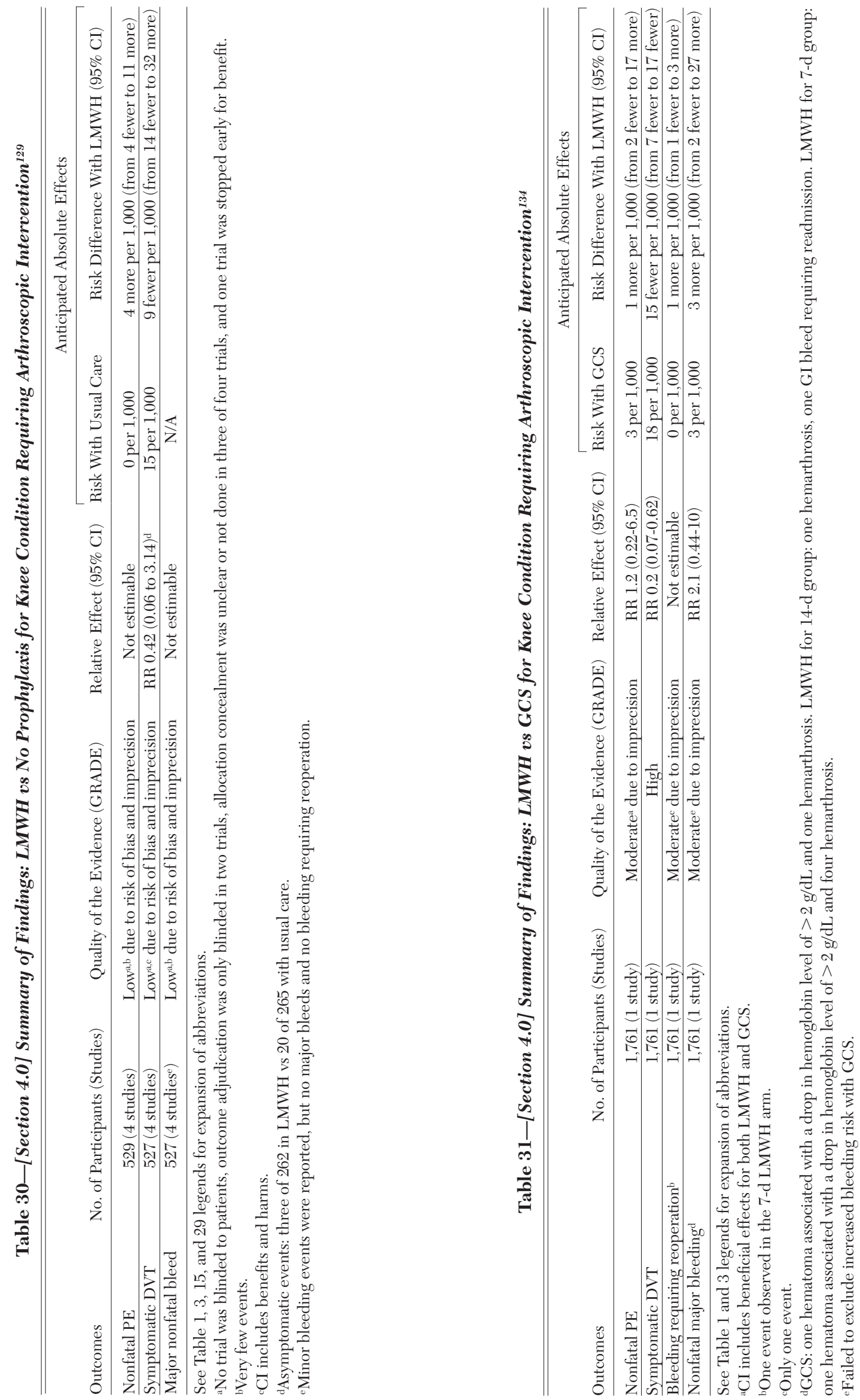
Comparisons where additional data are particularly needed include the following:

- Major orthopedic surgery: IPCD ( \pm aspirin) vs LMWH

- HFS: preoperative IPCD plus LMWH followed by postoperative IPCD plus LMWH vs preoperative IPCD alone followed by postoperative IPCD plus LMWH

- Major orthopedic surgery: aspirin vs LMWH

- Major orthopedic surgery: mechanical device for 35 days vs 10 to 14 days

- Lower-leg injury: anticoagulant thromboprophylaxis vs aspirin stratified by type of injury and procedure and expected degree of immobility

- The influence of antithrombotic regimens, separately and combined, on perioperative and postoperative venous and arterial thromboembolism.

\section{Conclusions}

VTE is an important complication after major orthopedic surgery, and numerous approaches to its prevention have been evaluated. This article reviews the effectiveness and safety of these approaches and provides guidelines using methods that differ somewhat from prior versions. First, recommendations have been based on patient-important outcomes that include symptomatic PE and DVT, bleeding, and death, whereas asymptomatic venous thrombosis identified by screening tests are not used as a basis for the guidelines. After our review, we recommend that all patients undergoing major orthopedic surgery receive prophylaxis with a pharmacologic agent or IPCD for a minimum of 10 to 14 days, and we suggest extending prophylaxis for up to 35 days. In patients at an increased risk of bleeding, we suggest the use of an IPCD or no prophylaxis. We do not recommend the use of IVC filter placement for primary prevention, and we recommend against DUS screening. For patients with isolated lower-extremity injuries requiring immobilization and for patients undergoing knee arthroscopy without a history of VTE, we suggest no thromboprophylaxis. Adherence to these guidelines will minimize the adverse consequences of VTE following orthopedic surgery.

\section{ACKNOWLEDGMENTS}

Author contributions: As Topic Editor, Dr Falck-Ytter oversaw the development of this article, including the data analysis and subsequent development of the recommendations contained herein. Dr Falck-Ytter: served as Topic Editor.

Dr Francis: served as Deputy Editor

Dr Johanson: served as a panelist.

Dr Curley: served as frontline clinician.

Dr Dahl: served as a panelist.

Dr Schulman: served as a panelist.

Dr Ortel: served as a panelist.
Dr Pauker: served as a panelist.

Dr Colwell: served as a panelist.

Financial/nonfinancial disclosures: The authors of this guideline provided detailed conflict of interest information related to each individual recommendation made in this article. A grid of these disclosures is available online at http://chestjournal.chestpubs.org/ content/141/2_suppl/e278S/suppl/DC1. In summary, the authors have reported to $C H E S T$ the following conflicts of interest: Dr Francis received research grant support from the National Heart, Lung, and Blood Institute and Eisai Co, Ltd, and served as a steering committee member for a clinical trial sponsored by Eisai Co, Ltd. Dr Dahl has participated in scientific and speaking activities directly and indirectly sponsored by Boehringer Ingelheim GmbH, GlaxoSmithKline plc, Sanofi-Aventis LLC, Bayer Healthcare Pharmaceuticals, and Pfizer Inc. Dr Ortel received research grant support from the National Heart, Lung, and Blood Institute; the Centers for Disease Control and Prevention; Eisai Co, LtD; GlaxoSmithKline plc; Pfizer Inc; and Daiichi Sankyo, and has been a consultant for Sanofi-Aventis LLC and Boehringer Ingelheim $\mathrm{GmbH}$. Dr Ortel has also received grant funds and speaking fees from Instrumentation Laboratories, Inc. Dr Colwell has been a consultant and received research funds from Medical Compression Systems, Ltd, but recused himself in determination of use of compression devices for the Antithrombotic Therapy and Prevention of Thrombosis 9th ed: American College of Chest Physicians Evidence-Based Clinical Practice Guidelines. Drs Falck-Ytter, Johanson, Curley, Schulman, and Pauker have reported that no potential conflicts of interest exist with any companies/organizations whose products or services may be discussed in this article.

Role of sponsors: The sponsors played no role in the development of these guidelines. Sponsoring organizations cannot recommend panelists or topics, nor are they allowed prepublication access to the manuscripts and recommendations. Guideline panel members, including the chair, and members of the Health \& Science Policy Committee are blinded to the funding sources. Further details on the Conflict of Interest Policy are available online at http://chestnet.org.

Endorsements: This guideline is endorsed by the American Association for Clinical Chemistry, the American College of Clinical Pharmacy, the American Society of Health-System Pharmacists, the American Society of Hematology, and the International Society of Thrombosis and Hematosis.

Additional information: The supplement Figures and Tables can be found in the Online Data Supplement at http://chestjournal. chestpubs.org/content/141/2_suppl/e278S/suppl/DC1.

\section{REFERENCES}

1. American Academy of Orthopaedic Surgeons. Total hip replacement. American Academy of Orthopaedic Surgeons Web site.http://orthoinfo.aaos.org/topic.cfm?topic $=$ a00377. Accessed December 12, 2011.

2. Guyatt GH, Eikelboom JW, Gould MK, et al. Approach to outcome measurement in the prevention of thrombosis in surgical and medical patients: antithrombotic therapy and prevention of thrombosis, 9th ed: American College of Chest Physicians evidence-based clinical practice guidelines. Chest. 2012;141(2)(suppl):e185S-e194S.

3. Hill J, Treasure T; National Clinical Guideline Centre for Acute and Chronic Conditions. Reducing the risk of venous thromboembolism in patients admitted to hospital: summary of NICE guidance. BMJ. 2010;340:c95.

4. Kakkar AK, Brenner B, Dahl OE, et al; RECORD2 Investigators. Extended duration rivaroxaban versus short-term enoxaparin for the prevention of venous thromboembolism after total hip arthroplasty: a double-blind, randomised controlled trial. Lancet. 2008;372(9632):31-39.

5. Eikelboom JW, Quinlan DJ, O’Donnell M. Major bleeding, mortality, and efficacy of fondaparinux in venous thromboembolism prevention trials. Circulation. 2009;120(20):2006-2011.

6. Sevitt S, Gallagher NG. Prevention of venous thrombosis and pulmonary embolism in injured patients. A trial of 
anticoagulant prophylaxis with phenindione in middle-aged and elderly patients with fractured necks of femur. Lancet. 1959;2(7110):981-989.

7. Myhre HO, Holen A. Thrombosis prophylaxis. Dextran or warfarin-sodium? A controlled clinical study [in Norwegian]. Nord Med. 1969;82(49):1534-1538.

8. Husted H, Otte KS, Kristensen BB, Ørsnes T, Wong C, Kehlet H. Low risk of thromboembolic complications after fast-track hip and knee arthroplasty. Acta Orthop. 2010;81(5): 599-605.

9. Galasko CS, Edwards DH, Fearn CB, Barber HM. The value of low dosage heparin for the prophylaxis of thromboembolism in patients with transcervical and intertrochanteric femoral fractures. Acta Orthop Scand. 1976;47(3):276-282.

10. Sautter RD, Koch EL, Myers WO, et al. Aspirinsulfinpyrazone in prophylaxis of deep venous thrombosis in total hip replacement. JAMA. 1983;250(19):2649-2654.

11. Borgstroem S, Greitz T, Van Der Linden W, Molin J, Rudics I. Anticoagulant prophylaxis of venous thrombosis in patients with fractured neck of the femur; a controlled clinical trial using venous phlebography. Acta Chir Scand. 1965; 129:500-508.

12. Eskeland G, Solheim K, Skjörten F. Anticoagulant prophylaxis, thromboembolism and mortality in elderly patients with hip fractures. A controlled clinical trial. Acta Chir Scand. 1966;131(1):16-29.

13. Bjørnarå BT, Gudmundsen TE, Dahl OE. Frequency and timing of clinical venous thromboembolism after major joint surgery. J Bone Joint Surg Br. 2006;88(3):386-391.

14. Lassen MR, Gallus A, Raskob GE, Pineo G, Chen D, Ramirez LM; ADVANCE-3 Investigators. Apixaban versus enoxaparin for thromboprophylaxis after hip replacement. N Engl J Med. 2010;363(26):2487-2498.

15. Lassen MR, Raskob GE, Gallus A, Pineo G, Chen D, Hornick P; ADVANCE-2 Investigators. Apixaban versus enoxaparin for thromboprophylaxis after knee replacement (ADVANCE-2): a randomised double-blind trial. Lancet. 2010;375(9717):807-815.

16. Lassen MR, Raskob GE, Gallus A, Pineo G, Chen D, Portman RJ. Apixaban or enoxaparin for thromboprophylaxis after knee replacement [published correction appears in N Engl J Med. 2009;36(18):1814]. N Engl J Med. 2009; 361(6):594-604.

17. Lassen MR, Davidson BL, Gallus A, Pineo G, Ansell J, Deitchman D. The efficacy and safety of apixaban, an oral, direct factor Xa inhibitor, as thromboprophylaxis in patients following total knee replacement. J Thromb Haemost. 2007; 5(12):2368-2375.

18. Eriksson BI, Borris LC, Dahl OE, et al; ODIXa-HIP Study Investigators. A once-daily, oral, direct factor Xa inhibitor, rivaroxaban (BAY 59-7939), for thromboprophylaxis after total hip replacement. Circulation. 2006;114(22):2374-2381.

19. Eriksson BI, Borris LC, Friedman RJ, et al; RECORD1 Study Group. Rivaroxaban versus enoxaparin for thromboprophylaxis after hip arthroplasty. $N$ Engl J Med. 2008; 358(26):2765-2775

20. Turpie AG, Fisher WD, Bauer KA, et al; OdiXa-Knee Study Group. BAY 59-7939: an oral, direct factor Xa inhibitor for the prevention of venous thromboembolism in patients after total knee replacement. A phase II dose-ranging study. J Thromb Haemost. 2005;3(11):2479-2486.

21. Lassen MR, Ageno W, Borris LC, et al; RECORD3 Investigators. Rivaroxaban versus enoxaparin for thromboprophylaxis after total knee arthroplasty. $N$ Engl J Med. 2008;358(26):2776-2786.

22. Turpie AG, Lassen MR, Davidson BL, et al; RECORD4 Investigators. Rivaroxaban versus enoxaparin for thrombo- prophylaxis after total knee arthroplasty (RECORD4): a randomised trial. Lancet. 2009;373(9676):1673-1680.

23. Eriksson BI, Dahl OE, Huo MH, et al; RE-NOVATE II Study Group. Oral dabigatran versus enoxaparin for thromboprophylaxis after primary total hip arthroplasty (RE-NOVATE II*). A randomised, double-blind, non-inferiority trial. Thromb Haemost. 2011;105(4):721-729.

24. Eriksson BI, Dahl OE, Rosencher N, et al; RE-NOVATE Study Group. Dabigatran etexilate versus enoxaparin for prevention of venous thromboembolism after total hip replacement: a randomised, double-blind, non-inferiority trial. Lancet. 2007;370(9591):949-956.

25. Ginsberg JS, Davidson BL, Comp PC, et al; RE-MOBILIZE Writing Committee. Oral thrombin inhibitor dabigatran etexilate vs North American enoxaparin regimen for prevention of venous thromboembolism after knee arthroplasty surgery. J Arthroplasty. 2009;24(1):1-9.

26. Eriksson BI, Dahl OE, Rosencher N, et al; RE-MODEL Study Group. Oral dabigatran etexilate vs. subcutaneous enoxaparin for the prevention of venous thromboembolism after total knee replacement: the RE-MODEL randomized trial. J Thromb Haemost. 2007;5(11):2178-2185.

27. White RH, Romano PS, Zhou H, Rodrigo J, Bargar W. Incidence and time course of thromboembolic outcomes following total hip or knee arthroplasty. Arch Intern Med. 1998;158(14):1525-1531.

28. Eriksson BI, Lassen MR; PENTasaccharide in HIp-FRActure Surgery Plus Investigators. Duration of prophylaxis against venous thromboembolism with fondaparinux after hip fracturesurgery:amulticenter,randomized, placebo-controlled, double-blind study. Arch Intern Med. 2003;163(11): 1337-1342.

29. White RH, Zhou H, Romano PS. Incidence of symptomatic venous thromboembolism after different elective or urgent surgical procedures. Thromb Haemost. 2003;90(3):446-455.

30. Pulmonary Embolism Prevention (PEP) Trial Collaborative Group. Prevention of pulmonary embolism and deep vein thrombosis with low dose aspirin: Pulmonary Embolism Prevention (PEP) trial. Lancet. 2000;355(9212):1295-1302.

31. Chin PL, Amin MS, Yang KY, Yeo SJ, Lo NN. Thromboembolic prophylaxis for total knee arthroplasty in Asian patients: a randomised controlled trial. J Orthop Surg (Hong Kong). 2009;17(1):1-5.

32. Fuji T, Ochi T, Niwa S, Fujita S. Prevention of postoperative venous thromboembolism in Japanese patients undergoing total hip or knee arthroplasty: two randomized, double-blind, placebo-controlled studies with three dosage regimens of enoxaparin. J Orthop Sci. 2008;13(5):442-451.

33. Lassen MR, Borris LC, Christiansen HM, et al. Heparin/ dihydroergotamine for venous thrombosis prophylaxis: comparison of low-dose heparin and low molecular weight heparin in hip surgery. Br J Surg. 1988;75(7):686-689.

34. Leclerc JR, Geerts WH, Desjardins L, et al. Prevention of deep vein thrombosis after major knee surgery-a randomized, double-blind trial comparing a low molecular weight heparin fragment (enoxaparin) to placebo. Thromb Haemost. 1992;67(4):417-423.

35. Levine MN, Gent M, Hirsh J, et al. Ardeparin (low-molecularweight heparin) vs graduated compression stockings for the prevention of venous thromboembolism. A randomized trial in patients undergoing knee surgery. Arch Intern Med. 1996;156(8):851-856.

36. Samama CM, Clergue F, Barre J, Montefiore A, Ill P, Samii $\mathrm{K}$; Arar Study Group. Low molecular weight heparin associated with spinal anaesthesia and gradual compression stockings in total hip replacement surgery. Br J Anaesth. 1997;78(6):660-665. 
37. Tørholm C, Broeng L, Jørgensen PS, et al. Thromboprophylaxis by low-molecular-weight heparin in elective hip surgery. A placebo controlled study. J Bone Joint Surg Br. 1991;73(3):434-438.

38. Turpie AG, Levine MN, Hirsh J, et al. A randomized controlled trial of a low-molecular-weight heparin (enoxaparin) to prevent deep-vein thrombosis in patients undergoing elective hip surgery. N Engl J Med. 1986;315(15):925-929.

39. Yoo MC, Kang CS, Kim YH, Kim SK. A prospective randomized study on the use of nadroparin calcium in the prophylaxis of thromboembolism in Korean patients undergoing elective total hip replacement. Int Orthop. 1997;21(6): 399-402.

40. Dahl OE, Quinlan DJ, Bergqvist D, Eikelboom JW. A critical appraisal of bleeding events reported in venous thromboembolism prevention trials of patients undergoing hip and knee arthroplasty. J Thromb Haemost. 2010;8(9):1966-1975.

41. Pedersen AB, Sorensen HT, Mehnert F, Overgaard S, Johnsen SP. Risk factors for venous thromboembolism in patients undergoing total hip replacement and receiving routine thromboprophylaxis. J Bone Joint Surg Am. 2010; 92(12):2156-2164.

42. Leizorovicz A, Turpie AG, Cohen AT, Wong L, Yoo MC, Dans A; SMART Study Group. Epidemiology of venous thromboembolism in Asian patients undergoing major orthopedic surgery without thromboprophylaxis. The SMART study. J Thromb Haemost. 2005;3(1):28-34.

43. White RH, Gettner S, Newman JM, Trauner KB, Romano PS. Predictors of rehospitalization for symptomatic venous thromboembolism after total hip arthroplasty. $N$ Engl J Med. 2000;343(24):1758-1764.

44. Mantilla CB, Horlocker TT, Schroeder DR, Berry DJ, Brown DL. Risk factors for clinically relevant pulmonary embolism and deep venous thrombosis in patients undergoing primary hip or knee arthroplasty. Anesthesiology. 2003:99(3):552-560, discussion 5A.

45. Heit JA, Silverstein MD, Mohr DN, Petterson TM, O'Fallon WM, Melton LJ III. Risk factors for deep vein thrombosis and pulmonary embolism: a population-based case-control study. Arch Intern Med. 2000;160(6):809-815.

46. Guyatt GH, Norris SL, Schulman S, et al. Methodology for the development of antithrombotic therapy and prevention of thrombosis guidelines: antithrombotic therapy and prevention of thrombosis, 9th ed: American College of Chest Physicians evidence-based clinical practice guidelines. Chest. 2012;141(2)(suppl):53S-70S.

47. Lassen MR, Borris LC, Christiansen HM, et al. Prevention of thromboembolism in 190 hip arthroplasties. Comparison of LMW heparin and placebo. Acta Orthop Scand. 1991; 62(1):33-38

48. Warwick D, Bannister GC, Glew D, et al. Perioperative lowmolecular-weight heparin. Is it effective and safe. J Bone Joint Surg Br. 1995;77(5):715-719.

49. Jørgensen PS, Knudsen JB, Broeng L, et al. The thromboprophylactic effect of a low-molecular-weight heparin (Fragmin) in hip fracture surgery. A placebo-controlled study. Clin Orthop Relat Res. 1992;(278):95-100.

50. Sourmelis S, Patoulis G, Tzortzis G. Prevention of deep vein thrombosis with low molecular weight heparin in fractures of the hip [abstract]. J Bone Joint Surg Br. 1995; 77 (B)(supp II):173.

51. O’Donnell M, Linkins LA, Kearon C, Julian J, Hirsh J. Reduction of out-of-hospital symptomatic venous thromboembolism by extended thromboprophylaxis with lowmolecular-weight heparin following elective hip arthroplasty: a systematic review. Arch Intern Med. 2003;163(11): 1362-1366.
52. Hull RD, Pineo GF, Stein PD, et al. Extended out-ofhospital low-molecular-weight heparin prophylaxis against deep venous thrombosis in patients after elective hip arthroplasty: a systematic review. Ann Intern Med. 2001;135(10): 858-869.

53. Eikelboom JW, Quinlan DJ, Douketis JD. Extendedduration prophylaxis against venous thromboembolism after total hip or knee replacement: a meta-analysis of the randomised trials. Lancet. 2001;358(9275):9-15.

54. Bergqvist D, Benoni G, Björgell O, et al. Low-molecularweight heparin (enoxaparin) as prophylaxis against venous thromboembolism after total hip replacement. $N$ Engl J Med. 1996;335(10):696-700.

55. Comp PC, Spiro TE, Friedman RJ, et al; Enoxaparin Clinical Trial Group. Prolonged enoxaparin therapy to prevent venous thromboembolism after primary hip or knee replacement. J Bone Joint Surg Am. 2001;83-A(3):336-345.

56. Dahl OE, Andreassen G, Aspelin T, et al. Prolonged thromboprophylaxis following hip replacement surgeryresults of a double-blind, prospective, randomised, placebocontrolled study with dalteparin (Fragmin). Thromb Haemost. 1997;77(1):26-31.

57. Haentjens P. Venous thromboembolism after total hip arthroplasty_review of incidence and prevention during hospitalization and after hospital discharge. Acta Orthop Belg. 2000;66:1-8.

58. Hull RD, Pineo GF, Francis C, et al; North American Fragmin Trial Investigators. Low-molecular-weight heparin prophylaxis using dalteparin extended out-of-hospital vs in-hospital warfarin/out-of-hospital placebo in hip arthroplasty patients: a double-blind, randomized comparison. Arch Intern Med. 2000;160(14):2208-2215.

59. Lassen MR, Borris LC, Anderson BS, et al. Efficacy and safety of prolonged thromboprophylaxis with a low molecular weight heparin (dalteparin) after total hip arthroplasty-the Danish Prolonged Prophylaxis (DaPP) Study. Thromb Res. 1998;89(6):281-287.

60. Planes A, Vochelle N, Darmon JY, et al. Efficacy and safety of postdischarge administration of enoxaparin in the prevention of deep venous thrombosis after total hip replacement. A prospective randomised double-blind placebo-controlled trial. Drugs. 1996;52(suppl 7):47-54.

61. Morris GK, Mitchell JR. Warfarin sodium in prevention of deep venous thrombosis and pulmonary embolism in patients with fractured neck of femur. Lancet. 1976;2(7991): 869-872.

62. Alfaro MJ, Páramo JA, Rocha E. Prophylaxis of thromboembolic disease and platelet-related changes following total hip replacement: a comparative study of aspirin and heparindihydroergotamine. Thromb Haemost. 1986;56(1):53-56.

63. Dechavanne M, Ville D, Viala JJ, et al. Controlled trial of platelet anti-aggregating agents and subcutaneous heparin in prevention of postoperative deep vein thrombosis in high risk patients. Haemostasis. 1975;4(2):94-100.

64. Harris WH, Salzman EW, Athanasoulis CA, Waltman AC, DeSanctis RW. Aspirin prophylaxis of venous thromboembolism after total hip replacement. $N$ Engl J Med. 1977;297(23):1246-1249.

65. McBride JA, Turpie AG, Kraus V, Hilz C. Proceedings: failure of aspirin and dipyridamole to influence the incidence of leg scan detected venous thrombosis after elective hip surgery. Thromb Diath Haemorrh. 1975;34(2):564.

66. McKenna R, Galante J, Bachmann F, Wallace DL, Kaushal PS, Meredith P. Prevention of venous thromboembolism after total knee replacement by high-dose aspirin or intermittent calf and thigh compression. BMJ. 1980;280(6213): 514-517. 
67. Encke A, Stock C, Dumke HO. Double-blind study for the prevention of postoperative thrombosis [in German]. Chirurg. 1976;47(12):670-673.

68. Morris GK, Mitchell JR. Preventing venous thromboembolism in elderly patients with hip fractures: studies of lowdose heparin, dipyridamole, aspirin, and flurbiprofen. BMJ. 1977;1(6060):535-537.

69. Powers PJ, Gent M, Jay RM, et al. A randomized trial of less intense postoperative warfarin or aspirin therapy in the prevention of venous thromboembolism after surgery for fractured hip. Arch Intern Med. 1989;149(4):771-774.

70. Snook GA, Chrisman OD, Wilson TC. Thromboembolism after surgical treatment of hip fractures. Clin Orthop Relat Res. 1981;(155):21-24.

71. Wood EH, Prentice CR, McGrouther DA, Sinclair J, McNicol GP. Trial of aspirin and RA 233 in prevention of post-operative deep vein thrombosis. Thromb Diath Haemorrh. 1973;30(1):18-24.

72. Zekert F, Kohn P, Vormittag E, Poigenfürst J, Thien M. Prevention of thromboembolism using acetylsalicylic acid in the surgery of hip-joint proximal fractures [in German]. Monatsschr Unfallheilkd Versicher Versorg Verkehrsmed. 1974; 77(3):97-110.

73. Hui AC, Heras-Palou C, Dunn I, et al. Graded compression stockings for prevention of deep-vein thrombosis after hip and knee replacement. J Bone Joint Surg Br. 1996;78(4): 550-554.

74. Dennis M, Sandercock PA, Reid J, et al; CLOTS Trials Collaboration. Effectiveness of thigh-length graduated compression stockings to reduce the risk of deep vein thrombosis after stroke (CLOTS trial 1): a multicentre, randomised controlled trial. Lancet. 2009;373(9679):1958-1965.

75. Muir KW, Watt A, Baxter G, Grosset DG, Lees KR. Randomized trial of graded compression stockings for prevention of deep-vein thrombosis after acute stroke. QJM. 2000;93(6):359-364.

76. Hull RD, Raskob GE, Gent M, et al. Effectiveness of intermittent pneumatic leg compression for preventing deep vein thrombosis after total hip replacement. JAMA. 1990;263(17):2313-2317.

77. Wilson NV, Das SK, Kakkar VV, et al. Thrombo-embolic prophylaxis in total knee replacement. Evaluation of the A-V Impulse System. J Bone Joint Surg Br. 1992;74(1):50-52.

78. Bachmann F, McKenna R, Meredith P, Carta S. Intermittent pneumatic compression of leg and thigh: a new successful method for the prevention of postoperative thrombosis [in German]. Schweiz Med Wochenschr. 1976;106(50):1819-1821.

79. Fisher CG, Blachut PA, Salvian AJ, Meek RN, O'Brien PJ. Effectiveness of pneumatic leg compression devices for the prevention of thromboembolic disease in orthopaedic trauma patients: a prospective, randomized study of compression alone versus no prophylaxis. J Orthop Trauma. 1995;9(1):1-7.

80. Urbankova J, Quiroz R, Kucher N, Goldhaber SZ. Intermittent pneumatic compression and deep vein thrombosis prevention. A meta-analysis in postoperative patients. Thromb Haemost. 2005;94(6):1181-1185.

81. Comerota AJ, Katz ML, White JV. Why does prophylaxis with external pneumatic compression for deep vein thrombosis fail? Am J Surg. 1992;164(3):265-268.

82. Cornwell EE III, Chang D, Velmahos G, et al. Compliance with sequential compression device prophylaxis in at-risk trauma patients: a prospective analysis. Am Surg. 2002; 68(5):470-473.

83. Murakami M, McDill TL, Cindrick-Pounds L, et al. Deep venous thrombosis prophylaxis in trauma: improved compliance with a novel miniaturized pneumatic compression device. J Vasc Surg. 2003;38(5):923-927.
84. Fuji T, Fujita S, Ochi T. Fondaparinux prevents venous thromboembolism after joint replacement surgery in Japanese patients. Int Orthop. 2008;32(4):443-451.

85. Hull RD, Pineo GF, Francis C, et al; The North American Fragmin Trial Investigators. Low-molecular-weight heparin prophylaxis using dalteparin in close proximity to surgery vs warfarin in hip arthroplasty patients: a double-blind, randomized comparison. Arch Intern Med. 2000;160(14): 2199-2207.

86. Strebel N, Prins M, Agnelli G, Büller HR. Preoperative or postoperative start of prophylaxis for venous thromboembolism with low-molecular-weight heparin in elective hip surgery? Arch Intern Med. 2002;162(13):1451-1456.

87. Collins R, Scrimgeour A, Yusuf S, Peto R. Reduction in fatal pulmonary embolism and venous thrombosis by perioperative administration of subcutaneous heparin. Overview of results of randomized trials in general, orthopedic, and urologic surgery. N Engl J Med. 1988;318(18):1162-1173.

88. Clagett GP, Reisch JS. Prevention of venous thromboembolism in general surgical patients. Results of meta-analysis. Ann Surg. 1988;208(2):227-240.

89. Colwell CW Jr, Collis DK, Paulson R, et al. Comparison of enoxaparin and warfarin for the prevention of venous thromboembolic disease after total hip arthroplasty. Evaluation during hospitalization and three months after discharge. J Bone Joint Surg Am. 1999;81(7):932-940.

90. Francis CW, Pellegrini VD Jr, Totterman S, et al. Prevention of deep-vein thrombosis after total hip arthroplasty. Comparison of warfarin and dalteparin. J Bone Joint Surg Am. 1997;79(9):1365-1372.

91. Fitzgerald RH Jr, Spiro TE, Trowbridge AA, et al; Enoxaparin Clinical Trial Group. Prevention of venous thromboembolic disease following primary total knee arthroplasty. A randomized, multicenter, open-label, parallel-group comparison of enoxaparin and warfarin. J Bone Joint Surg Am. 2001; 83-A(6):900-906.

92. Heit JA, Berkowitz SD, Bona R, et al; Ardeparin Arthroplasty Study Group. Efficacy and safety of low molecular weight heparin (ardeparin sodium) compared to warfarin for the prevention of venous thromboembolism after total knee replacement surgery: a double-blind, dose-ranging study. Thromb Haemost. 1997;77(1):32-38.

93. Leclerc JR, Geerts WH, Desjardins L, et al. Prevention of venous thromboembolism after knee arthroplasty. A randomized, double-blind trial comparing enoxaparin with warfarin. Ann Intern Med. 1996;124(7):619-626.

94. RD Heparin Arthroplasty Group. RD heparin compared with warfarin for prevention of venous thromboembolic disease following total hip or knee arthroplasty. J Bone Joint Surg Am. 1994;76(8):1174-1185.

95. Hull R, Raskob G, Pineo G, et al. A comparison of subcutaneous low-molecular-weight heparin with warfarin sodium for prophylaxis against deep-vein thrombosis after hip or knee implantation. N Engl J Med. 1993;329(19):1370-1376.

96. Samama CM, Vray M, Barré J, et al; SACRE Study Investigators. Extended venous thromboembolism prophylaxis after total hip replacement: a comparison of low-molecularweight heparin with oral anticoagulant. Arch Intern Med. 2002;162(19):2191-2196.

97. Westrich GH, Bottner F, Windsor RE, Laskin RS, Haas SB, Sculco TP. VenaFlow plus Lovenox vs VenaFlow plus aspirin for thromboembolic disease prophylaxis in total knee arthroplasty. J Arthroplasty. 2006;21(6 suppl 2):139-143.

98. Graor RASJ, Lotke PA, Davidson BL. RD heparin (ardeparin sodium) vs. aspirin to prevent deep venous thrombosis after hip or knee replacement surgery [abstract]. Chest. 1992;102(suppl):118S. 
99. Lassen MR, Bauer KA, Eriksson BI, Turpie AG; European Pentasaccharide Elective Surgery Study (EPHESUS) Steering Committee. Postoperative fondaparinux versus preoperative enoxaparin for prevention of venous thromboembolism in elective hip-replacement surgery: a randomised doubleblind comparison. Lancet. 2002;359(9319):1715-1720.

100. Turpie AG, Bauer KA, Eriksson BI, Lassen MR; PENTATHALON 2000 Study Steering Committee. Postoperative fondaparinux versus postoperative enoxaparin for prevention of venous thromboembolism after elective hipreplacement surgery: a randomised double-blind trial. Lancet. 2002;359(9319):1721-1726.

101. Bauer KA, Eriksson BI, Lassen MR, Turpie AG; Steering Committee of the Pentasaccharide in Major Knee Surgery Study. Fondaparinux compared with enoxaparin for the prevention of venous thromboembolism after elective major knee surgery. N Engl J Med. 2001;345(18):1305-1310.

102. Eriksson BI, Bauer KA, Lassen MR, Turpie AG; Steering Committee of the Pentasaccharide in Hip-Fracture Surgery Study. Fondaparinux compared with enoxaparin for the prevention of venous thromboembolism after hip-fracture surgery. N Engl J Med. 2001;345(18):1298-1304.

103. Agnelli G, Bergqvist D, Cohen AT, Gallus AS, Gent M; PEGASUS investigators. Randomized clinical trial of postoperative fondaparinux versus perioperative dalteparin for prevention of venous thromboembolism in high-risk abdominal surgery. Br J Surg. 2005;92(10):1212-1220.

104. Eriksson BI, Borris L, Dahl OE, et al; ODIXa-HIP Study Investigators. Oral, direct Factor Xa inhibition with BAY 59-7939 for the prevention of venous thromboembolism after total hip replacement. J Thromb Haemost. 2006;4(1): 121-128.

105. Bailey JP, Kruger MP, Solano FX, Zajko AB, Rubash HE. Prospective randomized trial of sequential compression devices vs low-dose warfarin for deep venous thrombosis prophylaxis in total hip arthroplasty. J Arthroplasty. 1991; 6(suppl):S29-S35.

106. Francis CW, Pellegrini VD Jr, Marder VJ, et al. Comparison of warfarin and external pneumatic compression in prevention of venous thrombosis after total hip replacement. JAMA. 1992;267(21):2911-2915.

107. Paiement G, Wessinger SJ, Waltman AC, Harris WH. Lowdose warfarin versus external pneumatic compression for prophylaxis against venous thromboembolism following total hip replacement. J Arthroplasty. 1987;2(1):23-26.

108. Kaempffe FA, Lifeso RM, Meinking C. Intermittent pneumatic compression versus coumadin. Prevention of deep vein thrombosis in lower-extremity total joint arthroplasty. Clin Orthop Relat Res. 1991;(269):89-97.

109. Pitto RP, Hamer H, Heiss-Dunlop W, Kuehle J. Mechanical prophylaxis of deep-vein thrombosis after total hip replacement a randomised clinical trial. J Bone Joint Surg Br. 2004; 86(5):639-642.

110. Stone MH, Limb D, Campbell P, Stead D, Culleton G. A comparison of intermittent calf compression and enoxaparin for thromboprophylaxis in total hip replacement. A pilot study. Int Orthop. 1996;20(6):367-369.

111. Warwick D, Harrison J, Glew D, Mitchelmore A, Peters TJ, Donovan J. Comparison of the use of a foot pump with the use of low-molecular-weight heparin for the prevention of deep-vein thrombosis after total hip replacement. A prospective, randomized trial. J Bone Joint Surg Am. 1998;80(8):1158-1166.

112. Blanchard J, Meuwly JY, Leyvraz PF, et al. Prevention of deep-vein thrombosis after total knee replacement. Randomised comparison between a low-molecular-weight heparin (nadroparin) and mechanical prophylaxis with a foot-pump system. J Bone Joint Surg Br. 1999;81(4): 654-659.

113. Colwell CW Jr, Froimson MI, Mont MA, et al. Thrombosis prevention after total hip arthroplasty: a prospective, randomized trial comparing a mobile compression device with low-molecular-weight heparin. J Bone Joint Surg Am. 2010;92(3):527-535.

114. Gelfer Y, Tavor H, Oron A, Peer A, Halperin N, Robinson D. Deep vein thrombosis prevention in joint arthroplasties: continuous enhanced circulation therapy vs low molecular weight heparin. J Arthroplasty. 2006;21(2):206-214.

115. Kakkos SK, Caprini JA, Geroulakos G, Nicolaides AN, Stansby GP, Reddy DJ. Combined intermittent pneumatic leg compression and pharmacological prophylaxis for prevention of venous thromboembolism in high-risk patients. Cochrane Database Syst Rev. 2008;(4):CD005258.

116. Borow M, Goldson HJ. Prevention of postoperative deep venous thrombosis and pulmonary emboli with combined modalities. Am Surg. 1983;49(11):599-605.

117. Bradley JG, Krugener GH, Jager HJ. The effectiveness of intermittent plantar venous compression in prevention of deep venous thrombosis after total hip arthroplasty. J Arthroplasty. 1993;8(1):57-61.

118. Eisele R, Kinzl L, Koelsch T. Rapid-inflation intermittent pneumatic compression for prevention of deep venous thrombosis. J Bone Joint Surg Am. 2007;89(5):1050-1056.

119. Silbersack Y, Taute BM, Hein W, Podhaisky H. Prevention of deep-vein thrombosis after total hip and knee replacement. Low-molecular-weight heparin in combination with intermittent pneumatic compression. J Bone Joint Surg Br. 2004;86(6):809-812.

120. Edwards JZ, Pulido PA, Ezzet KA, Copp SN, Walker RH, Colwell CW Jr. Portable compression device and lowmolecular-weight heparin compared with low-molecularweight heparin for thromboprophylaxis after total joint arthroplasty. J Arthroplasty. 2008;23(8):1122-1127.

121. Wilke T, Müller S. Nonadherence in outpatient thromboprophylaxis after major orthopedic surgery: a systematic review. Expert Rev Pharmacoecon Outcomes Res. 2010;10(6): 691-700.

122. Rajasekhar A, Lottenberg R, Lottenberg L, Liu H, Ang D. Pulmonary embolism prophylaxis with inferior vena cava filters in trauma patients: a systematic review using the metaanalysis of observational studies in epidemiology (MOOSE) guidelines. J Thromb Thrombolysis. 2011;32(1):40-46.

123. Bass AR, Mattern CJ, Voos JE, Peterson MG, Trost DW. Inferior vena cava filter placement in orthopedic surgery. Am J Orthop. 2010;39(9):435-439.

124. Robinson KS, Anderson DR, Gross M, et al. Ultrasonographic screening before hospital discharge for deep venous thrombosis after arthroplasty: the post-arthroplasty screening study. A randomized, controlled trial. Ann Intern Med. 1997; 127(6):439-445.

125. Schmidt B, Michler R, Klein M, Faulmann G, Weber C, Schellong S. Ultrasound screening for distal vein thrombosis is not beneficial after major orthopedic surgery. A randomized controlled trial. Thromb Haemost. 2003;90(5): 949-954.

126. Geerts WH, Bergqvist D, Pineo GF, et al; American College of Chest Physicians. Prevention of venous thromboembolism: American College of Chest Physicians evidence-based clinical practice guidelines (8th edition). Chest. 2008;133(6 suppl):381S-453S.

127. Testroote M, Stigter W, de Visser DC, Janzing H. Low molecular weight heparin for prevention of venous thromboembolism in patients with lower-leg immobilization. Cochrane Database Syst Rev. 2008;(4):CD006681. 
128. Selby R, Geerts WH, Kreder HJ, et al. Clinically-Important Venous ThromboEmbolism (CIVTE) following isolated leg fractures distal to the knee: epidemiology and preventions: the D-KAF (Dalteparin in Knee to Ankle Fracture) trial [abstract]. J Thromb Haemost. 2007;5(suppl 2):O-T-051.

129. Ramos J, Perrotta C, Badariotti G, Berenstein G. Interventions for preventing venous thromboembolism in adults undergoing knee arthroscopy. Cochrane Database Syst Rev. 2008; (4):CD005259.

130. Canata G, Chiey A. Prevention of venous thromboembolism after ACL reconstruction: a prospective, randomized study. ISAKOS (International Society of Arthroscopy, Knee Surgery and Orthopaedic Sports Medicine). 2003; Poster 71-2003.

131. Michot M, Conen D, Holtz D, et al. Prevention of deepvein thrombosis in ambulatory arthroscopic knee surgery: A randomized trial of prophylaxis with low-molecular weight heparin. Arthroscopy. 2002;18(3):257-263.
132. Roth P. Prophylaxis of deepvein thrombosis in outpatients undergoing arthroscopic meniscus operation [Thromboembolieprophylaxe bei ambulant durchgefürten arthroskopischen Meniskusoperationen]. Orthopädische Praxis. 1995; 5:345-348.

133. Wirth T, Schneider B, Misselwitz F, et al. Prevention of venous thromboembolism after knee arthroscopy with lowmolecular weight heparin (reviparin): results of a randomized controlled trial. Arthroscopy. 2001;17(4):393-399.

134. Camporese G, Bernardi E, Prandoni P, et al; KANT (Knee Arthroscopy Nadroparin Thromboprophylaxis) Study Group. Low-molecular-weight heparin versus compression stockings for thromboprophylaxis after knee arthroscopy: a randomized trial. Ann Intern Med. 2008;149(2):73-82.

135. Dahl OE, Borris LC, Bergqvist D, et al; International Surgical Thrombosis Forum. Major joint replacement. A model for antithrombotic drug development: from proof-ofconcept to clinical use. Int Angiol. 2008;27(1):60-67. 